Supporting Information for

\title{
Supramolecular Affinity Labeling of Histone Peptides Containing Trimethyllysine and Its Application to Histone Deacetylase Assays
}

\author{
Isaiah N. Gober and Marcey L. Waters* \\ Department of Chemistry, CB 3290, UNC Chapel Hill, Chapel Hill, NC 27599 \\ mlwaters@email.unc.edu
}

Pages S2-S8 Synthesis and characterization of 5

Pages S9-S13 Peptide synthesis and characterization

Page S14 Extinction coefficient determination of 4

Pages S15-S27 Binding measurements by isothermal titration calorimetry

Pages S28-S29 LCMS characterization of CX $\mathrm{CX}_{4}$-ONBD labeling of K9K14 and K9me 314

Pages S30-S36 HPLC analysis of labeling

Pages S37-S40 $\quad \mathrm{Kme}_{3} / \mathrm{K}$ Competition labeling experiments

Pages S41-S42 Turn-on fluorescence affinity labeling control experiments

Page S43 In vitro HDAC assay

Pages S43-S45 HPLC analysis of HDAC1 and HDAC3/NCROR1 reactions

Pages S46-S48 Turn-on fluorescence HDAC1 activity assay

Pages S49-S50 Turn-on fluorescence HDAC3/NCOR1 activity assay

Page S51 Z Factor calculation

Page S52 References 
Scheme S1. Synthesis of $\mathrm{CX}_{4}-\mathrm{ONBD}$ probe 5.<smiles>O=[N+]([O-])c1ccc(Cl)c2nonc12</smiles>

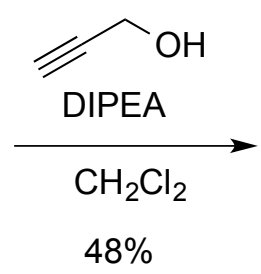<smiles>C#CCOc1ccc([N+](=O)[O-])c2nonc12</smiles>

1

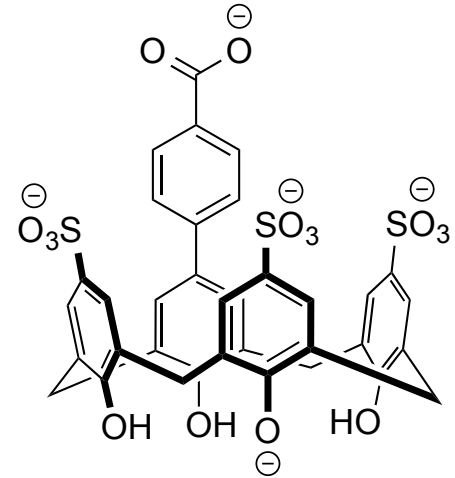

2<smiles>CC(CCN)OCC(C)(C)N</smiles><smiles>COC(=O)C(Cl)C(=O)OC(C)(C)C</smiles>

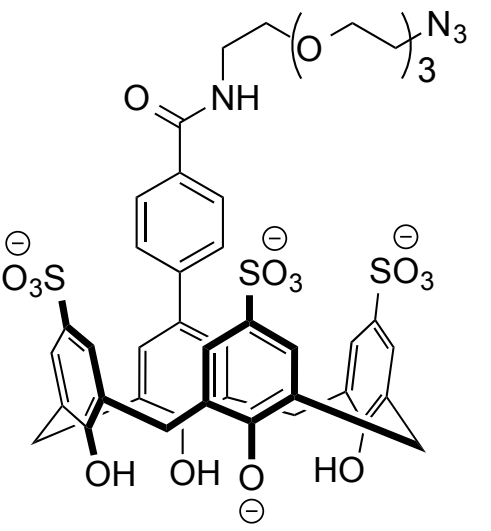

4

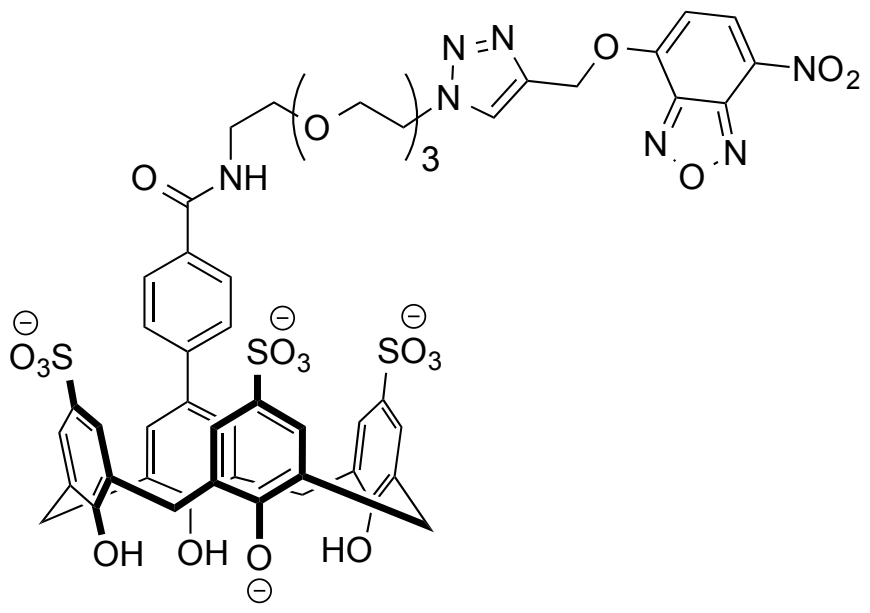

5

Synthesis of 1. 4-chloro-nitrobenzo[c][1,2,5]oxadiazole ( $0.100 \mathrm{~g}, 0.50 \mathrm{mmol}, 1$ equiv.) was dissolved in $5 \mathrm{~mL} \mathrm{CH}_{2} \mathrm{Cl}_{2}$ under a nitrogen atmosphere. To this solution was added a mixture of 
propargyl alcohol ( $0.029 \mathrm{~mL}, 0.50 \mathrm{mmol}, 1$ equiv.) and DIPEA ( $0.087 \mathrm{~mL}, 0.50 \mathrm{mmol}, 1$ equiv.) in $5 \mathrm{~mL} \mathrm{CH}_{2} \mathrm{Cl}_{2}$, and stirring was continued for $72 \mathrm{~h}$. The solvent was removed under reduced pressure, and the crude product was purified by column chromatography (EtOAc/Hexanes 1:1) to give the product as a yellow-brown solid $(0.053 \mathrm{~g}, 48 \%)$. ${ }^{1} \mathrm{H} \mathrm{NMR}\left(\mathrm{CDCl}_{3}, 400 \mathrm{MHz}\right): 8.558$ (d, 1H, CH), 6.880 (d, 1H, CH), 5.129 (d, 2H, $\left.\mathrm{CH}_{2}\right), 2.720$ (t, 1H, CH). MS (calculated): 242.02 $\left[\mathrm{M}+\mathrm{Na}^{+}\right]$. HRMS (observed, ESI+): $242.01701\left[\mathrm{M}+\mathrm{Na}^{+}\right]$.

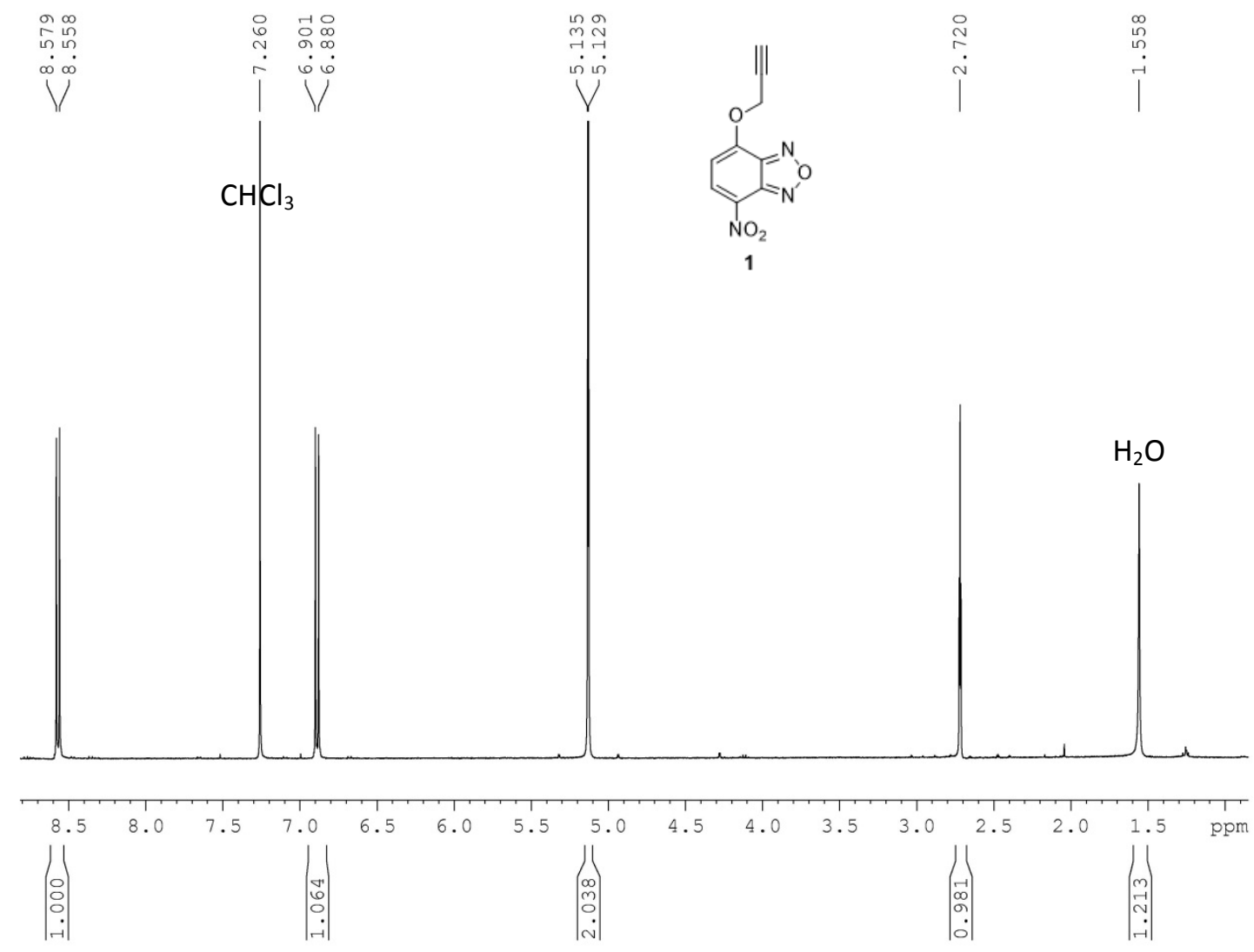

Figure S1. 1D ${ }^{1} \mathrm{H}-\mathrm{NMR}(400 \mathrm{MHz})$ of Compound 1 in $\mathrm{CDCl}_{3}$.

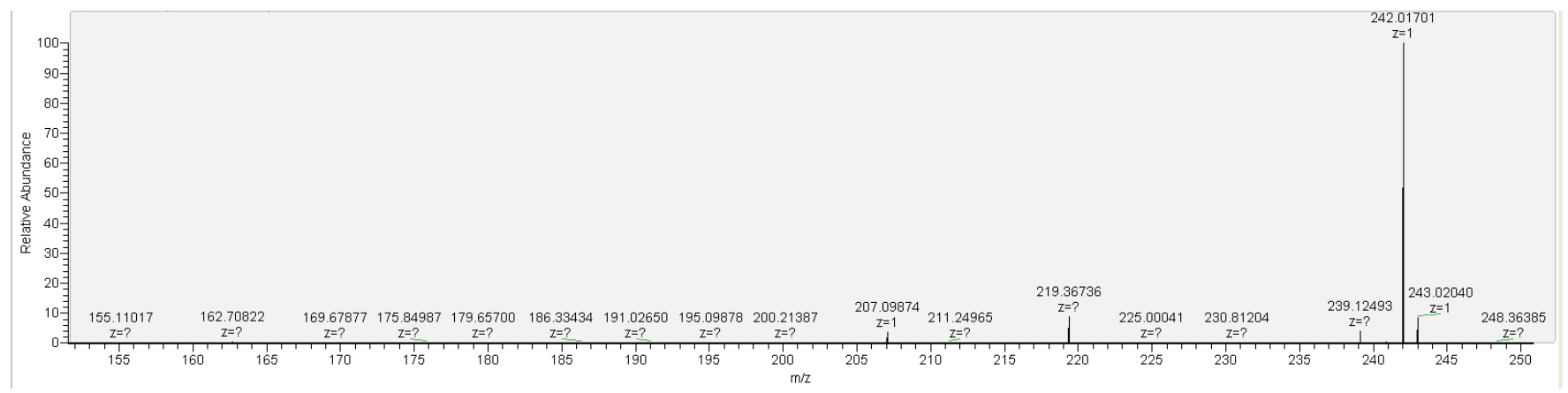


Figure S2. High resolution mass spectrum of Compound 1.

Synthesis of 2. Compound 2 was synthesized according to published procedure ${ }^{1}$ on a $0.5 \mathrm{~g}$ scale but with a modified purification procedure. After completion of the reaction, solvent was removed under reduced pressure. The residue was taken up in $\mathrm{MeOH} / \mathrm{H}_{2} \mathrm{O}(1: 1)$, and palladium was removed by QuadraPure ${ }^{\circledR}$ TU resin. The resin $(0.5 \mathrm{~g})$ was added to the solution and heated to reflux under nitrogen for $24 \mathrm{~h}$. The mixture was filtered, and the solvent was removed under reduced pressure. The crude product was used without further purification.

Synthesis of 3 . Compound 3 was prepared according to published procedure ${ }^{2}$.

Synthesis of 4. EDC- $\mathrm{HCl}(0.087 \mathrm{~g}, 0.45 \mathrm{mmol}, 2$ equiv. $)$ and $\mathrm{N}$-hydroxysuccinimide $(0.050 \mathrm{~g}$, $0.43 \mathrm{mmol}, 2$ equiv.) were added to a solution of $2(0.176 \mathrm{~g}, 0.22 \mathrm{mmol}, 1$ equiv. $)$ in $5 \mathrm{~mL}$ $\mathrm{DMF} / \mathrm{H}_{2} \mathrm{O}(1: 1)$ under a nitrogen atmosphere, and the mixture was stirred for $1 \mathrm{~h} .3(0.100 \mathrm{~g}$, $0.46 \mathrm{mmol}, 2.1$ equiv.) was added, and the solution was allowed to stir at room temperature overnight. The solvent was removed under reduced pressure, and the resulting residue was used in the next step without further purification. ${ }^{1} \mathrm{H}$ NMR $\left(\mathrm{D}_{2} \mathrm{O}, 600 \mathrm{MHz}\right): 7.718(\mathrm{~d}, 2 \mathrm{H}), 7.660(\mathrm{~d}$, 2H), 7.587 (d, 2H), $7.498(\mathrm{~d}, 2 \mathrm{H}), 7.478(\mathrm{~s}, 2 \mathrm{H}), 7.464(\mathrm{~s}, 2 \mathrm{H}), 4.280(\mathrm{~d}, 2 \mathrm{H}), 3.509-3.633$ (m, 12H), $3.321(\mathrm{~s}, 2 \mathrm{H}), 3.052(\mathrm{~s}, 2 \mathrm{H}), 2.765(\mathrm{~s}, 2 \mathrm{H}), 2.263(\mathrm{~s}, 2 \mathrm{H}), 1.787$ (t, 2H). MS (calculated): 983.18 [M-H], $1005.16\left[\mathrm{M}-2 \mathrm{H}+\mathrm{Na}^{+}\right], 491.09[\mathrm{M}-2 \mathrm{H}], 502.58\left[\mathrm{M}-3 \mathrm{H}+\mathrm{Na}^{+}\right]$. HRMS (observed, ESI-) 983.17713 [M-H], $1005.15929\left[\mathrm{M}-2 \mathrm{H}+\mathrm{Na}^{+}\right], 491.08576[\mathrm{M}-2 \mathrm{H}], 502.57840\left[\mathrm{M}-3 \mathrm{H}+\mathrm{Na}^{+}\right]$.

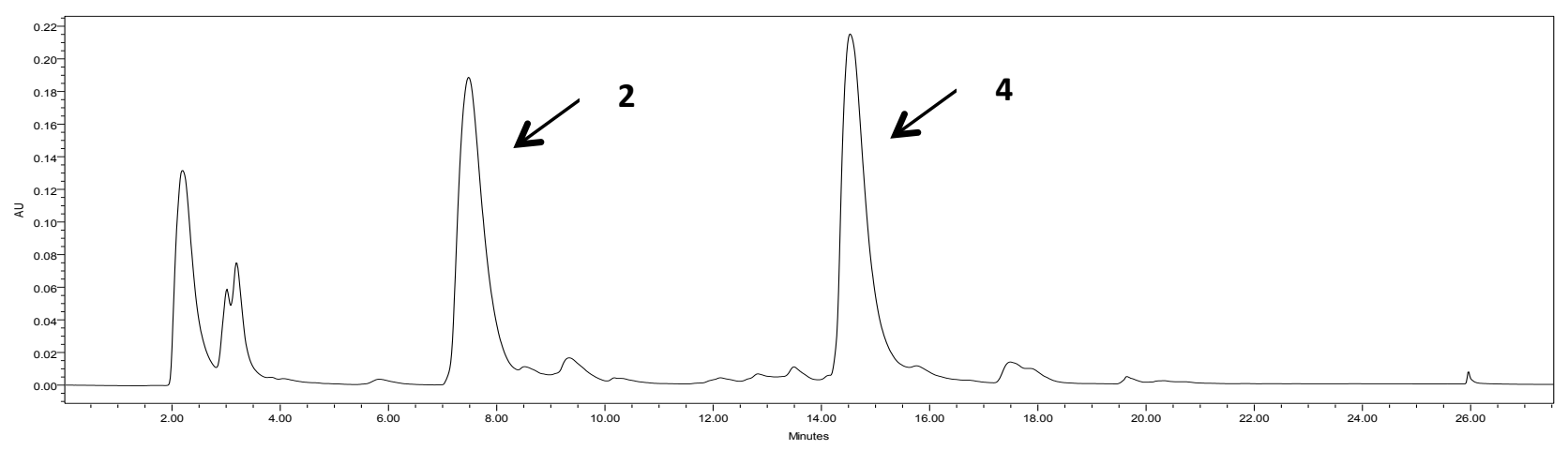

Figure S3. Crude semi-preparative HPLC trace of the synthesis of $\mathbf{4}$ from $\mathbf{3}$ at $280 \mathrm{~nm}$. 


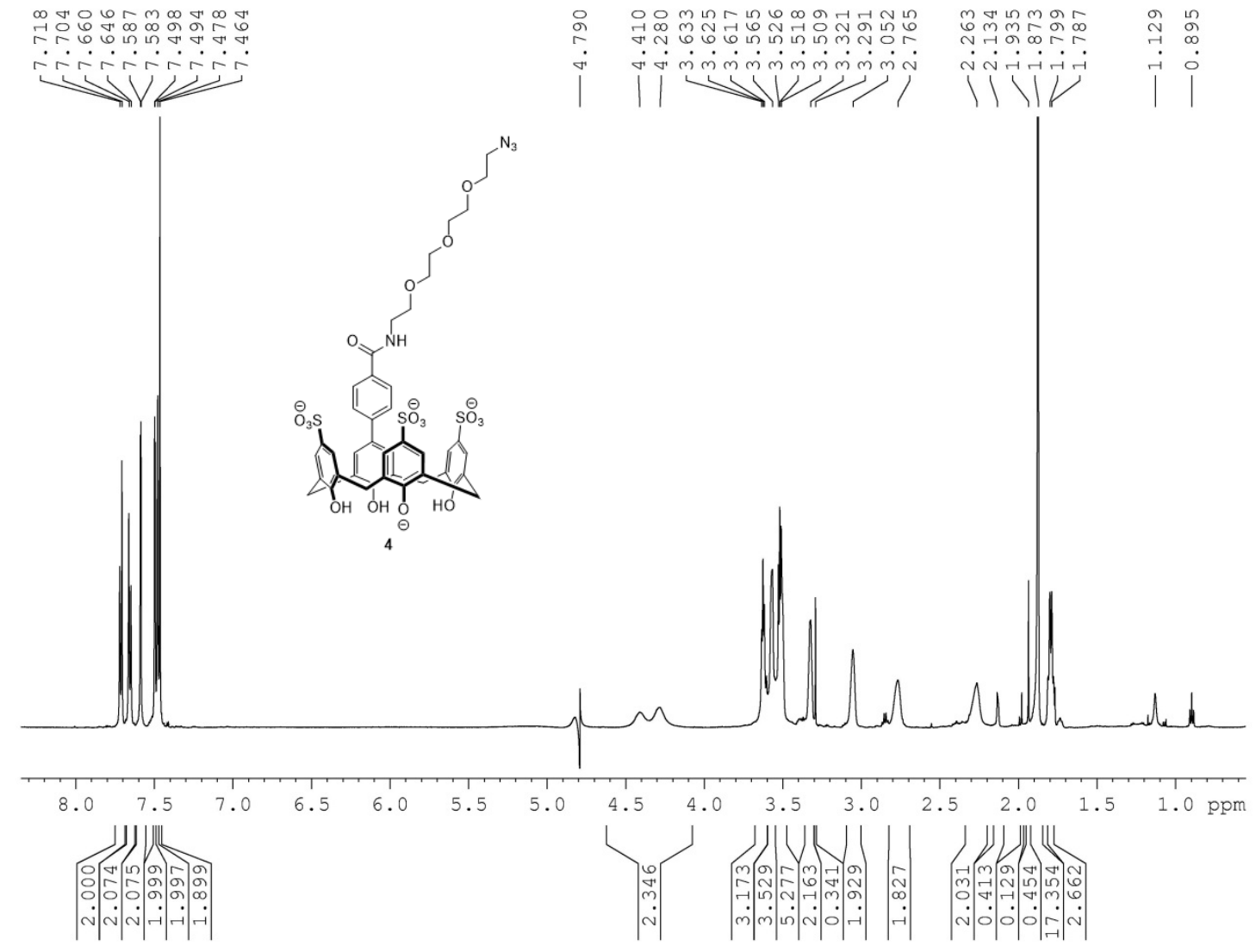

Figure S4. ${ }^{1} \mathrm{H}-\mathrm{NMR}(600 \mathrm{MHz})$ of Compound 4 in $\mathrm{D}_{2} \mathrm{O}$. 

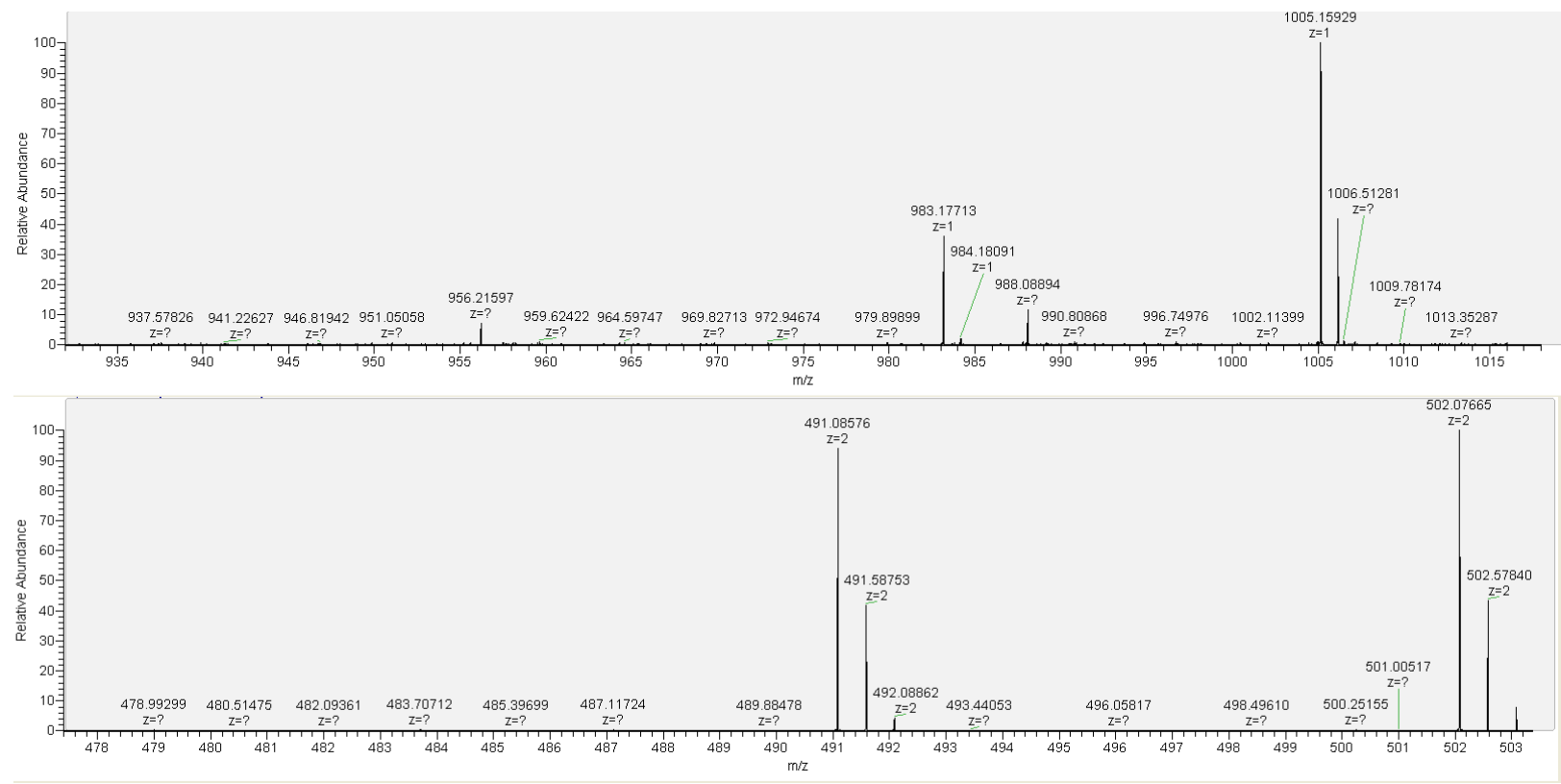

Figure S5. High resolution mass spectrum of Compound 4.

Synthesis of 5: The crude residue containing 4 ( $0.037 \mathrm{~g}, 0.038 \mathrm{mmol}, 1$ equiv.) and 1 ( $0.049 \mathrm{~g}$, $0.22 \mathrm{mmol}, 5.8$ equiv.) were dissolved in $5 \mathrm{~mL} \mathrm{DMF} / 100 \mathrm{mM}$ sodium acetate, $\mathrm{pH} 5.5$ (4:1). Copper iodide $(0.001 \mathrm{~g}, 0.005 \mathrm{mmol}, 0.13$ equiv.) was added, and the solution was allowed to stir at room temperature for $48 \mathrm{~h}$. The solvent was removed under reduced pressure, and the resulting residue was purified by semi-preparative reversed-phase HPLC (solvent A: $10 \mathrm{mM}$ $\mathrm{NH}_{4} \mathrm{OAc}$ in 9:1 $\mathrm{H}_{2} \mathrm{O}: \mathrm{CH}_{3} \mathrm{CN}$; solvent B: $10 \mathrm{mM} \mathrm{NH}_{4} \mathrm{OAc}$ in 9:1 $\mathrm{CH}_{3} \mathrm{CN}: \mathrm{H}_{2} \mathrm{O}$ ) using the gradient: $0-100 \% \mathrm{~B}$ from $0-60 \mathrm{~min}$ with a flow rate of $4.0 \mathrm{~mL} / \mathrm{min}$ to produce the desired compound in 14\% yield. ${ }^{1} \mathrm{H}$ NMR $\left(\mathrm{D}_{2} \mathrm{O}, 600 \mathrm{MHz}\right): 7.996(\mathrm{~s}, 1 \mathrm{H}), 7.662(\mathrm{~s}, 2 \mathrm{H}), 7.639(\mathrm{~s}, 2 \mathrm{H})$, 7.264-7.295 (m, 4H), 7.104-7.128 (m, 5H), $6.630(\mathrm{~d}, 1 \mathrm{H}), 5.167(\mathrm{~s}, 2 \mathrm{H}), 4.502(\mathrm{t}, 2 \mathrm{H}), 3.841(\mathrm{t}$, $2 \mathrm{H}), 3.506-3.657(\mathrm{~m}, 12 \mathrm{H})$. MS (calculated) $1202.21[\mathrm{M}-\mathrm{H}], 1224.18\left[\mathrm{M}-2 \mathrm{H}+\mathrm{Na}^{+}\right], 600.60[\mathrm{M}-$ 2H], 611.59 [M-3H+Na ${ }^{+}$. HRMS (observed, ESI-) 1202.20580 [M-H], 1224.18764 [M$\left.2 \mathrm{H}+\mathrm{Na}^{+}\right], 600.59975[\mathrm{M}-2 \mathrm{H}], 611.59092\left[\mathrm{M}-3 \mathrm{H}+\mathrm{Na}^{+}\right]$. 


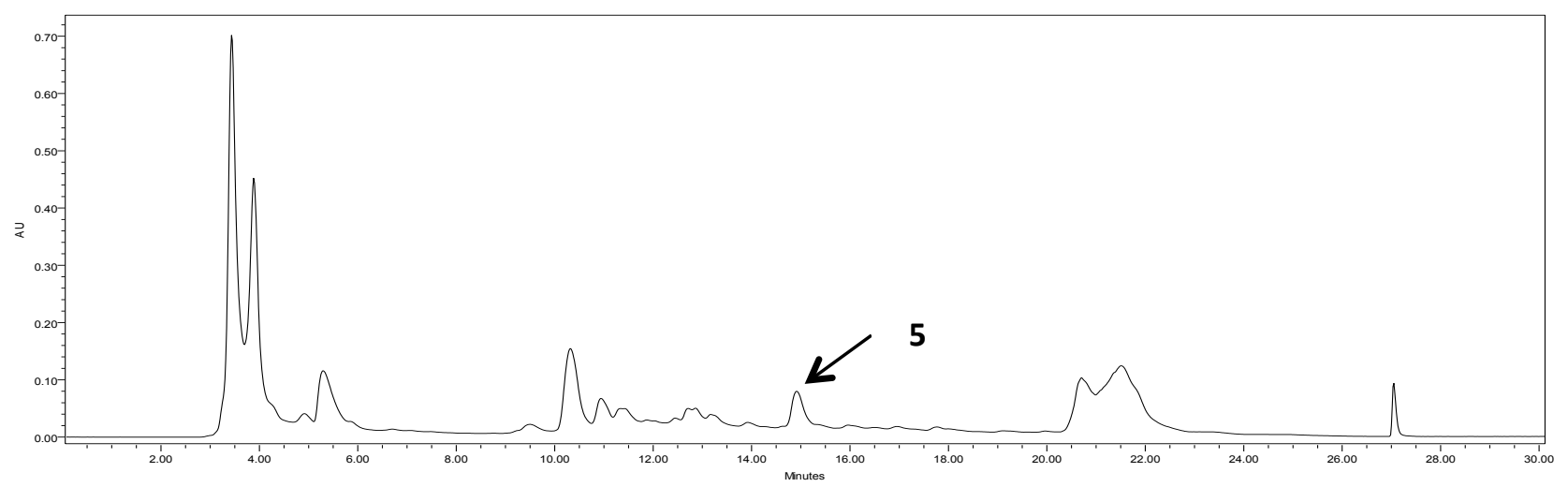

Figure S6. Crude semi-preparative HPLC trace of 5 at $280 \mathrm{~nm}$.

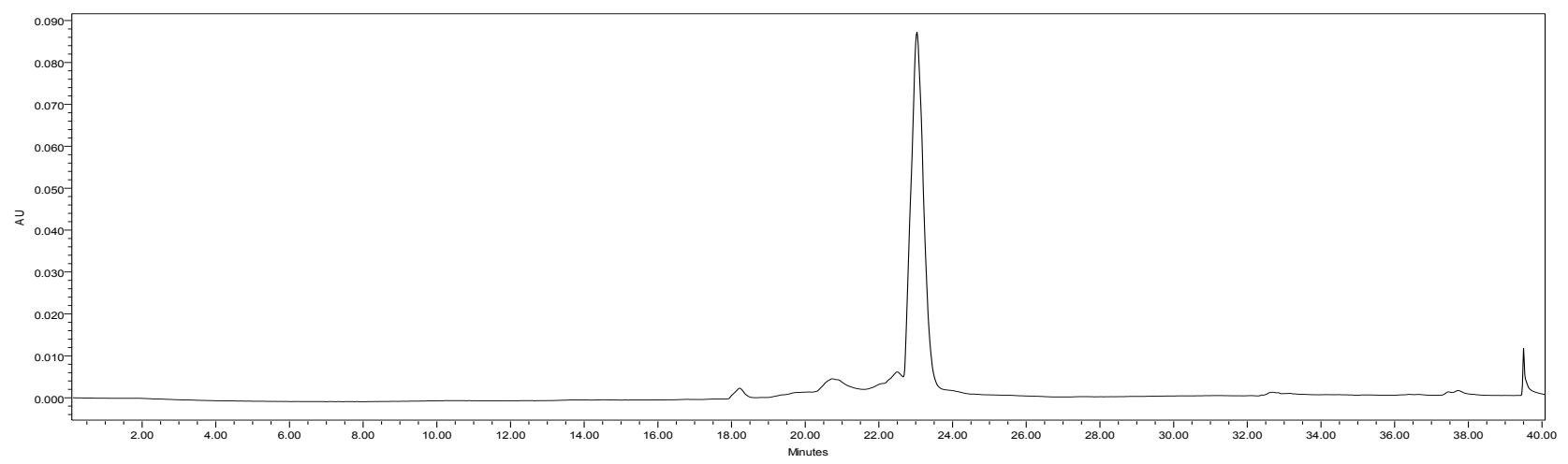

Figure S7. Semi-preparative HPLC trace prior to second purification of 5 at $280 \mathrm{~nm}$. 


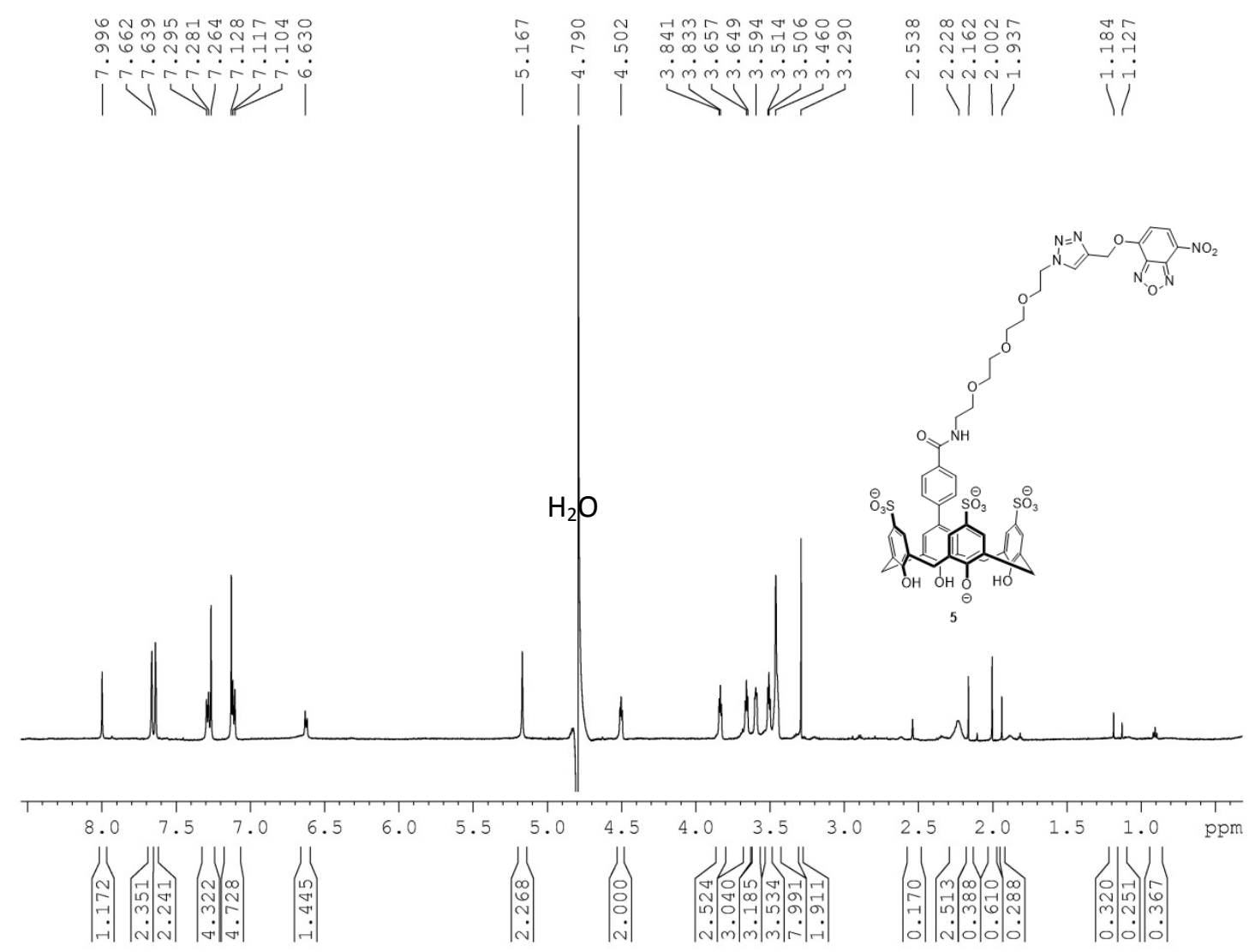

Figure S8. ${ }^{1} \mathrm{H}-\mathrm{NMR}(600 \mathrm{MHz})$ of Compound 5 in $\mathrm{D}_{2} \mathrm{O}$.

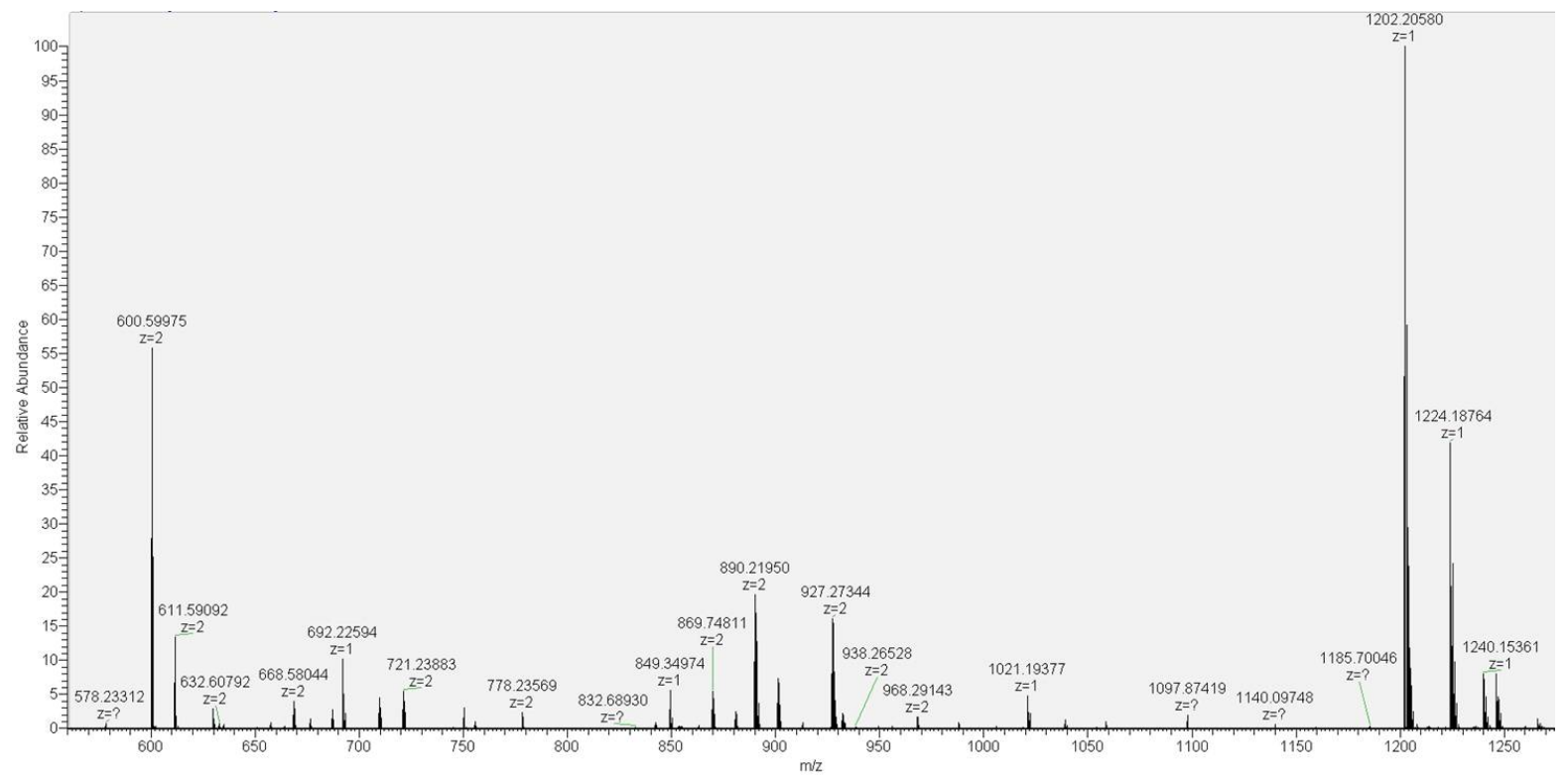

Figure S9. High resolution mass spectrum of compound 5 (ESI-). 


\section{Peptide Synthesis}

Peptides were synthesized on a $0.6 \mathrm{mmol}$ scale via solid-phase peptide synthesis in a peptide synthesis flask using Fmoc protected amino acids. Coupling reagents were HOBt/HBTU in DMF (4 equiv each), with coupling times of $60 \mathrm{~min}$, followed by rinsing with $\mathrm{DMF}, \mathrm{MeOH}$, and $\mathrm{CH}_{2} \mathrm{Cl}_{2}$. Deprotection was performed with $20 \%$ piperidine in DMF. All peptides were acylated at the N-terminus with a solution of 5\% acetic anhydride and 6\% 2,6-lutidine in DMF. Cleavage was performed using a cocktail of $95 \% \mathrm{TFA} / 2.5 \%$ triisopropylsilane $/ 2.5 \% \mathrm{H}_{2} \mathrm{O}$ for 3 hours. Peptides were purified by semi-preparative reverse-phase HPLC on a $\mathrm{C} 18$ column at a flow rate of $4 \mathrm{~mL} / \mathrm{min}$. Peptides were purified with a linear gradient of $\mathrm{A}$ and $\mathrm{B}\left(\mathrm{A}: 95 \% \mathrm{H}_{2} \mathrm{O} / 5 \% \mathrm{CH}_{3} \mathrm{CN}\right.$ with $0.1 \%$ TFA, B: $95 \% \mathrm{CH}_{3} \mathrm{CN} / 5 \% \mathrm{H}_{2} \mathrm{O}$ with $0.1 \%$ TFA).

Methylated peptides were synthesized with 2 equivalents of Fmoc-Lys( $\mathrm{Me})_{2}-\mathrm{OH} \mathrm{HCl}$ purchased from EMP Millipore and coupled for 5 hours. The trimethyllysine containing peptides were synthesized by reacting corresponding dimethylated peptides $(0.06 \mathrm{mmol} \mathrm{scale})$ prior to cleavage from the resin with MTBD (7-Methyl-1,5,7-triazabicyclo[4.4.0]dec-5-ene, 10 equiv.) and methyl iodide (10 equiv.) in DMF ( $5 \mathrm{~mL}$ ) for 5 hours with bubbling nitrogen in a peptide flask. After washing the resin with DMF and $\mathrm{CH}_{2} \mathrm{Cl}_{2}$ and drying, the peptide was cleaved as normal.

Acetylated peptides were prepared from 4 equivalents of Fmoc-Lys(ivDde)-OH purchased from Chem Impex with 1 hour couplings. The ivDde group was deprotected using 5\% hydrazine hydrate in DMF ( $3 \times 10 \mathrm{~mL}$ ) for 5 minutes. After washing resin with DMF, $\mathrm{MeOH}$, and $\mathrm{CH}_{2} \mathrm{Cl}_{2}$, peptides were acetylated using a solution of 5\% acetic anhydride and 6\% 2,6-lutidine in DMF. Peptides were cleaved from the resin as normal after washing with $\mathrm{DMF}, \mathrm{MeOH}$, and $\mathrm{CH}_{2} \mathrm{Cl}_{2}$.

Peptides:

\section{K9K14: Ac-WGGQTARKSTGGK-NH 2}

K9me ${ }_{3} \mathrm{~K} 14:$ Ac-WGGQTARK $\left(\mathrm{me}_{3}\right) \mathrm{STGGK}-\mathrm{NH}_{2}$

K9me ${ }_{3}$ R14: Ac-WGGGQTARK(me $\left.{ }_{3}\right)$ STGGR-NH ${ }_{2}$

K4me ${ }_{3}$ K9ac: Ac-WGGTK(me $\left.{ }_{3}\right)$ QTARK(ac)STG-NH ${ }_{2}$

K4me3K9: Ac-WGGTKme ${ }_{3}$ QTARKSTG-NH 2

K27acK36me $:$ Ac-WGGRK(ac)SAPATGGVK(me m $_{3}$-NH2

K27K36me ${ }_{3}$ : Ac-WGGRKSAPATGGVK(me 3$)-\mathrm{NH}_{2}$

$\mathrm{RKme}_{3} \mathrm{GLLYK}: \mathrm{Ac}-\mathrm{RK}\left(\mathrm{me}_{3}\right) \mathrm{GLLYK} \mathrm{NH}_{2}$ 


\section{K9K14}

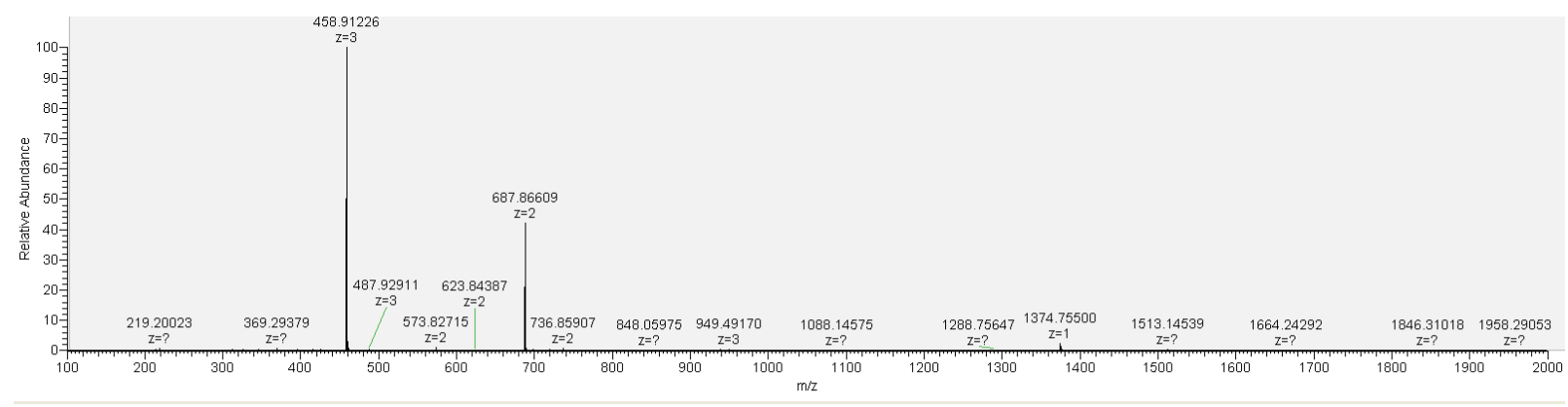

Figure S10. High resolution mass spectrum of K9 K14 (ESI +). MS calculated: 1374.73 [M+H], $687.87[\mathrm{M}+2 \mathrm{H}], 458.91[\mathrm{M}+3 \mathrm{H}]$. MS observed: $1374.75500[\mathrm{M}+\mathrm{H}], 687.86609[\mathrm{M}+2 \mathrm{H}]$, $458.91226[\mathrm{M}+3 \mathrm{H}]$.

\section{$\mathrm{K}^{2} \mathrm{me}_{3} \mathrm{~K} 14$}

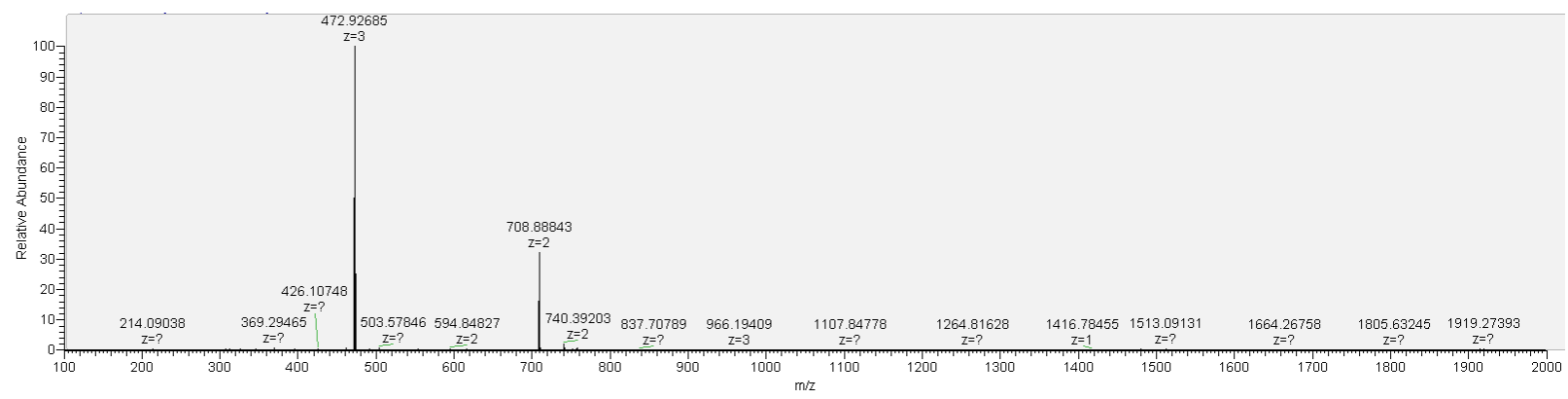

Figure S11. High resolution mass spectrum of K9me 3 K14 (ESI +). MS calculated: 1416.77 [M], $708.89[\mathrm{M}+\mathrm{H}], 472.93[\mathrm{M}+2 \mathrm{H}]$. MS observed: $1416.78455[\mathrm{M}], 708.88843[\mathrm{M}+\mathrm{H}], 472.92685$ $[\mathrm{M}+2 \mathrm{H}]$.

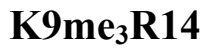

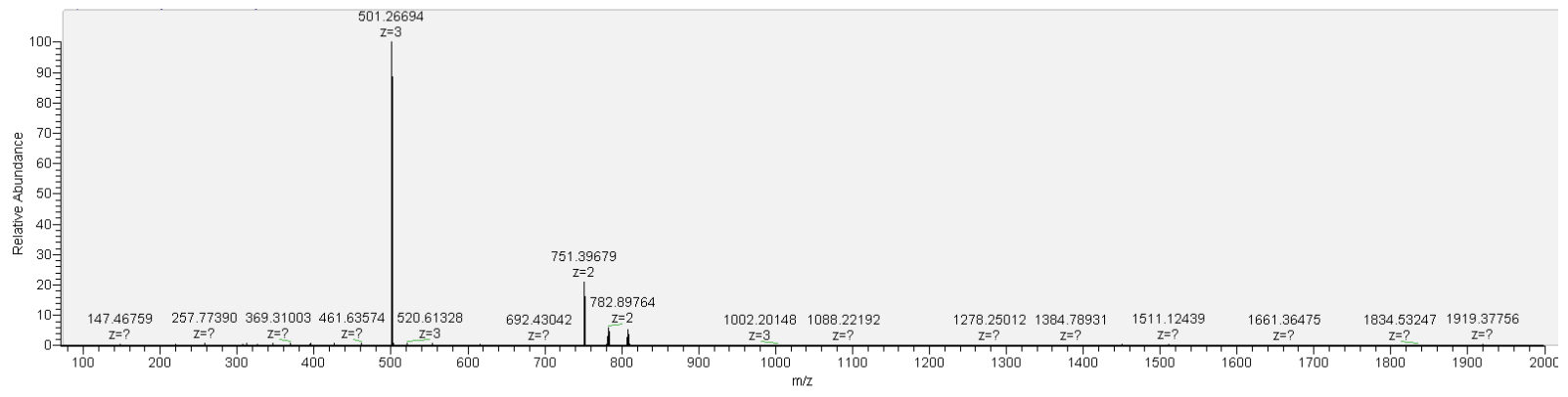

Figure S12. High resolution mass spectrum of K9me ${ }_{3}$ R14 (ESI +). MS calculated: 751.40 $[\mathrm{M}+1 \mathrm{H}], 501.27[\mathrm{M}+2 \mathrm{H}]$. Mass observed: $751.39679[\mathrm{M}+1 \mathrm{H}], 501.26694[\mathrm{M}+2 \mathrm{H}]$. 


\section{$\mathrm{K}_{4} \mathrm{me}_{3} \mathrm{K9a}$}

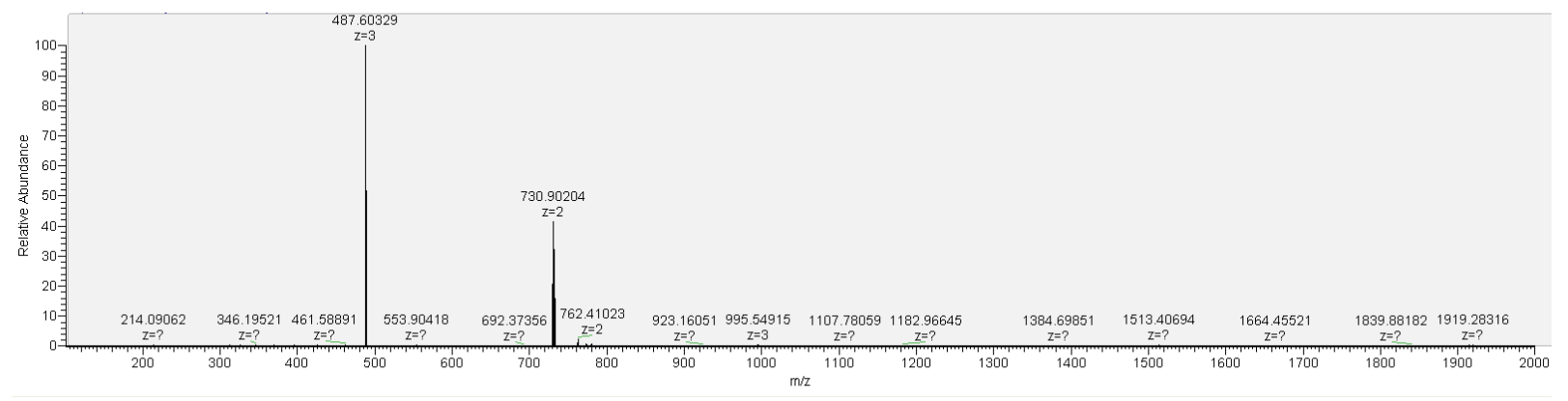

Figure S13. High resolution mass spectrum of K4me ${ }_{3} \mathrm{~K} 9$ (ESI +). MS calculated: 730.90 $[\mathrm{M}+\mathrm{H}], 487.61[\mathrm{M}+2 \mathrm{H}]$. MS observed: $730.90204[\mathrm{M}+\mathrm{H}], 487.60329[\mathrm{M}+2 \mathrm{H}]$.

\section{$\mathrm{K}_{4} \mathrm{me}_{3} \mathrm{K9ac}$}

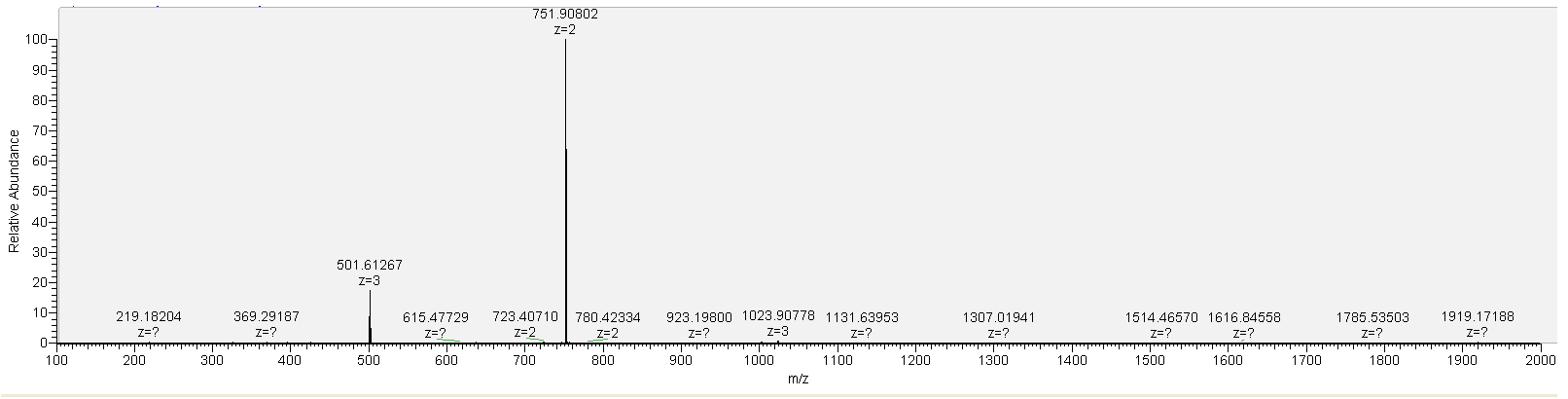

Figure S14. High resolution mass spectrum of $\mathrm{K} 4 \mathrm{me}_{3} \mathrm{~K} 9 \mathrm{ac}(\mathrm{ESI}+)$. MS calculated: 751.91 $[\mathrm{M}+\mathrm{H}], 501.61[\mathrm{M}+2 \mathrm{H}]$. MS observed: $751.90802[\mathrm{M}+\mathrm{H}], 501.61267[\mathrm{M}+2 \mathrm{H}]$. 


\section{$\mathrm{K}_{27 K 36 m e}$}

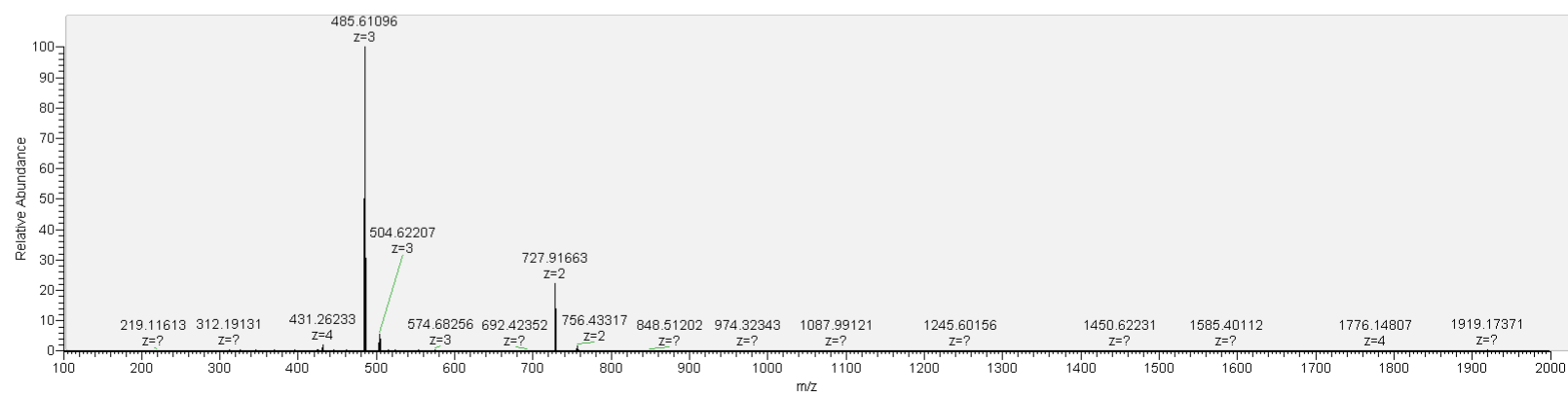

Figure S15. High resolution mass spectrum of K27 K36me 3 (ESI +). MS calculated: 727.91 $[\mathrm{M}+\mathrm{H}], 485.61[\mathrm{M}+2 \mathrm{H}]$. MS observed: $727.91663[\mathrm{M}+\mathrm{H}], 485.61096[\mathrm{M}+2 \mathrm{H}]$.

\section{$\mathrm{K}_{27} \mathbf{a c K 3 6 m e}_{3}$}

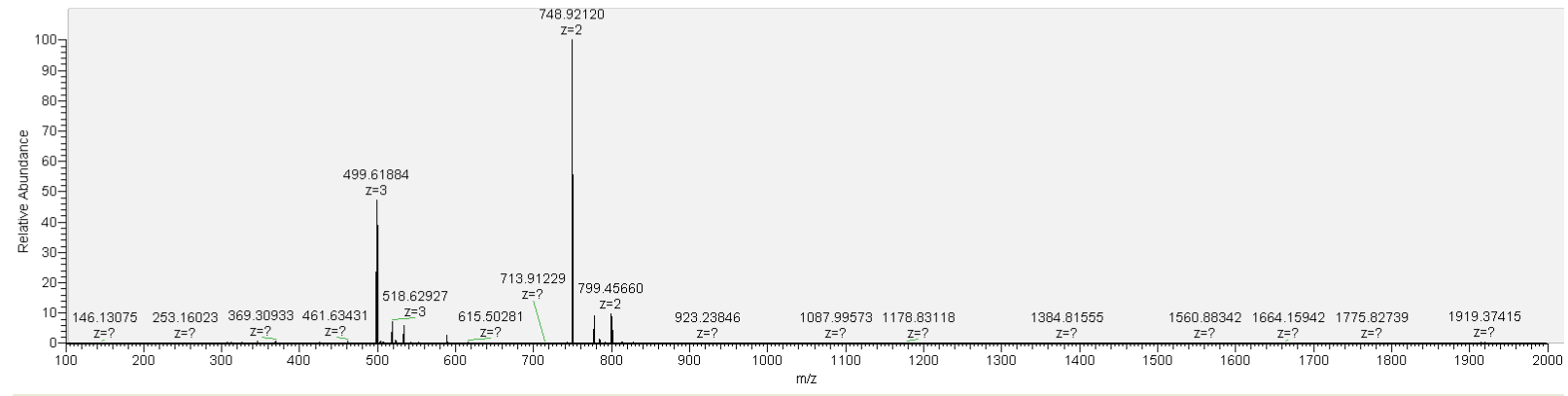

Figure S16. High resolution mass spectrum of K27ac K36me 3 (ESI +). MS calculated: 748.92 $[\mathrm{M}+\mathrm{H}], 499.62[\mathrm{M}+2 \mathrm{H}]$. MS observed: $748.92120[\mathrm{M}+\mathrm{H}], 499.61884[\mathrm{M}+2 \mathrm{H}]$.

\section{$\mathrm{K}_{23 \mathrm{~K} 27 \mathrm{me}_{3}}$}

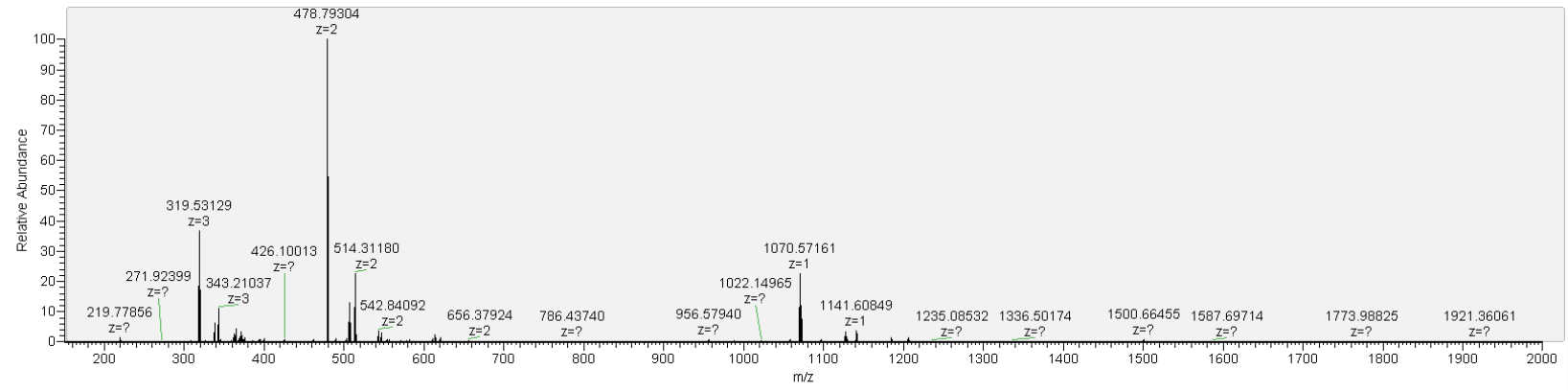

Figure S17. High resolution mass spectrum of K23K27me3 (ESI +). MS calculated: 956.58 [M], $1070.57[\mathrm{M}+\mathrm{TFA}+\mathrm{H}], 478.79[\mathrm{M}+\mathrm{H}], 319.53$ [M+2H]. MS observed: 956.57940 [M], $1070.57161[\mathrm{M}+\mathrm{TFA}+\mathrm{H}], 478.79304[\mathrm{M}+\mathrm{H}], 319.53129[\mathrm{M}+2 \mathrm{H}]$. 


\section{$\mathrm{K} 36 \mathrm{me}_{3} \mathrm{~K} 37$}

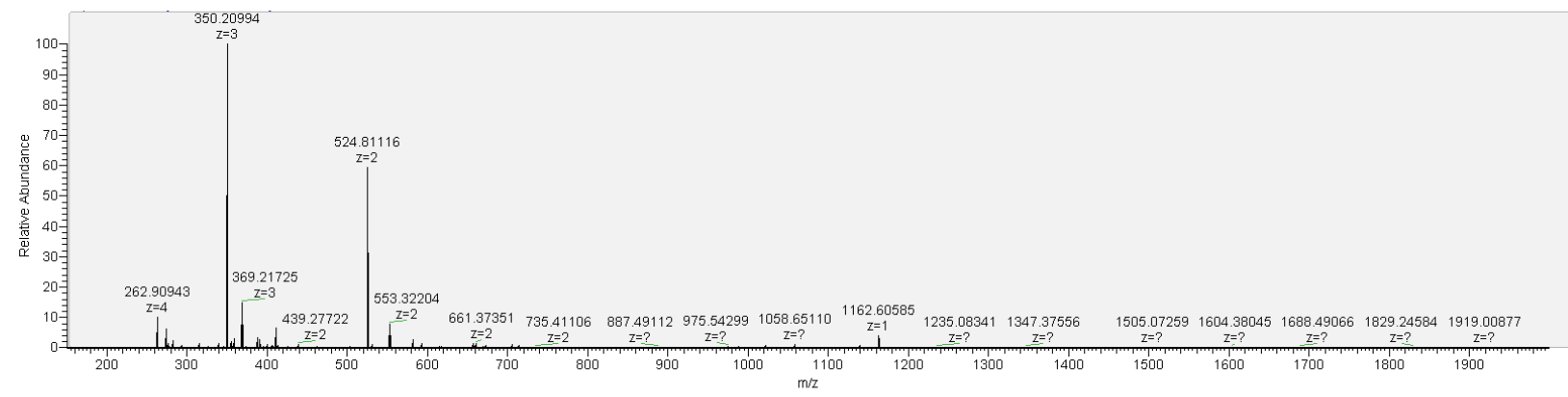

Figure S18. High resolution mass spectrum of K36me3K37 (ESI +). MS calculated: 1162.61 [M+TFA+H], $524.81[\mathrm{M}+\mathrm{H}], 350.21[\mathrm{M}+2 \mathrm{H}]$. MS observed: $1162.60585[\mathrm{M}+\mathrm{TFA}+\mathrm{H}]$, $524.81116[\mathrm{M}+\mathrm{H}], 350.20994[\mathrm{M}+2 \mathrm{H}]$.

\section{$\mathrm{K}_{4} \mathrm{me}_{3} \mathrm{~N}$ terminus}

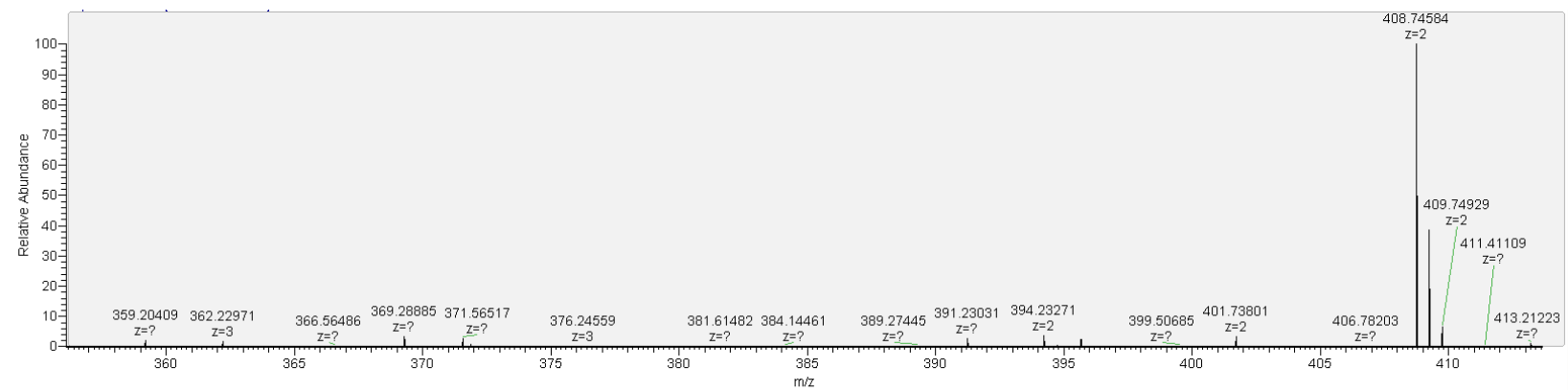

Figure S19. High resolution mass spectrum of K4me3 $\mathrm{N}$ terminus $(\mathrm{ESI}+)$. MS calculated: $408.74[\mathrm{M}+\mathrm{H}]$. MS observed: $408.74584[\mathrm{M}+\mathrm{H}]$.

\section{RKme $_{3}$ GLLYK}

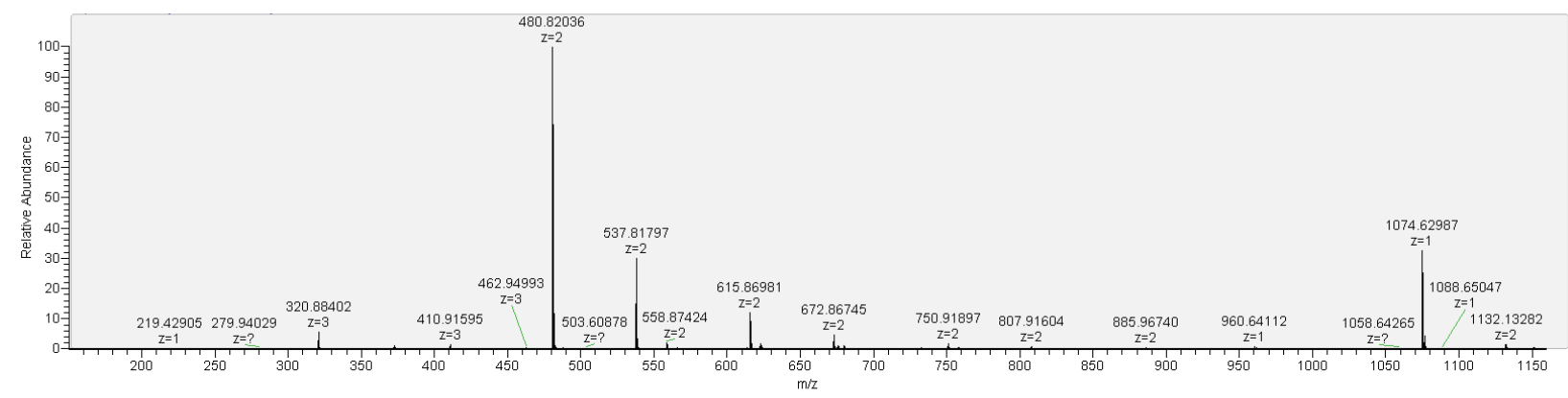

Figure S20. High resolution mass spectrum of K4me3 N terminus (ESI +). MS calculated: 960.64 [M], 1074.63 [M+TFA+H], 480.82 [M+H]. MS observed: 960.64112 [M], 1074.62987 $[\mathrm{M}+\mathrm{TFA}+\mathrm{H}], 480.82036[\mathrm{M}+\mathrm{H}]$. 


\section{Extinction Coefficient Determination for 4.}

Compound 4 was purified using reversed phase-HPLC with $10 \mathrm{mM} \mathrm{NH}_{4} \mathrm{OAc}$ as the mobile phase additive. After purification, 4 was lyophilized for five days to remove volatile $\mathrm{NH}_{4} \mathrm{OAc}$ salts. The dried compound was then dissolved in anhydrous methanol and filtered using a 0.33 $\mu \mathrm{m}$ filter to remove any remaining salts. Methanol was evaporated and $\mathbf{4}$ was further dried under vacuum. The mass was accurately determined, and a $1 \mathrm{mM}$ stock solution of 4 in $10 \mathrm{mM}$ sodium borate buffer, $100 \mathrm{mM} \mathrm{NaCl}, \mathrm{pH} 8.6$ was prepared. The stock solution was serially diluted (80:20, 4:buffer) to give 12 concentrations. The absorbance at $315 \mathrm{~nm}$ was measured for each concentration, which was then plotted against the concentration. The extinction coefficient of 4 was determined from the slope of the line of regression using Beer's law and was found to be $900 \mathrm{M}^{-1} \mathrm{~cm}^{-1}$.

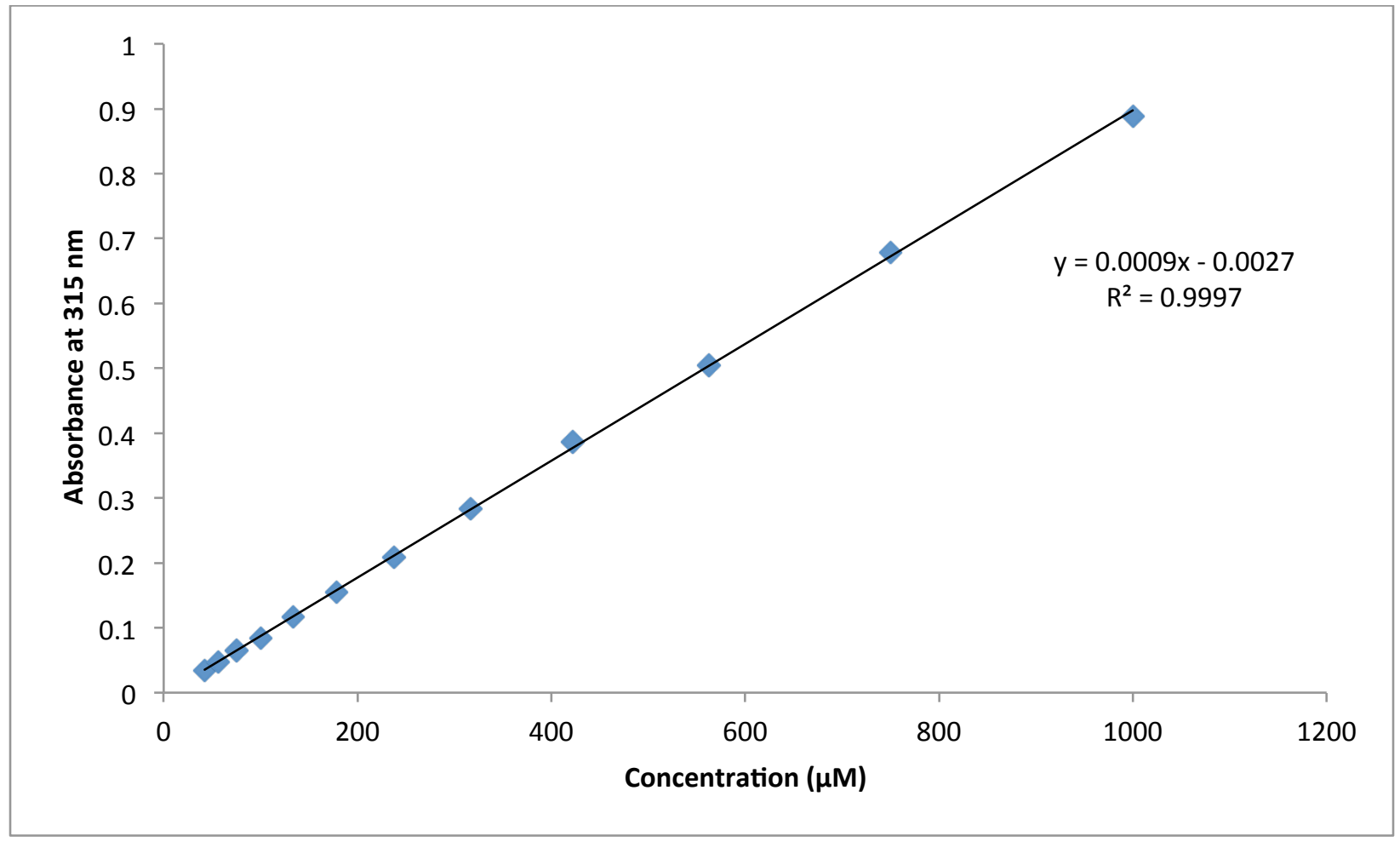

Figure S21. Extinction coefficient determination of $\mathbf{4}$ from the slope of the line of regression. 


\section{Isothermal Titration Calorimetry}

ITC binding experiments were conducted using a Microcal AutoITC200. Titrations were performed at $25^{\circ} \mathrm{C}$ in $10 \mathrm{mM}$ potassium phosphate, $\mathrm{pH} 7.4$ or $10 \mathrm{mM}$ sodium borate, $100 \mathrm{mM}$ $\mathrm{NaCl}, \mathrm{pH}$ 8.6. The concentration of 5 was determined by measuring the UV-vis absorbance at 373 nm, using a NanoDrop2000 with a xenon flash lamp, 2048 element linear silicon CCD array detector, and $1 \mathrm{~mm}$ path length. The concentration of $\mathbf{4}$ was determined from UV-vis absorbance at $315 \mathrm{~nm}$. A solutions of $0.9-1.2 \mathrm{mM}$ of peptide was titrated into a $81-85 \mu \mathrm{M}$ solution of 4 or 5, using $2.0 \mu \mathrm{L}$ increments every $3 \mathrm{~min}$. Heats of dilution were subtracted prior to fitting. Binding curves were produced using the supplied Origin software and fit using one-site binding models.

Table S1. Summary of ITC data from using a one-site binding model. Values represent an average of 3 measurements. Errors are from standard deviation from three separate runs.

\begin{tabular}{|c|c|c|c|c|c|c|c|c|}
\hline Host & Peptide & Sequence & $\begin{array}{c}\text { Net } \\
\text { Charge }\end{array}$ & $\mathbf{K d}(\mu \mathrm{M})$ & $\begin{array}{c}\Delta \mathrm{H} \\
(\mathrm{Kcal} / \mathrm{mol}) \\
\end{array}$ & $\begin{array}{c}\mathrm{T} \Delta \mathrm{S} \\
\text { (Kcal/mol) } \\
\end{array}$ & $\mathbf{N}$ & $\begin{array}{c}\Delta G \\
(\mathrm{Kcal} / \mathrm{mol})\end{array}$ \\
\hline $5^{a}$ & $\mathrm{~K}_{9} \mathrm{me}_{3} \mathrm{R} 14$ & Ac-WGGQTARKme ${ }_{3}$ STGGR-NH ${ }_{2}$ & +3 & $4.8 \pm 1.5$ & $-6.6 \pm 0.4$ & $6.6 \pm 2.9$ & $1.03 \pm 0.04$ & $-7.3 \pm 0.2$ \\
\hline $4^{\mathrm{b}}$ & K9K14 & Ac-WGGQTARKSTGGK-NH & +3 & $390 \pm 440$ & - & - & $0.05 \pm 0.05$ & - \\
\hline $4^{b}$ & $\mathrm{~K} 9 \mathrm{me}_{3} \mathrm{~K} 14$ & Ac-WGGQTARKme ${ }_{3}$ STGGK-NH $_{2}$ & +3 & $18.3 \pm 7.7$ & $-4.9 \pm 0.7$ & $1.62 \pm 0.9$ & $0.53 \pm 0.006$ & $-6.5 \pm 0.2$ \\
\hline
\end{tabular}

(a) $10 \mathrm{mM}$ potassium phosphate, $\mathrm{pH} 7.4$; (b) $10 \mathrm{mM}$ sodium borate, $100 \mathrm{mM} \mathrm{NaCl}, \mathrm{pH} 8.6$

$\mathrm{N}$ values that deviate from 1 are likely due to the error in concentration determination for $\mathbf{4}$, but does not influence the measurement of $\mathrm{Kd}$. 


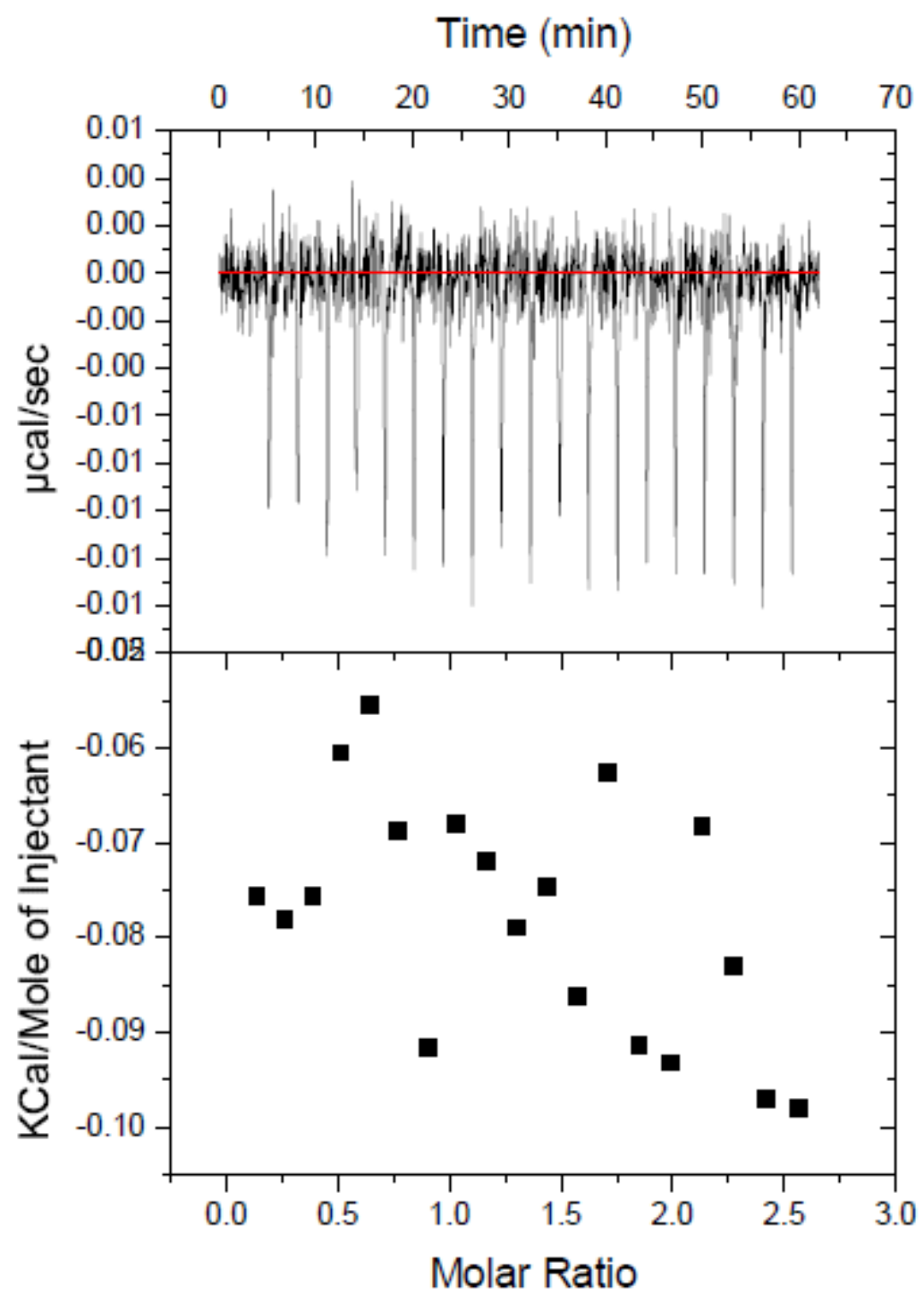

Figure S22. Heat of dilution for titrating $\mathrm{K} \mathrm{me}_{3} \mathrm{R} 14(1.22 \mathrm{mM})$ into $10 \mathrm{mM}$ potassium phosphate buffer $\mathrm{pH}$ 7.4. 


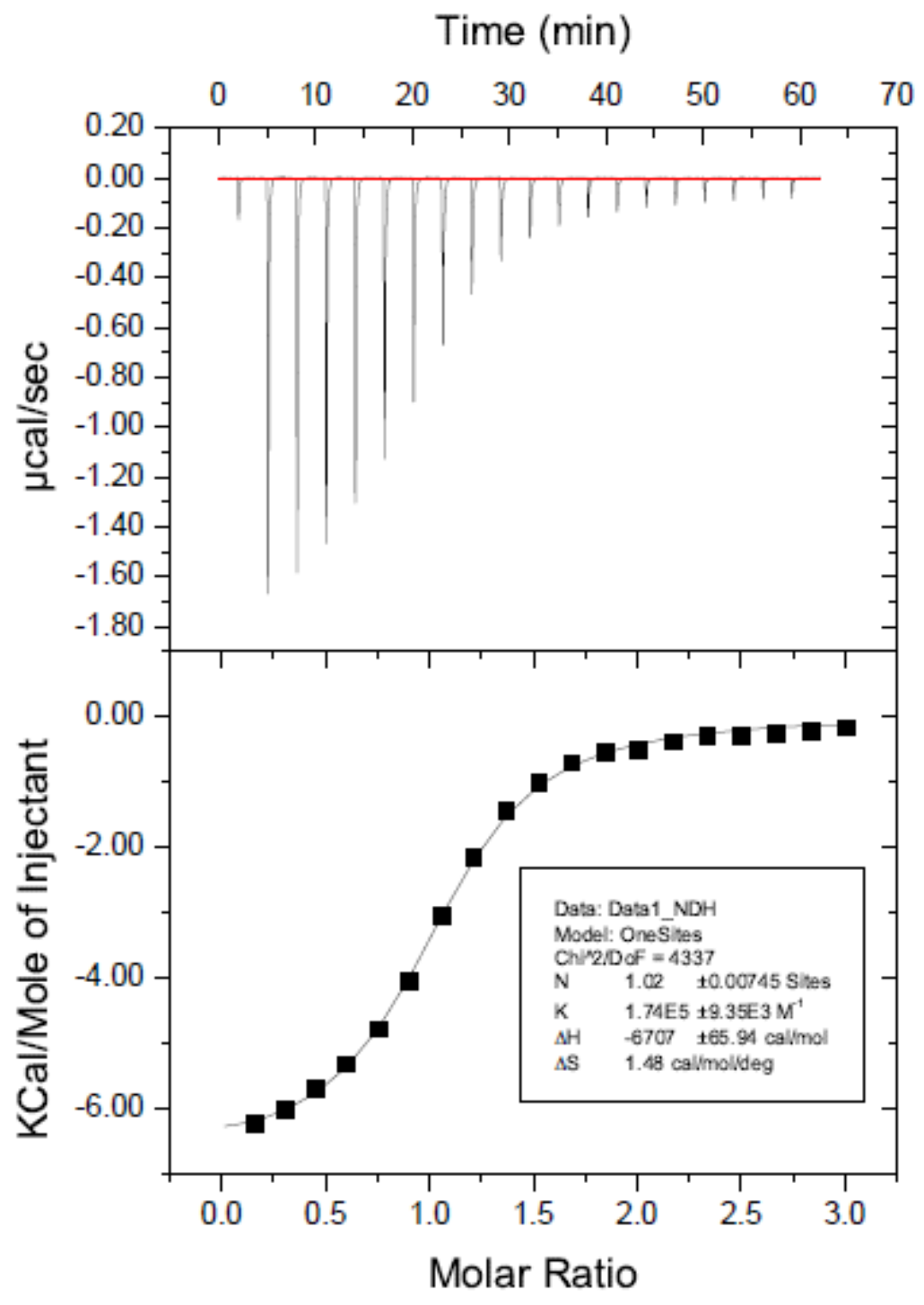

Figure S23. One trial of three of K9me $\mathrm{m}_{3} \mathrm{R} 14$ (Ac-WGGQTARK $\left.\left(\mathrm{me}_{3}\right) \mathrm{STGGR}-\mathrm{NH}_{2}\right)(1.22 \mathrm{mM})$ titrated into $5(82 \mu \mathrm{M})$ at $25^{\circ} \mathrm{C}$ in $10 \mathrm{mM}$ potassium phosphate buffer, pH 7.4 (Run 1). 


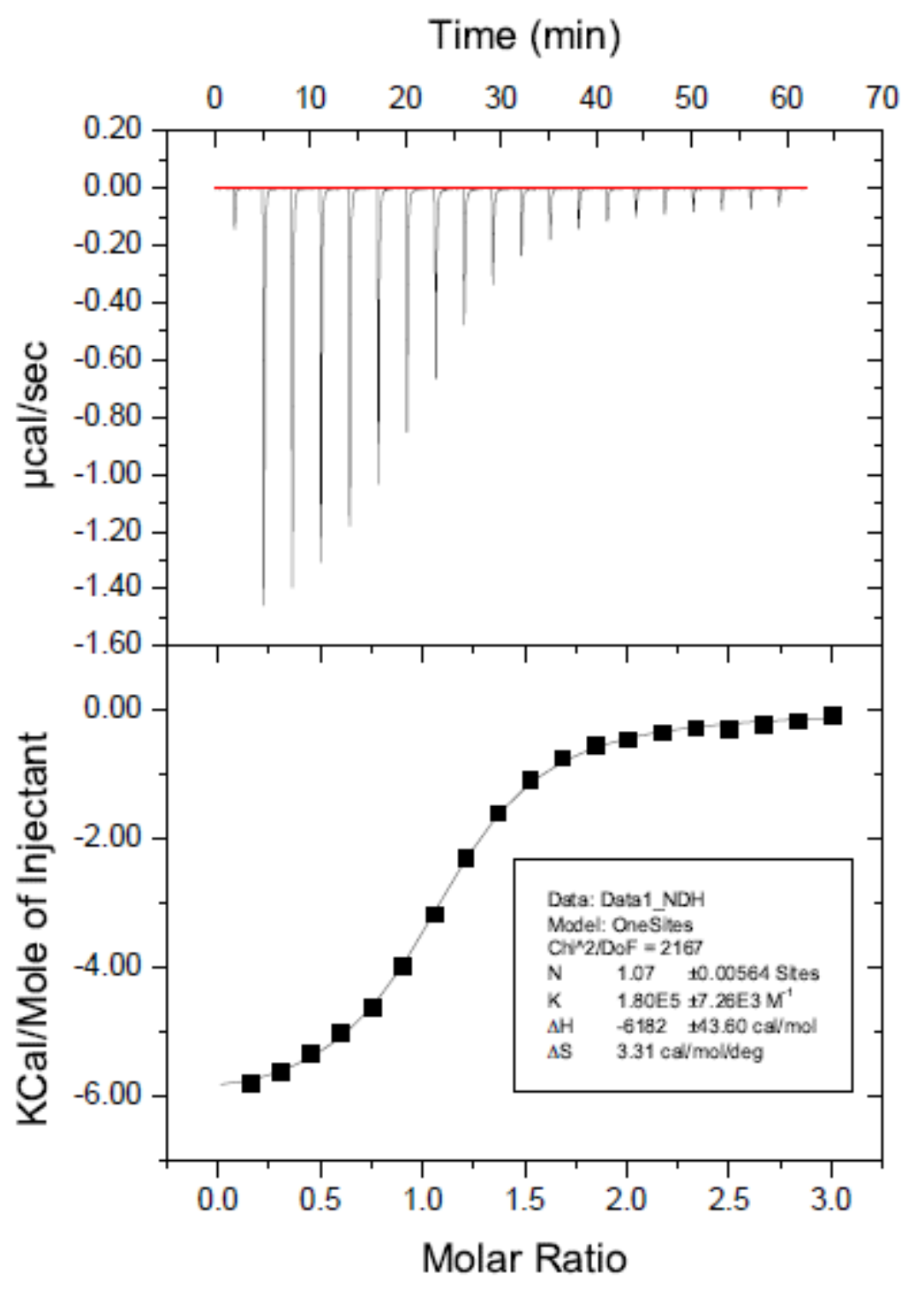

Figure S24. One trial of three of $\mathrm{K} \mathrm{me}_{3} \mathrm{R} 14$ (Ac-WGGQTARK(me $\left.\left.)_{3}\right)_{\mathrm{STGGR}-\mathrm{NH}_{2}}\right)(1.22 \mathrm{mM})$ titrated into $5(82 \mu \mathrm{M})$ at $25^{\circ} \mathrm{C}$ in $10 \mathrm{mM}$ potassium phosphate buffer, pH 7.4 (Run 2). 


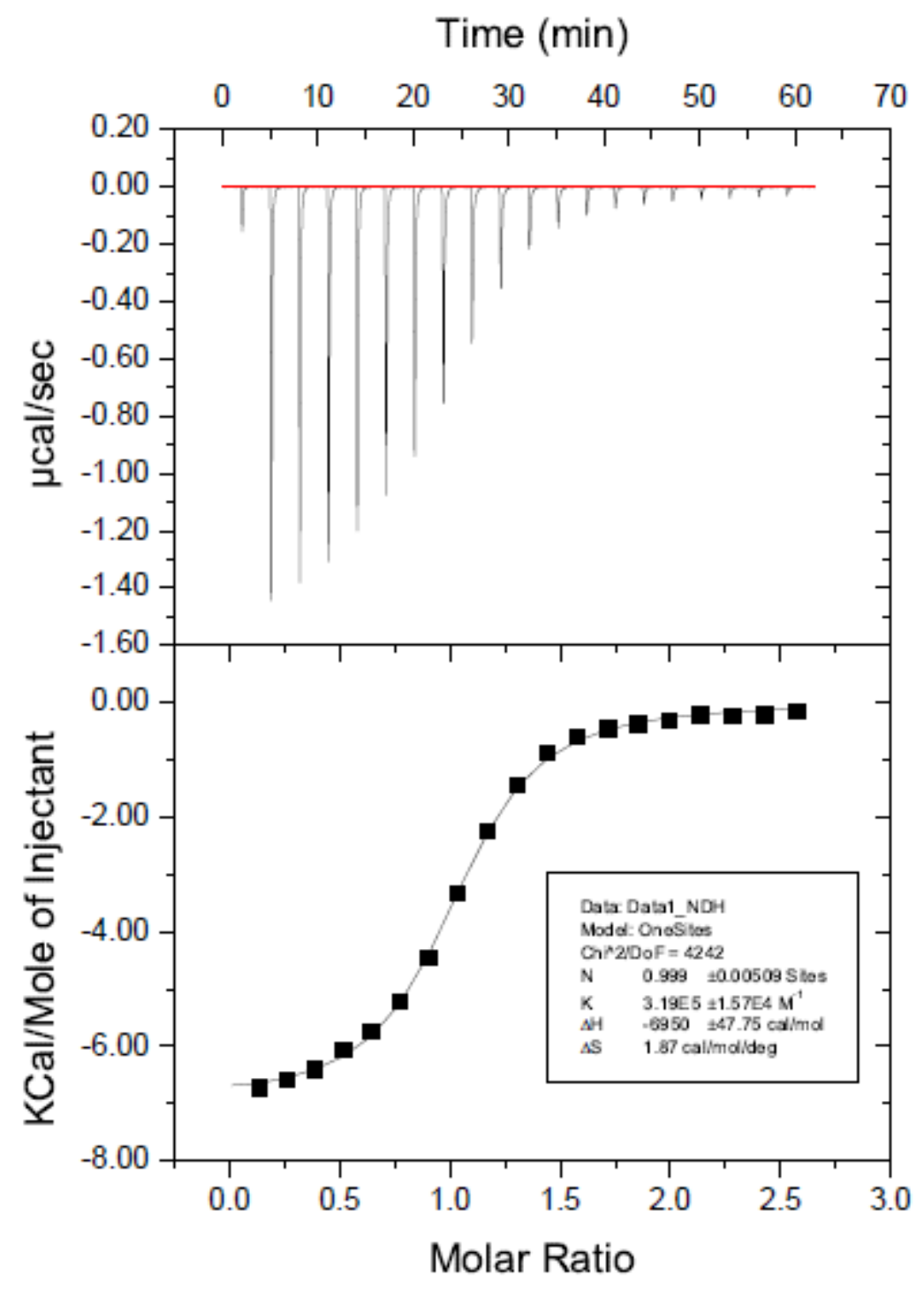

Figure S25. One trial of three of K9me ${ }_{3}$ R14 (Ac-WGGQTARK( $\left.\left.\mathrm{me}_{3}\right) \mathrm{STGGR}_{\mathrm{N}} \mathrm{NH}_{2}\right)(1.03 \mathrm{mM})$ titrated into $5(81 \mu \mathrm{M})$ at $25^{\circ} \mathrm{C}$ in $10 \mathrm{mM}$ potassium phosphate buffer, pH 7.4 (Run 3). 


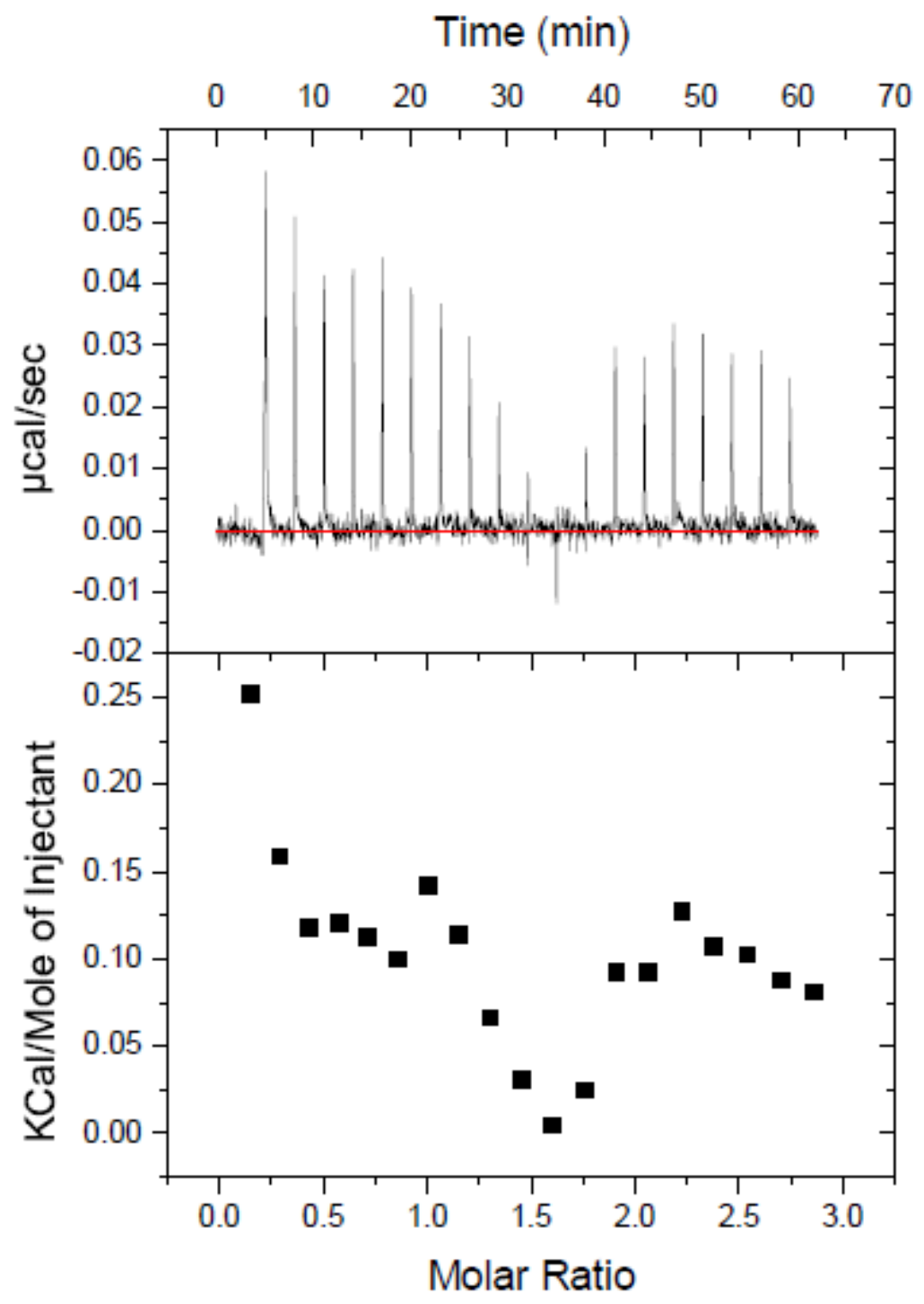

Figure S26. Heat of dilution for titrating K9K14 (Ac-WGGQTARKSTGGK-NH 2$)(1.43 \mathrm{mM})$ into $10 \mathrm{mM}$ sodium borate buffer $\mathrm{pH}$ 8.6. 


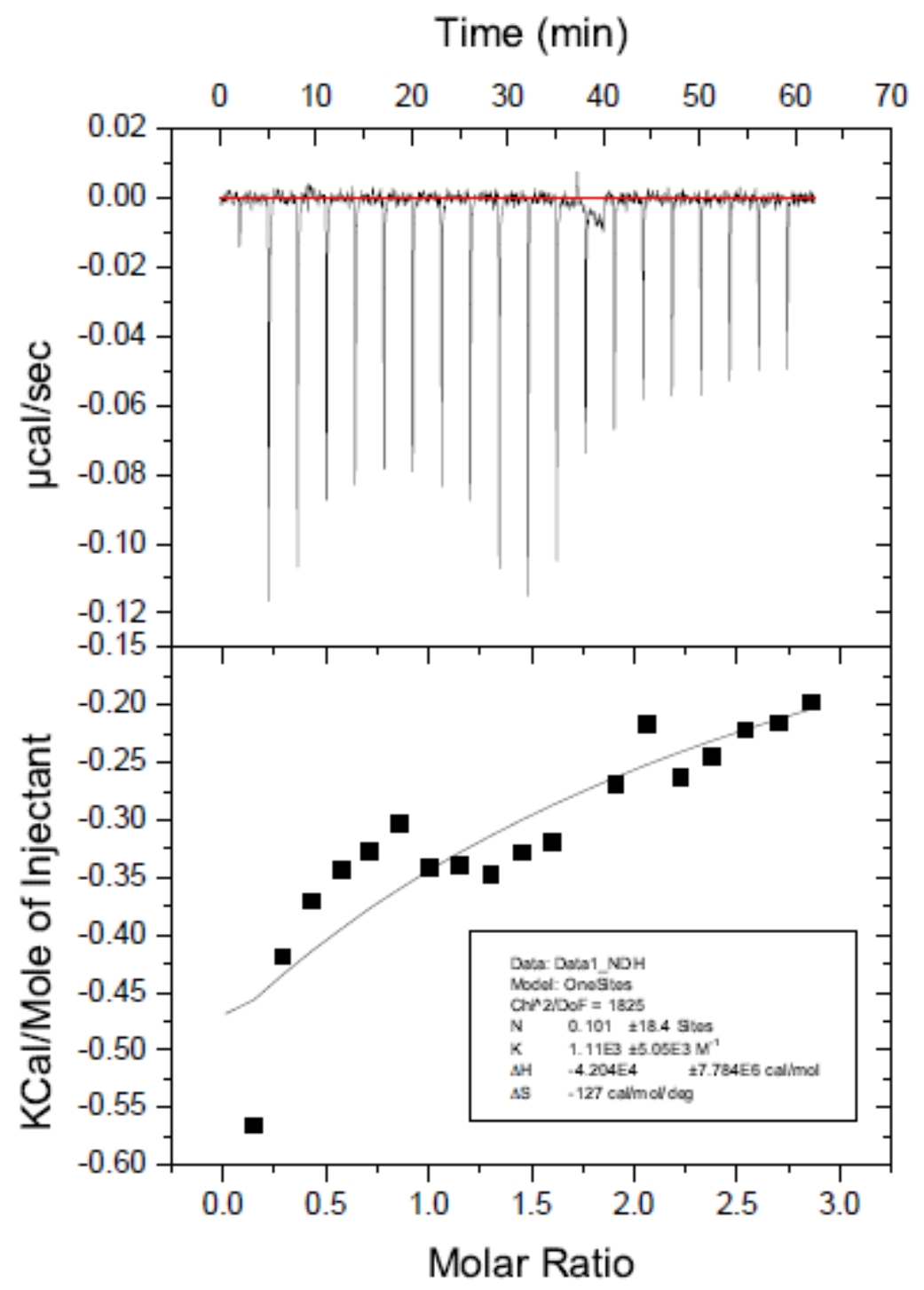

Figure S27. One trial of three of K9 K14 (Ac-WGGQTARKSTGGK-NH $)(1.43 \mathrm{mM})$ titrated into $4(101 \mu \mathrm{M})$ at $25^{\circ} \mathrm{C}$ in $10 \mathrm{mM}$ sodium borate buffer, $\mathrm{pH} 8.6$ (Run 1). 


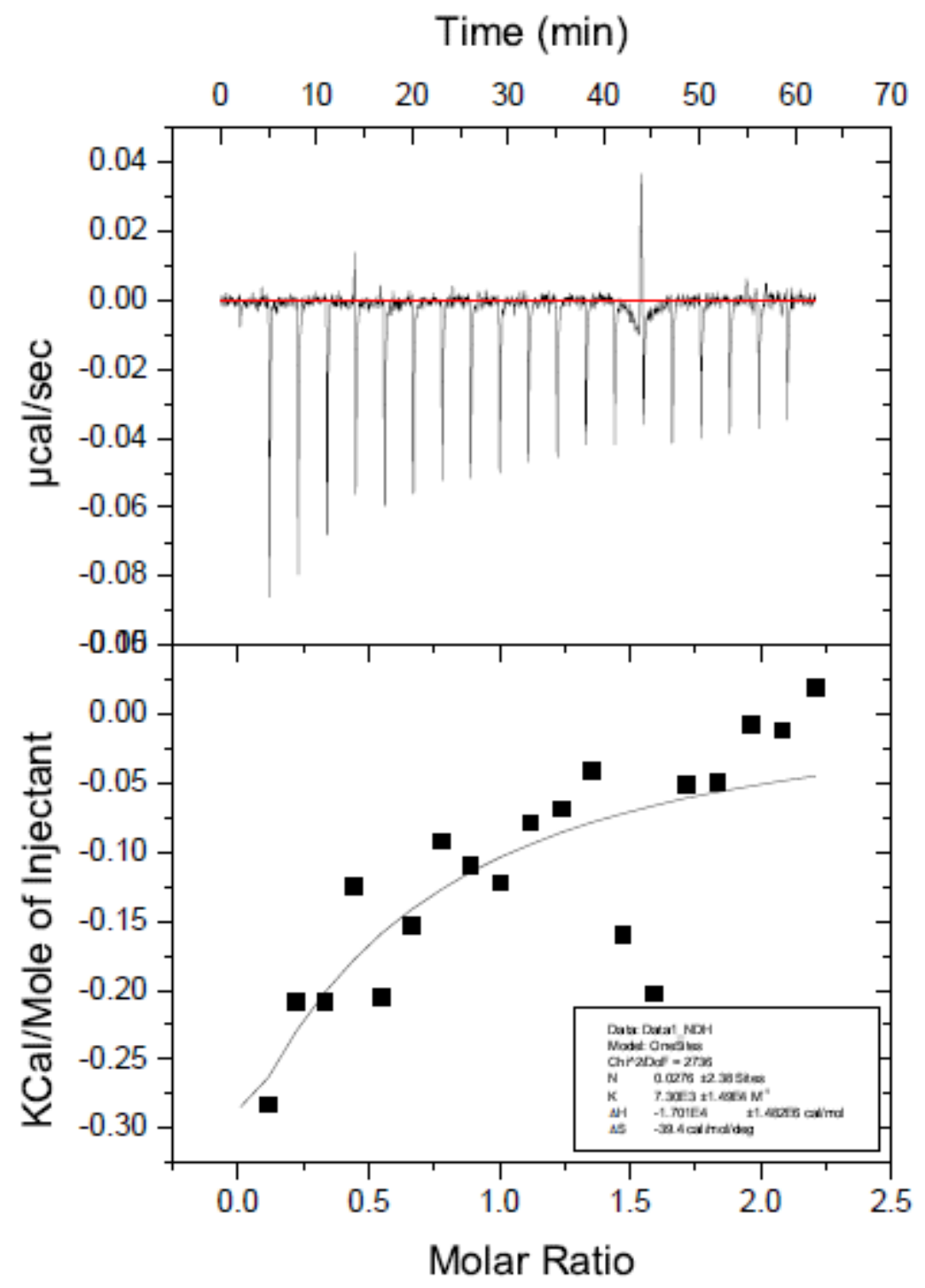

Figure S28. One trial of three of K9 K14 (Ac-WGGQTARKSTGGK-NH $\left.{ }_{2}\right)(0.93 \mathrm{mM})$ titrated into $4(85 \mu \mathrm{M})$ at $25^{\circ} \mathrm{C}$ in $10 \mathrm{mM}$ sodium borate buffer, $\mathrm{pH} 8.6$ (Run 1). 


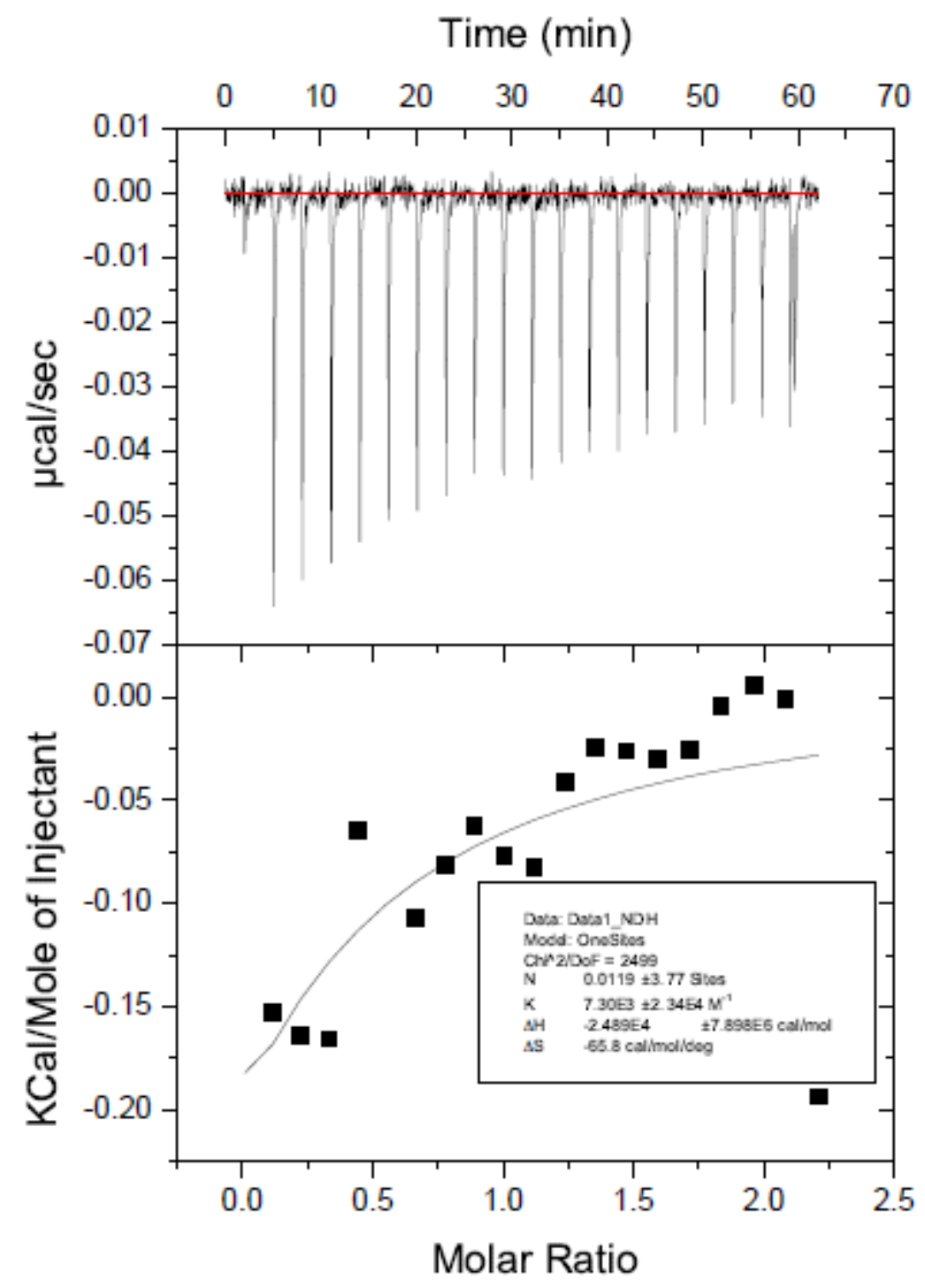

Figure S29. One trial of three of K9 K14 (Ac-WGGQTARKSTGGK-NH $)_{2}(0.93 \mathrm{mM})$ titrated into $4(85 \mu \mathrm{M})$ at $25^{\circ} \mathrm{C}$ in $10 \mathrm{mM}$ sodium borate buffer, $\mathrm{pH} 8.6$ (Run 2). 


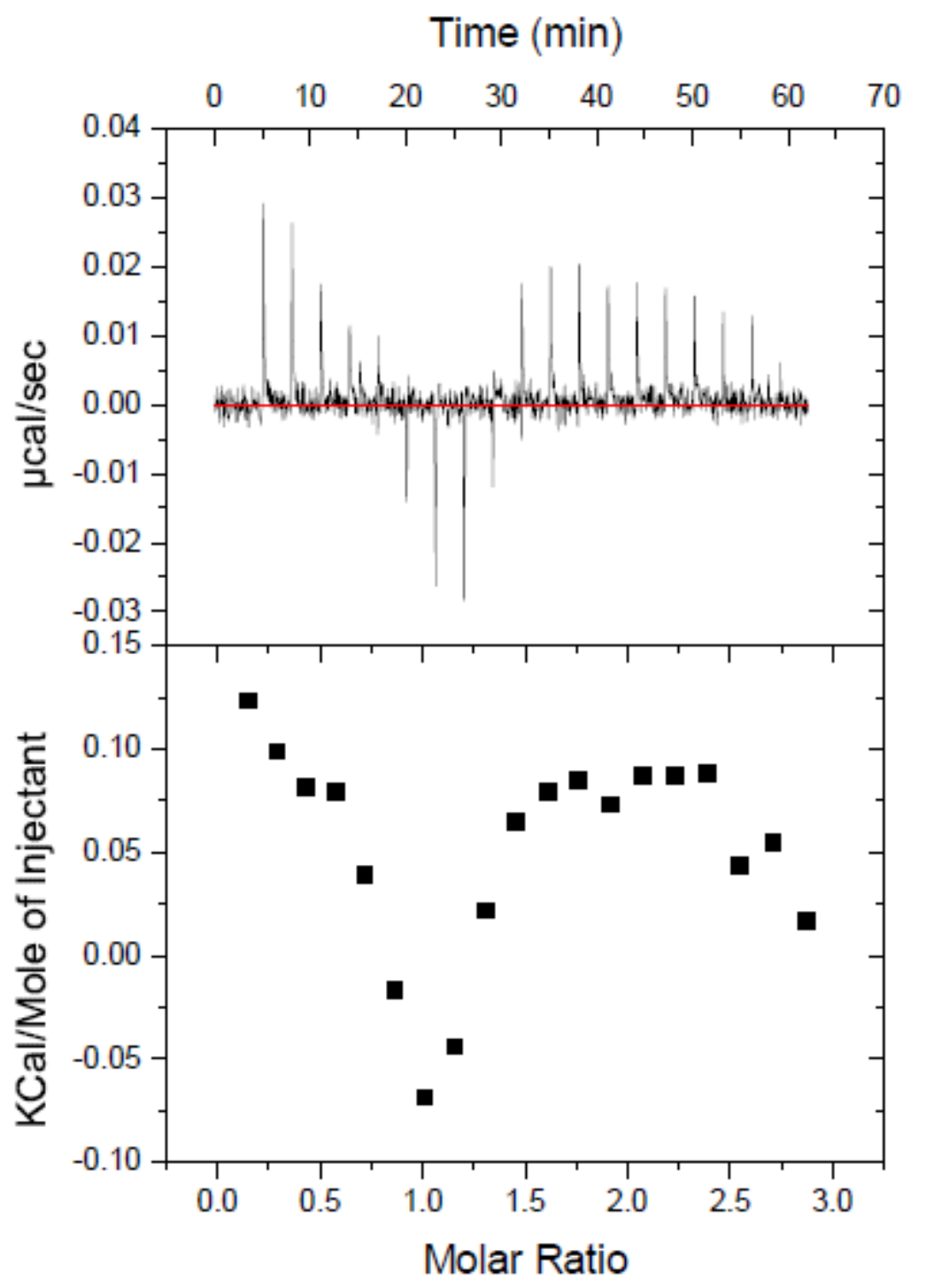

Figure S30. Heat of dilution for titrating K9me3K14 (Ac-WGGQTARKme $\left.{ }_{3} \mathrm{STGGK}_{\mathrm{NHH}}\right)(1.43$ $\mathrm{mM}$ ) into $10 \mathrm{mM}$ sodium borate buffer $\mathrm{pH}$ 8.6. 


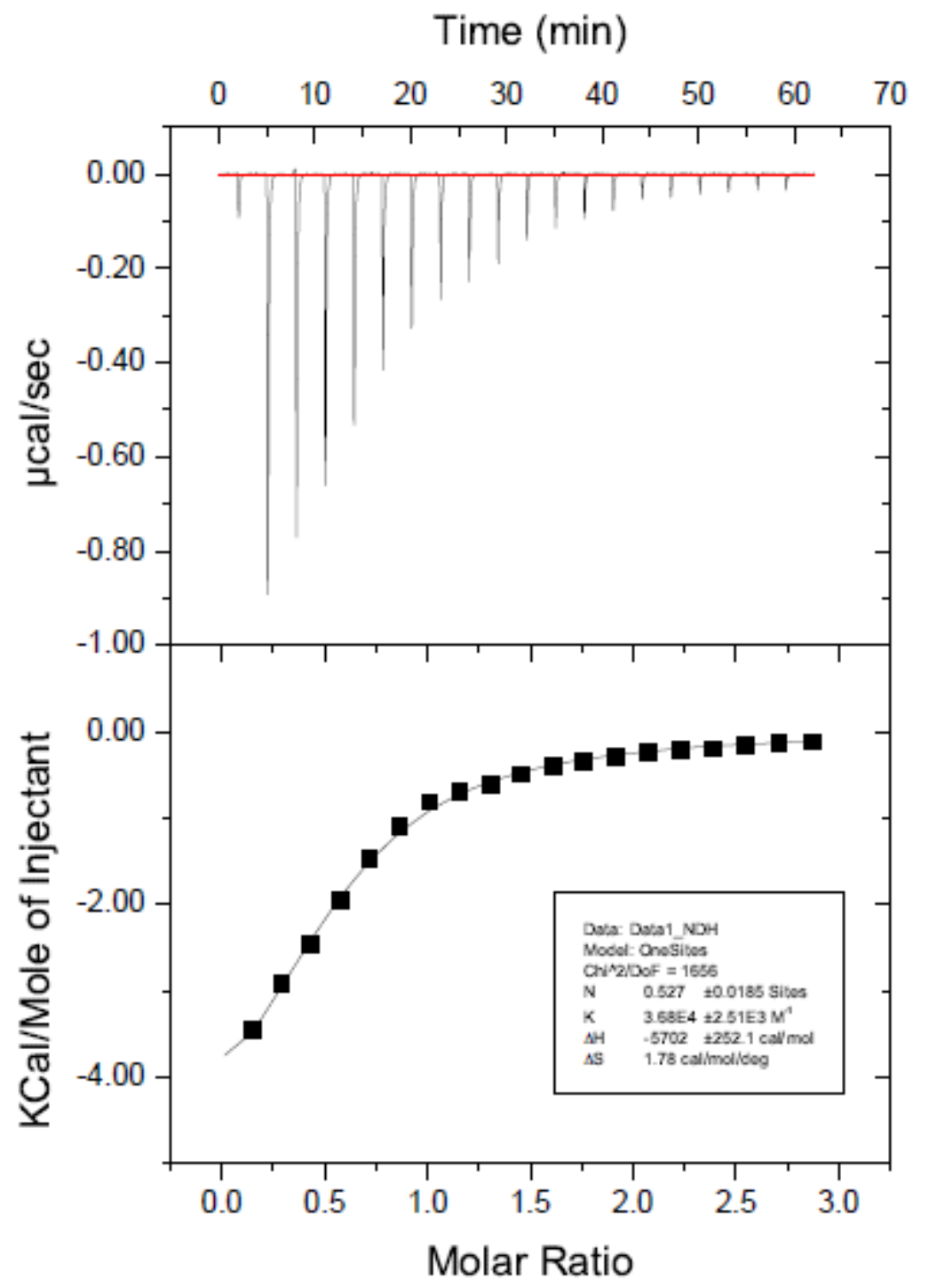

Figure S31. One trial of three of $\mathrm{K}^{2} \mathrm{me}_{3} \mathrm{~K} 14$ (Ac-WGGQTARKme $\left.\mathrm{STGGK}_{3} \mathrm{NH}_{2}\right)(1.43 \mathrm{mM})$ titrated into $4(101 \mu \mathrm{M})$ at $25{ }^{\circ} \mathrm{C}$ in $10 \mathrm{mM}$ sodium borate buffer, $\mathrm{pH} 8.6$ (Run 1). 


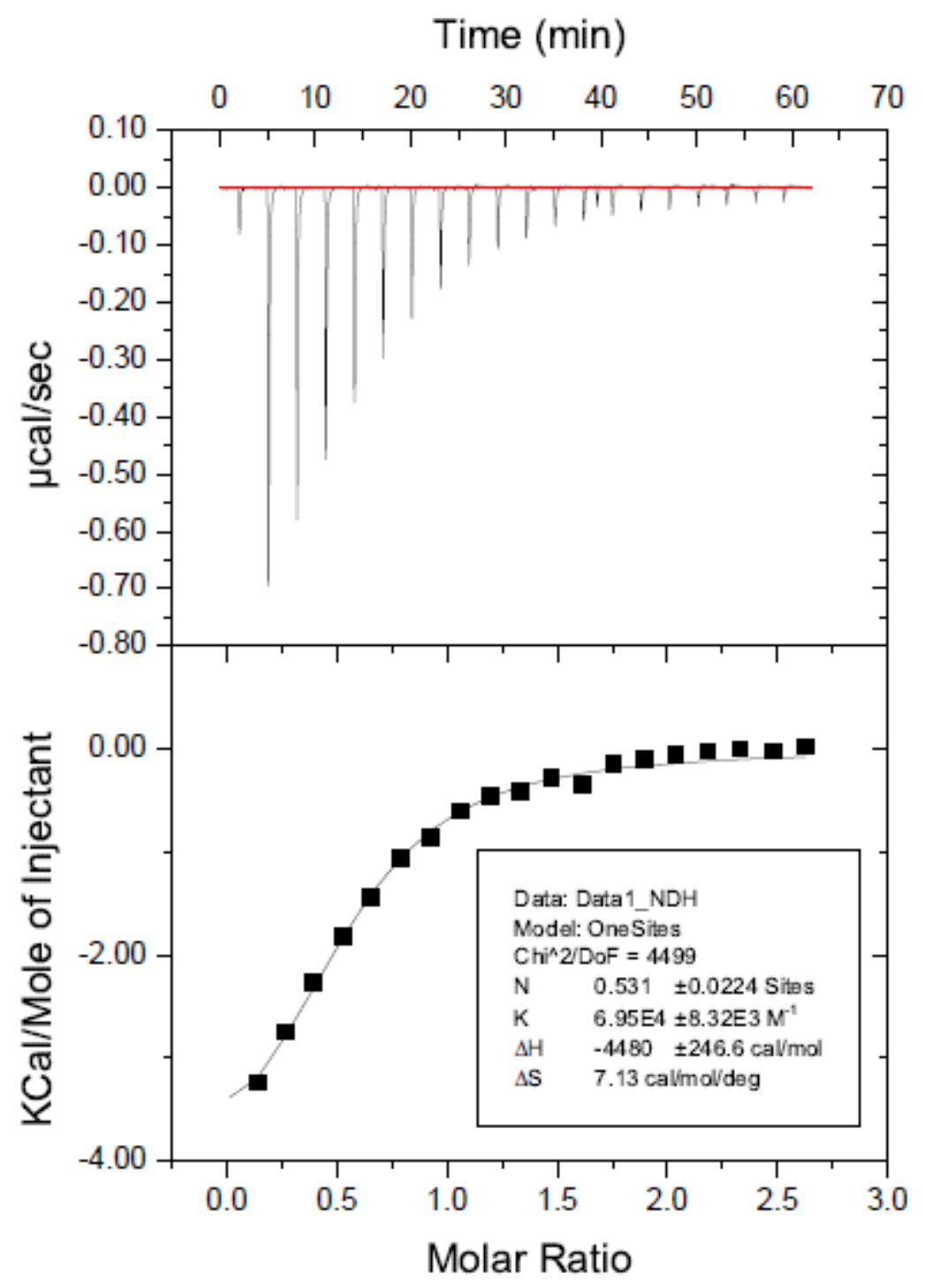

Figure S32. One trial of three of K9me 314 (Ac-WGGQTARK $\left.\left(\mathrm{me}_{3}\right) \mathrm{STGGK}-\mathrm{NH}_{2}\right)(1.11 \mathrm{mM})$ titrated into $4(85 \mu \mathrm{M})$ at $25{ }^{\circ} \mathrm{C}$ in $10 \mathrm{mM}$ sodium borate buffer, $\mathrm{pH} 8.6$ (Run 2). 


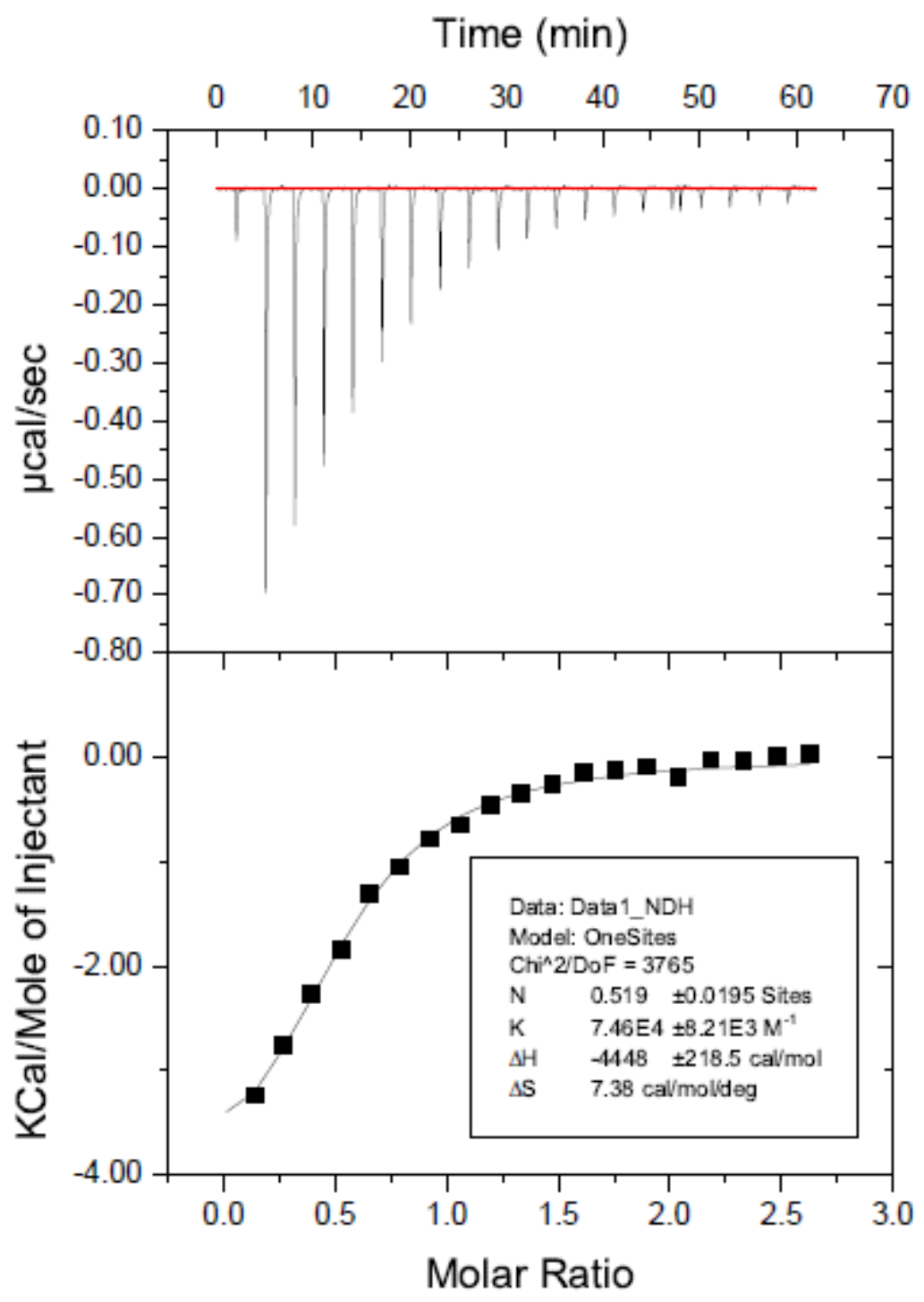

Figure S33. One trial of three of $\mathrm{K} 9 \mathrm{me}_{3} \mathrm{~K} 14$ (Ac-WGGQTARK $\left.\left(\mathrm{me}_{3}\right) \mathrm{STGGK}_{\mathrm{NH}}\right)(1.11 \mathrm{mM})$ titrated into $4(85 \mu \mathrm{M})$ at $25{ }^{\circ} \mathrm{C}$ in $10 \mathrm{mM}$ sodium borate buffer, $\mathrm{pH} 8.6$ (Run 3). 


\section{LCMS characterization of $\mathrm{CX}_{4}-\mathrm{ONBD}$ labeling of $\mathrm{K} 9 \mathrm{~K} 14$ and $\mathrm{K}^{-} \mathrm{me}_{3} \mathrm{~K} 14$}

Reactions were analyzed by LCMS using a C18 column at a flow rate of $0.2 \mathrm{~mL} / \mathrm{min}$.

Chromatographic separation was carried out using a 25 min linear gradient of solvent A $(95 \%$ $\mathrm{H}_{2} \mathrm{O}, 5 \% \mathrm{CH}_{3} \mathrm{CN}$, and $0.1 \%$ formic acid) and solvent $\mathrm{B}\left(95 \% \mathrm{CH}_{3} \mathrm{CN}, 5 \% \mathrm{H}_{2} \mathrm{O}\right.$, and $0.1 \%$ formic acid).

(a)

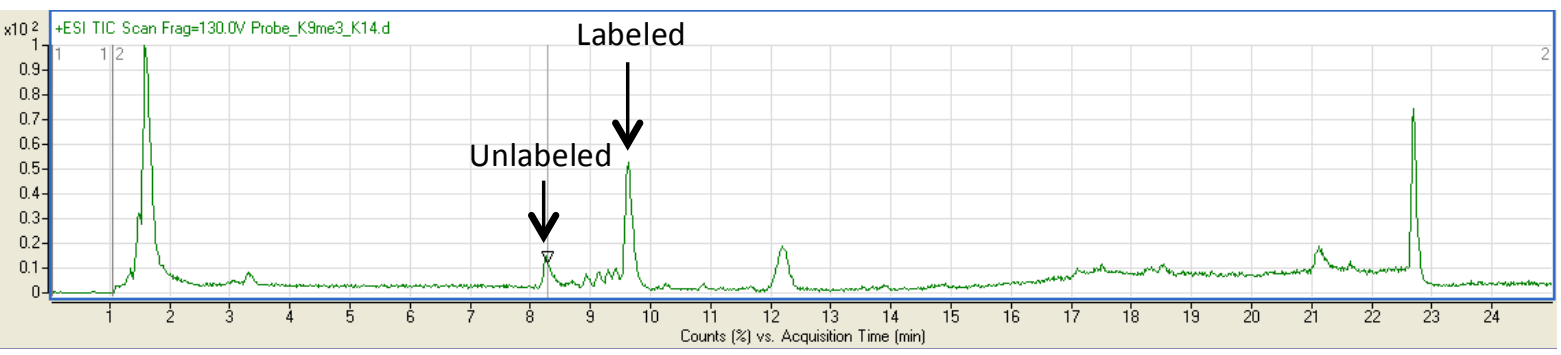

(b)
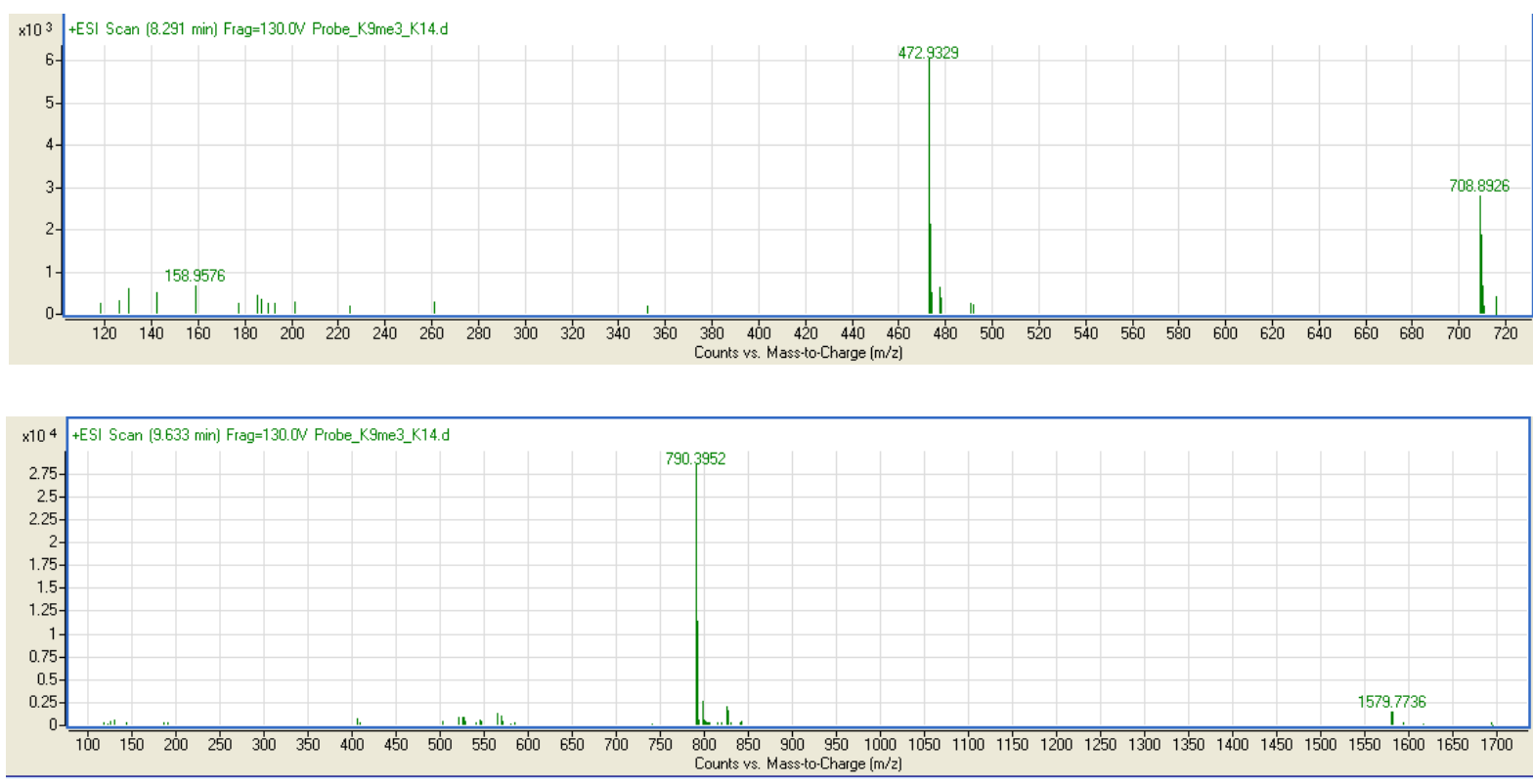

Figure S34. (a) LCMS absorbance trace of the reaction of $100 \mu \mathrm{M} 5$ with $100 \mu \mathrm{M} \mathrm{K} 9 \mathrm{me}_{3} \mathrm{~K} 14$ in $10 \mathrm{mM}$ sodium borate buffer, $\mathrm{pH} 8.6$ after 48 hours. (b) MS analysis of the peak at $\sim 8.25 \mathrm{~min}$ (unlabeled peptide). MS (calculated): $708.89(\mathrm{M}+2)$ [Unlabeled+1H], $472.93(\mathrm{M}+3)$ [Unlabeled+2H]. MS (observed, ESI+): $708.8926(\mathrm{M}+2)$ [Unlabeled+1H], $472.9329(\mathrm{M}+3)$ [Unlabeled $+2 \mathrm{H}]$. (c) MS analysis of the peak at $\sim 9.75$ min (labeled peptide). MS (calculated): $1579.77(\mathrm{M}+1)$ [Labeled], $790.39(\mathrm{M}+2)$ [Labeled+1H]. MS (observed, ESI+):1579.7736 (M+1) [Labeled], $790.3952(\mathrm{M}+2)$ [Labeled+1H]. 
(a)

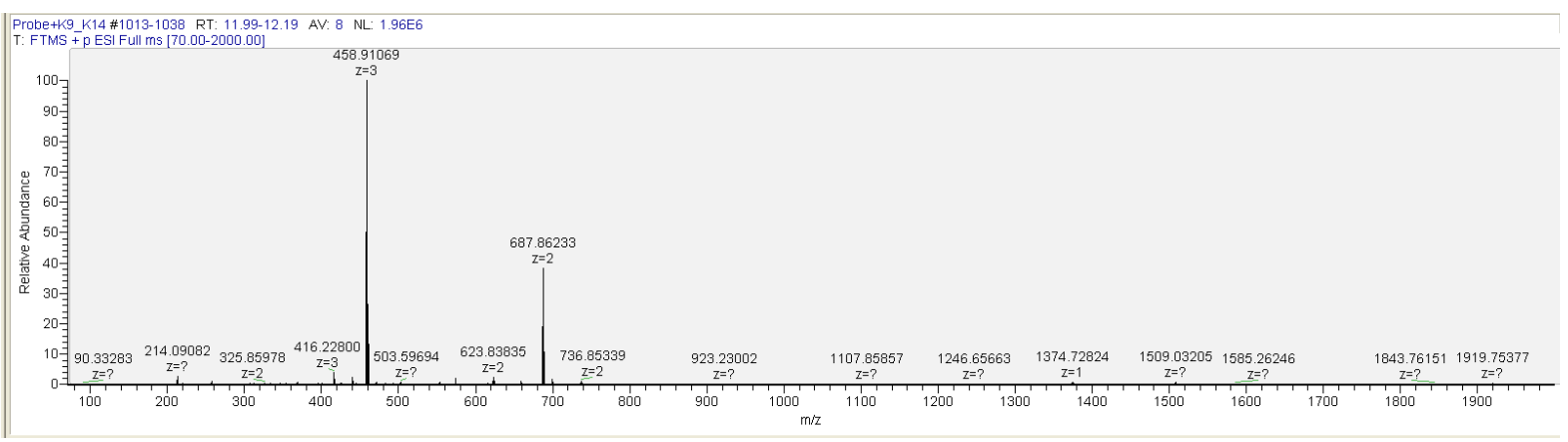

(b)

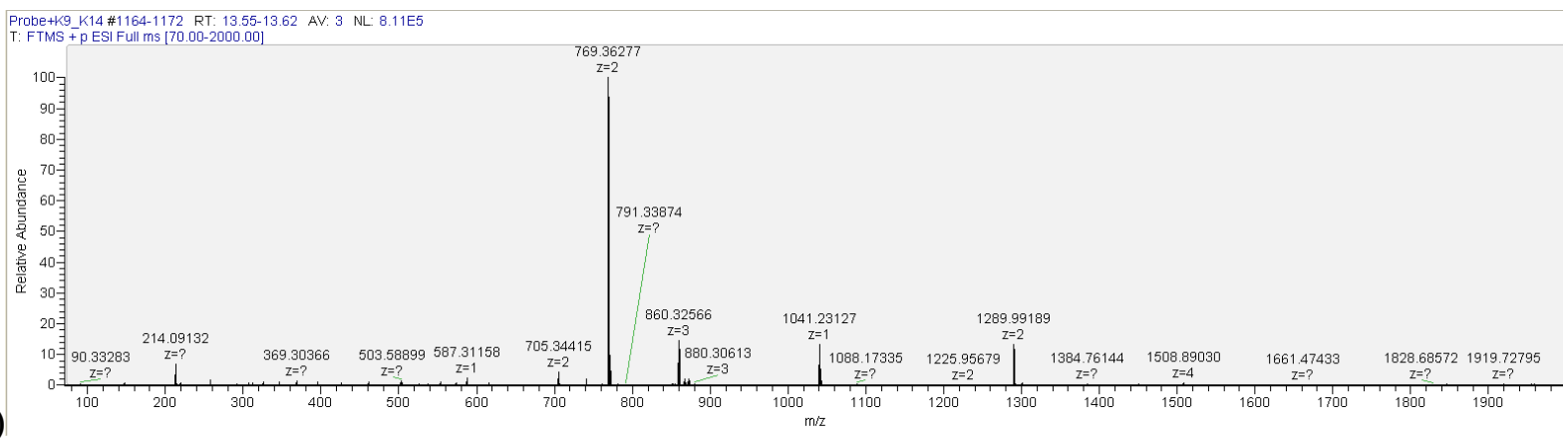

(c)

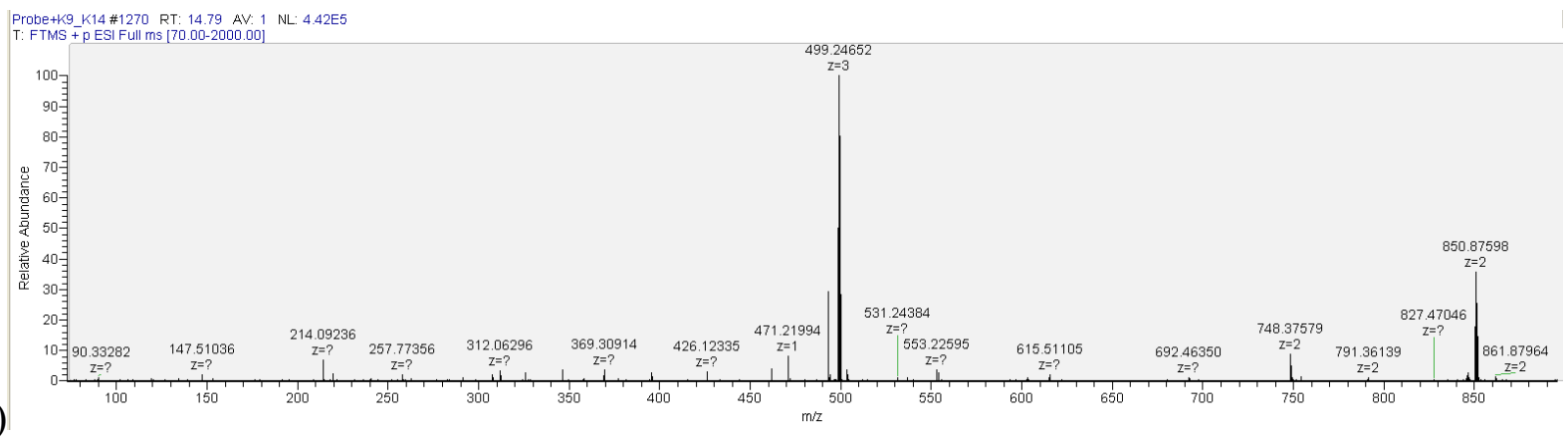

Figure S35. MS spectra of the reaction of $100 \mu \mathrm{M} 5$ with $100 \mu \mathrm{M}$ K9 K14 in $10 \mathrm{mM}$ sodium borate buffer, $\mathrm{pH} 8.6$ after 24 hours. (a) MS analysis of the peak at $\sim 12.09 \mathrm{~min}$ (unlabeled peptide). MS (calculated): $687.87(\mathrm{M}+2)$ [Unlabeled $+1 \mathrm{H}], 458.91(\mathrm{M}+3)$ [Unlabeled $+2 \mathrm{H}] . \mathrm{MS}$ (observed, ESI+): $687.86233(\mathrm{M}+2)$ [Unlabeled+1H], $458.91069(\mathrm{M}+3)$ [Unlabeled+2H]. (b) MS analysis of the peak at 13.37 min (singly labeled). MS (calculated): 769.37 (M+2) [MonoLabeled+2H]. MS (observed, ESI+): $769.36277(\mathrm{M}+2)$ [Mono-Labeled+2H]. (c) MS analysis of the peak at $\sim 14.79$ min (doubly labeled). MS (calculated): $850.88(\mathrm{M}+2)$ [Di-Labeled+2H]. MS (observed, ESI+): $850.87598(\mathrm{M}+2)$ [Di-Labeled+2H]. 


\section{HPLC Analysis of Labeling}

Reactions were analyzed by analytical HPLC using a C18 column at a flow rate of $1 \mathrm{~mL} / \mathrm{min}$. Chromatographic separation was carried out using a 45 min linear gradient of solvent A (95\% $\mathrm{H}_{2} \mathrm{O}, 5 \% \mathrm{CH}_{3} \mathrm{CN}$, and $0.1 \%$ TFA) and solvent $\mathrm{B}\left(95 \% \mathrm{CH}_{3} \mathrm{CN}, 5 \% \mathrm{H}_{2} \mathrm{O}\right.$, and $\left.0.1 \% \mathrm{TFA}\right)$. Absorbance was monitored at $214 \mathrm{~nm}$.
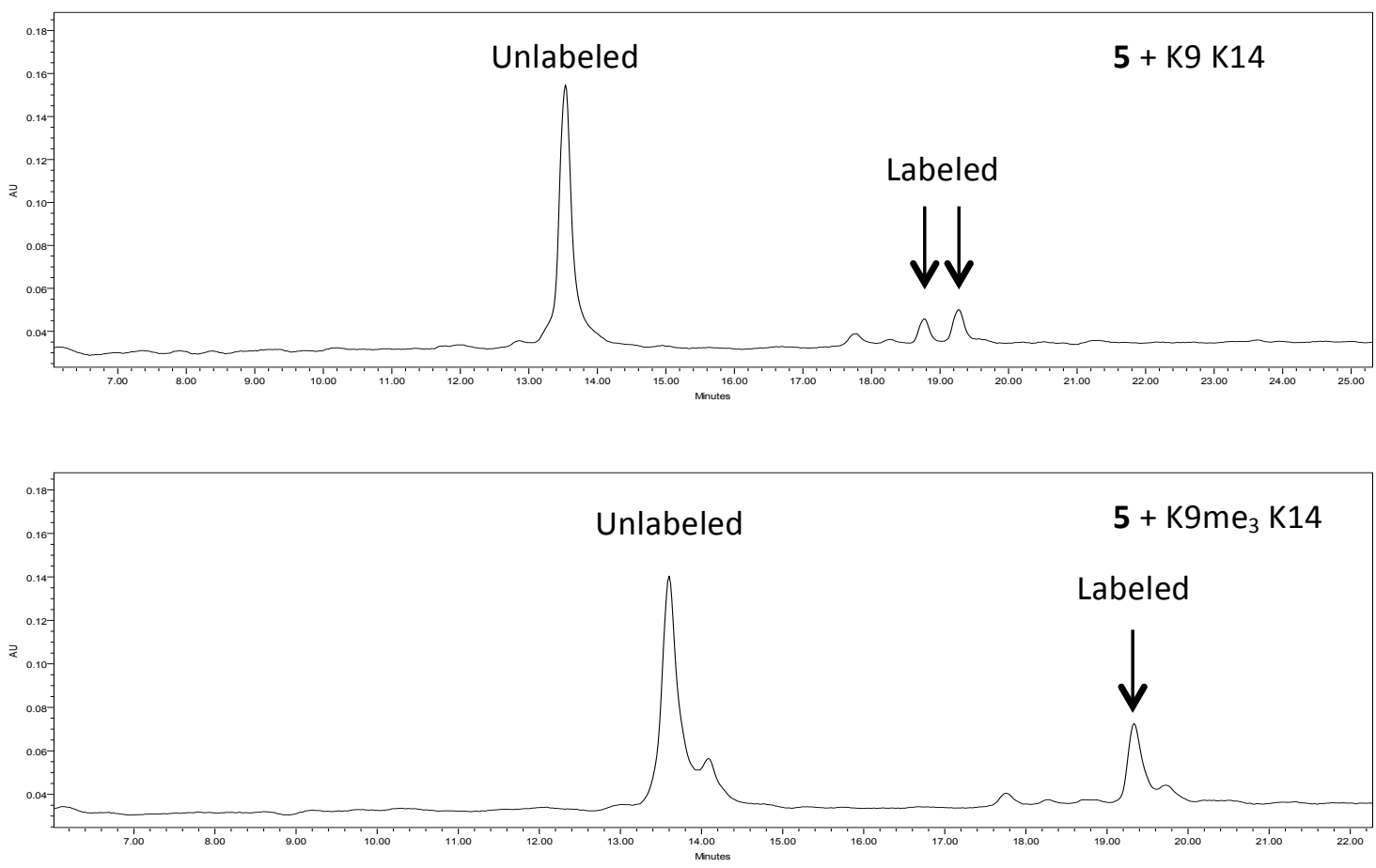

Figure S36. HPLC trace of the reaction of $100 \mu \mathrm{M} 5$ with $100 \mu \mathrm{M}$ K9 K14 (top) or $100 \mu \mathrm{M}$ $\mathrm{K} \mathrm{me}_{3} \mathrm{~K} 14$ (bottom) in $10 \mathrm{mM}$ potassium phosphate buffer, $\mathrm{pH} 7.4$ after 24 hours showing labeled and unlabeled peptide. . 

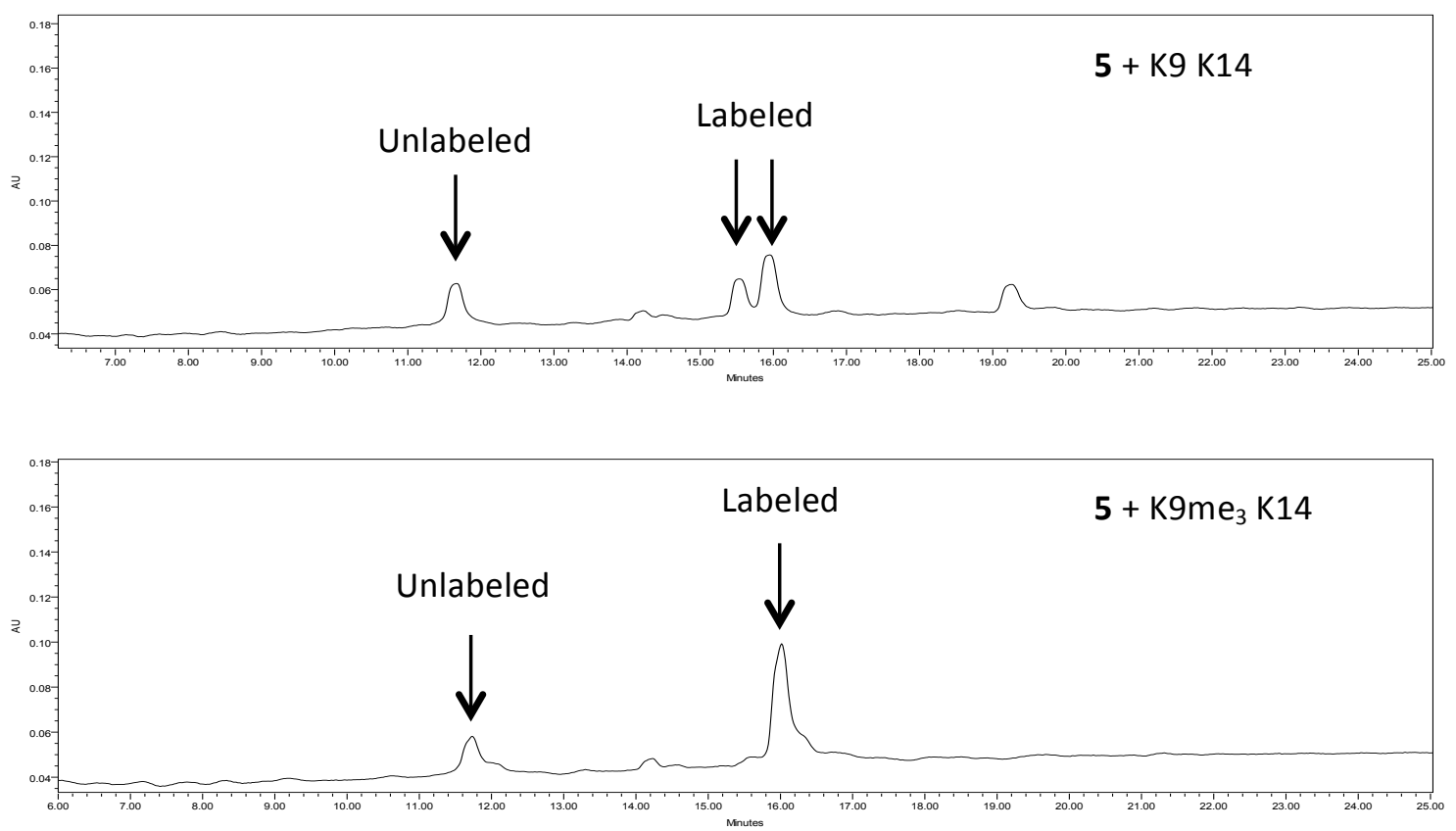

Figure S37. HPLC trace of the reaction of $100 \mu \mathrm{M} 5$ with $50 \mu \mathrm{M}$ K9 K14 (top) or $50 \mu \mathrm{M} \mathrm{K} 9 \mathrm{me}_{3}$ $\mathrm{K} 14$ (bottom) in $10 \mathrm{mM}$ sodium borate buffer, $\mathrm{pH} 8.6$ after 24 hours. 

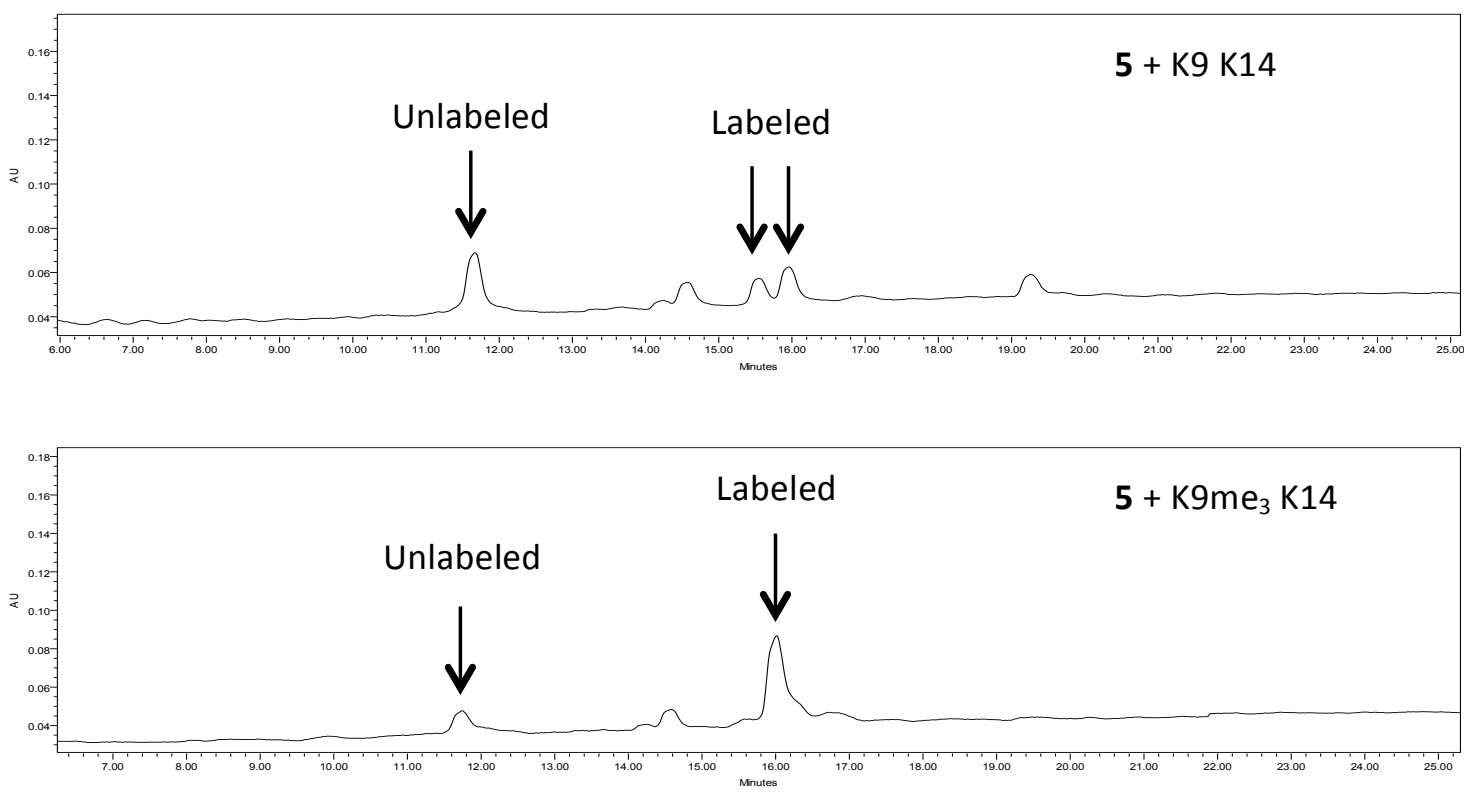

Figure S38. HPLC trace of the reaction of $100 \mu \mathrm{M} 5$ with $50 \mu \mathrm{M}$ K9 K14 (top) or $50 \mu \mathrm{M} \mathrm{K9me} 3$ $\mathrm{K} 14$ (bottom) in $10 \mathrm{mM}$ sodium borate buffer, $\mathrm{pH} 8.6,50 \mathrm{mM} \mathrm{NaCl}$ after 24 hours. 

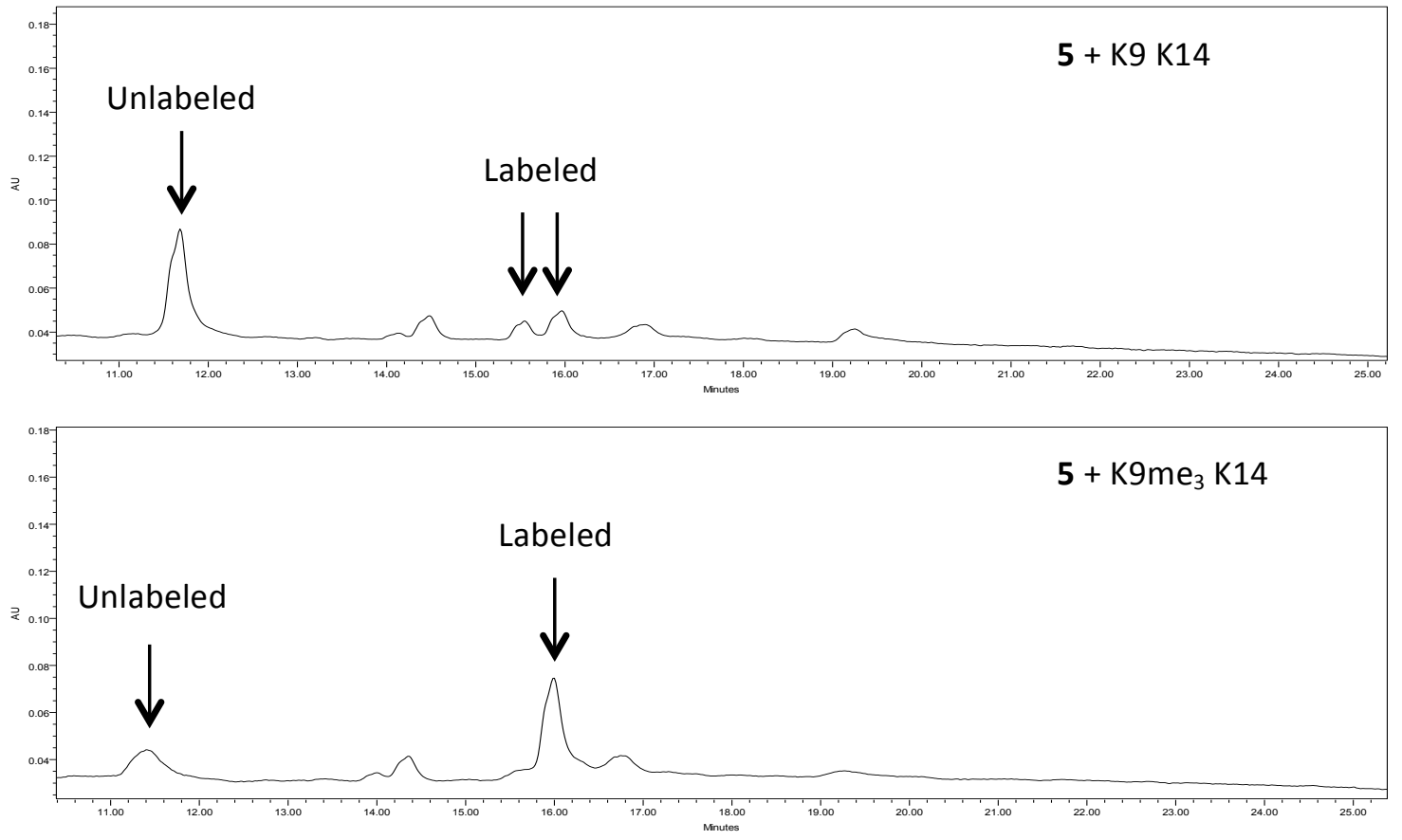

Figure S39. HPLC trace of the reaction of $100 \mu \mathrm{M} 5$ with $30 \mu \mathrm{M}$ K9 K14 (top) or $30 \mu \mathrm{M}$ K9me3 K14 (bottom) in $10 \mathrm{mM}$ sodium borate buffer, $\mathrm{pH} 8.6,100 \mathrm{mM} \mathrm{NaCl}$ after $24 \mathrm{~h}$. 

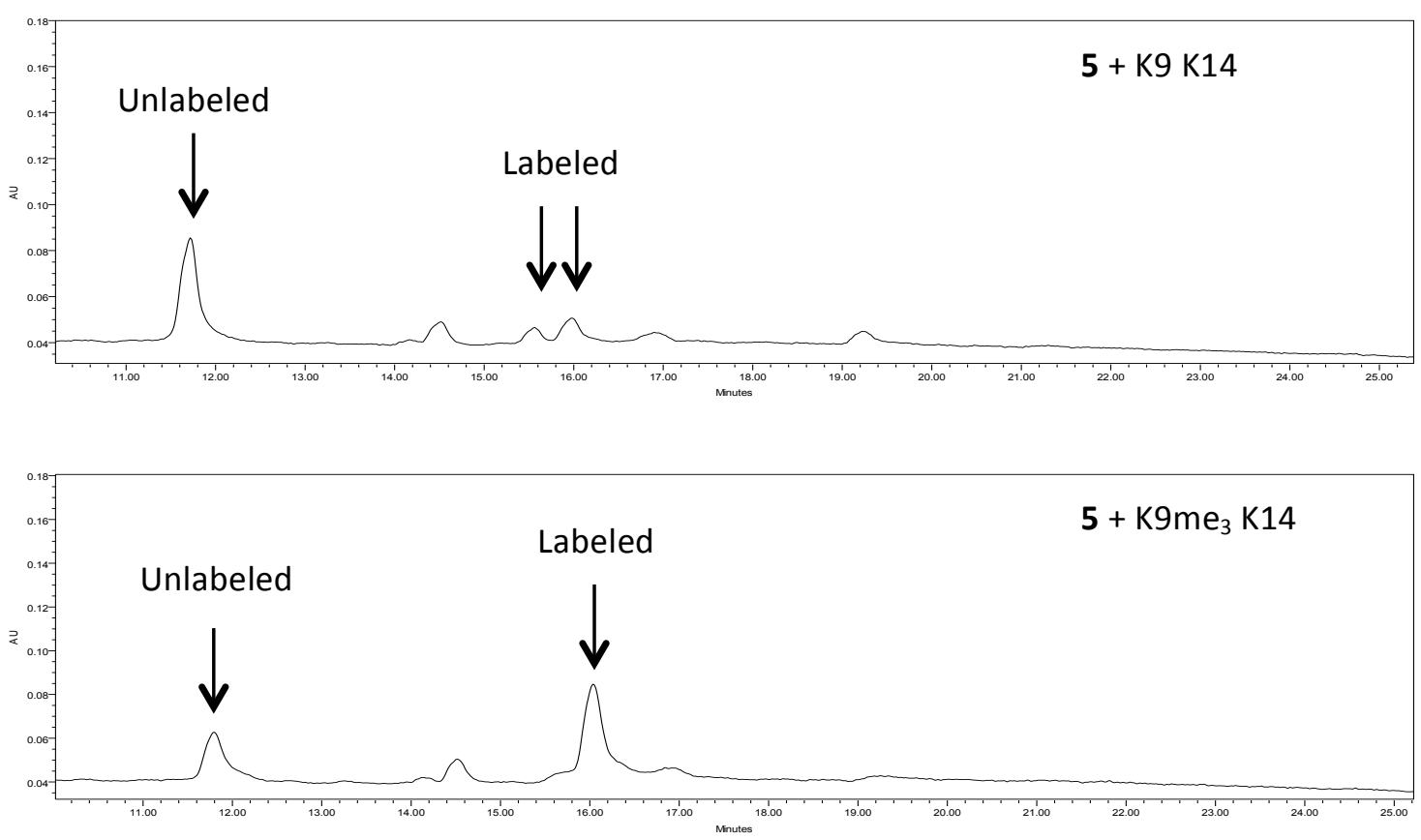

Figure S40. HPLC trace of the reaction of $100 \mu \mathrm{M} 5$ with $30 \mu \mathrm{M}$ K9 K14 (top) or $30 \mu \mathrm{M}$ K9me3 K14 (bottom) in $10 \mathrm{mM}$ sodium borate buffer, $\mathrm{pH} 8.6,150 \mathrm{mM} \mathrm{NaCl}$ after 24 h showing labeled and unlabeled peptide. 

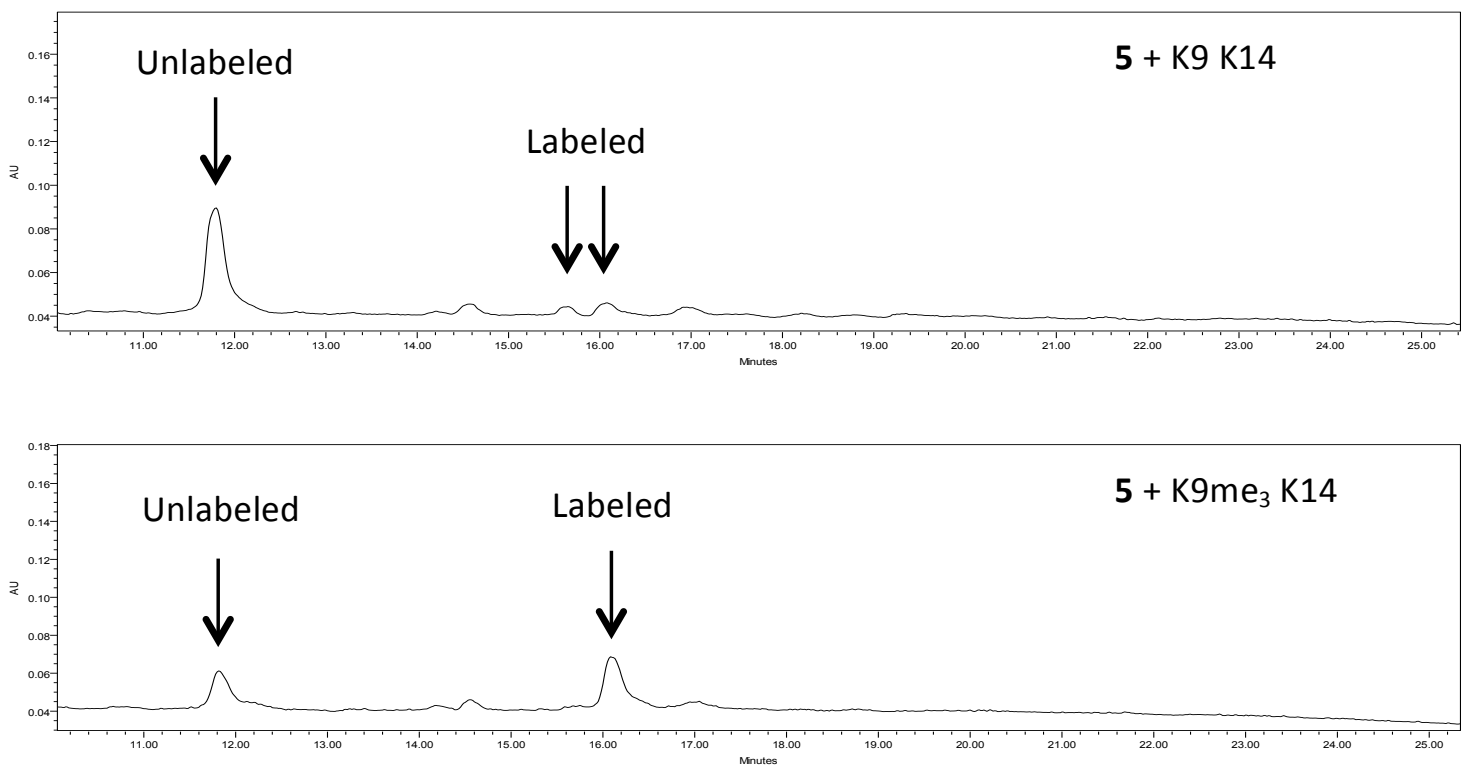

Figure S41. HPLC trace of the reaction of $40 \mu \mathrm{M} 5$ with $20 \mu \mathrm{M}$ K9 K14 (top) or $20 \mu \mathrm{M} \mathrm{K9me}$ $\mathrm{K} 14$ (bottom) in $10 \mathrm{mM}$ sodium borate buffer, $\mathrm{pH} 8.6,100 \mathrm{mM} \mathrm{NaCl}$ after 24 hours showing labeled and unlabeled peptide. 


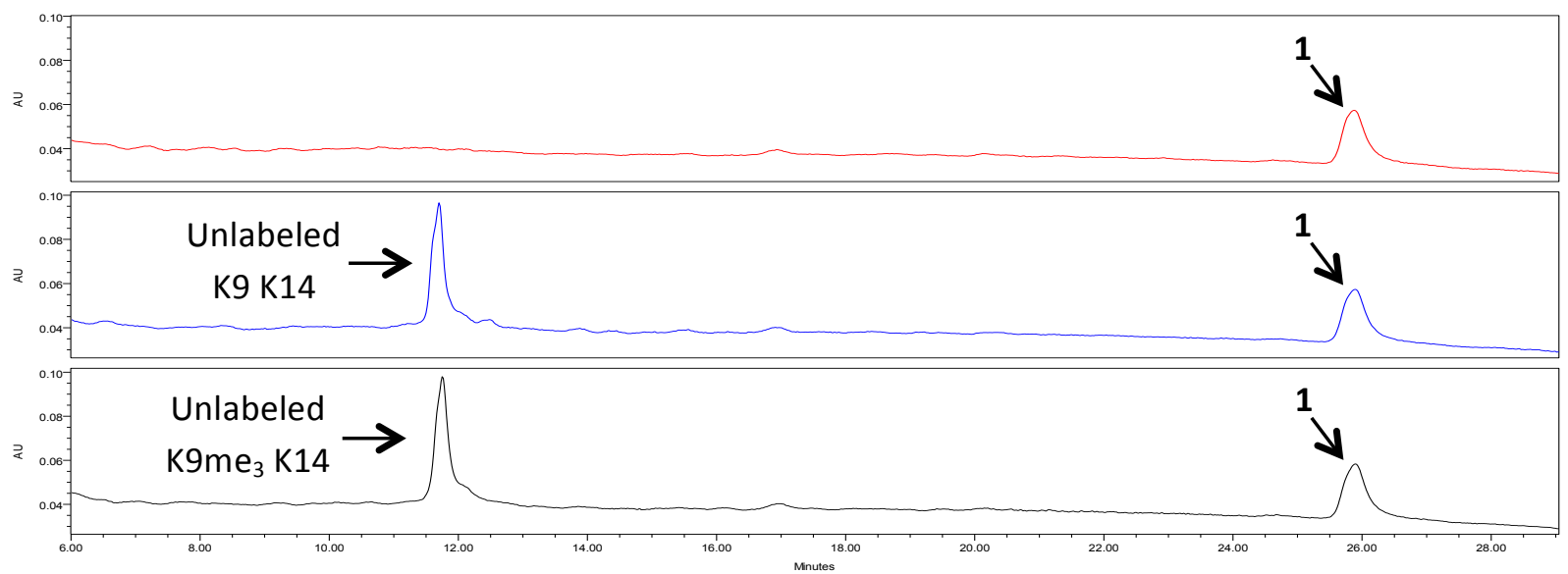

Figure S42. HPLC trace of the reaction of $40 \mu \mathrm{M} 1$ with $20 \mu \mathrm{M}$ K9 K14 (blue) or $20 \mu \mathrm{M} \mathrm{K} 9 \mathrm{me}_{3}$ $\mathrm{K} 14$ (black) in $10 \mathrm{mM}$ sodium borate buffer, $\mathrm{pH} 8.6,100 \mathrm{mM} \mathrm{NaCl}$ after 24 hours demonstrating that the peptides do not react with a probe lacking the recognition motif. 


\section{$\mathrm{Kme}_{3} / \mathrm{K}$ Competition Labeling Experiment}

To assess the ability of probe 5 to selectively label trimethylated peptides in the presence of a lysine-containing peptide, competition labeling experiments were conducted. RKme ${ }_{3} \mathrm{GLLYK}$ was used for the trimethylated peptide, and K9K14 was used for the unmodified lysine peptide. Two conditions were tested: one reacting $40 \mu \mathrm{M}$ of 5 with a mixture of $20 \mu \mathrm{M} \mathrm{RKme}{ }_{3} \mathrm{GLLYK}$ and $40 \mu \mathrm{M}$ K9K14 and another reacting $40 \mu \mathrm{M}$ of 5 with $30 \mu \mathrm{M}$ RKme $_{3}$ GLLYK and $30 \mu \mathrm{M}$ K9K14. Reactions were analyzed by analytical HPLC using a C18 column at a flow rate of 1 $\mathrm{mL} / \mathrm{min}$. Chromatographic separation was carried out using a $100 \mathrm{~min}$ linear gradient of solvent A $\left(95 \% \mathrm{H}_{2} \mathrm{O}, 5 \% \mathrm{CH}_{3} \mathrm{CN}\right.$, and $0.1 \%$ TFA) and solvent $\mathrm{B}\left(95 \% \mathrm{CH}_{3} \mathrm{CN}, 5 \% \mathrm{H}_{2} \mathrm{O}\right.$, and $0.1 \%$ TFA). Absorbance was monitored at $214 \mathrm{~nm}$.

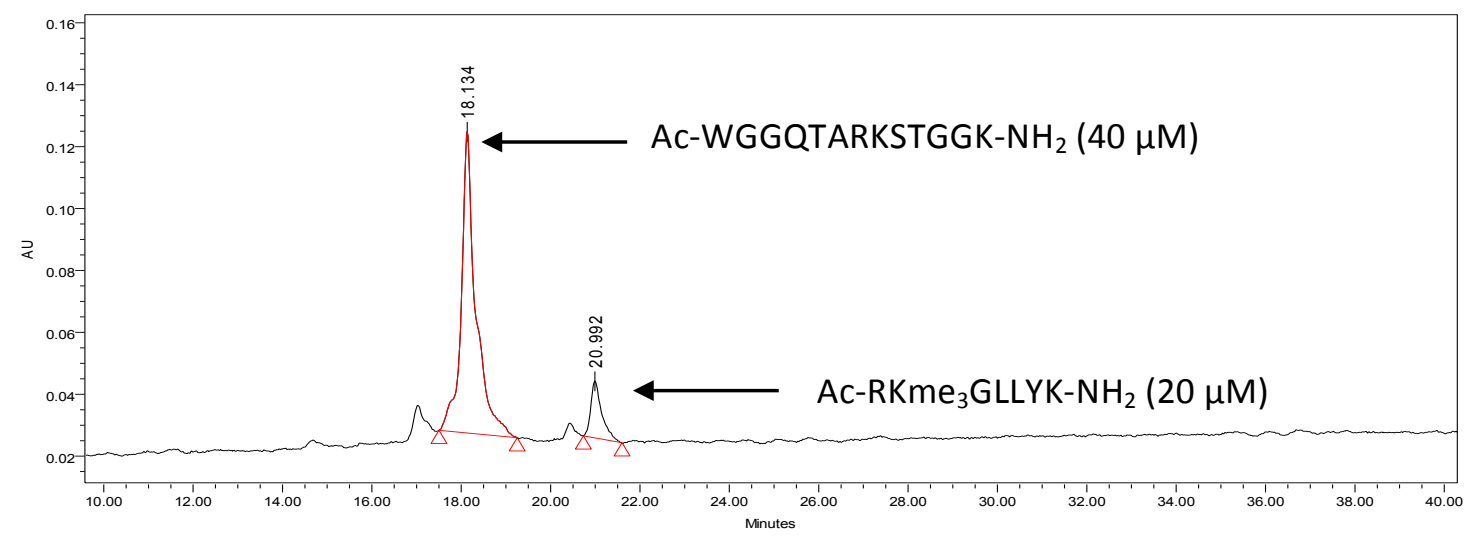

Figure S43. HPLC trace of a mixture of $40 \mu \mathrm{M} \mathrm{K9K} 14$ and $20 \mu \mathrm{M} \mathrm{RKme}_{3} \mathrm{GLLYK}$ in $10 \mathrm{mM}$ sodium borate buffer, $\mathrm{pH} 8.6,100 \mathrm{mM} \mathrm{NaCl}$ to provide a concentration reference.

Table S2. Summary of peak integration data. Error is estimated to be near $10 \%$.

\begin{tabular}{|r|r|r|r|r|}
\hline & Retention Time & Area & \% Area & Height \\
\hline 1 & 18.134 & 2210624 & 87.60 & 97325 \\
\hline 2 & 20.992 & 312987 & 12.40 & 18352 \\
\hline
\end{tabular}




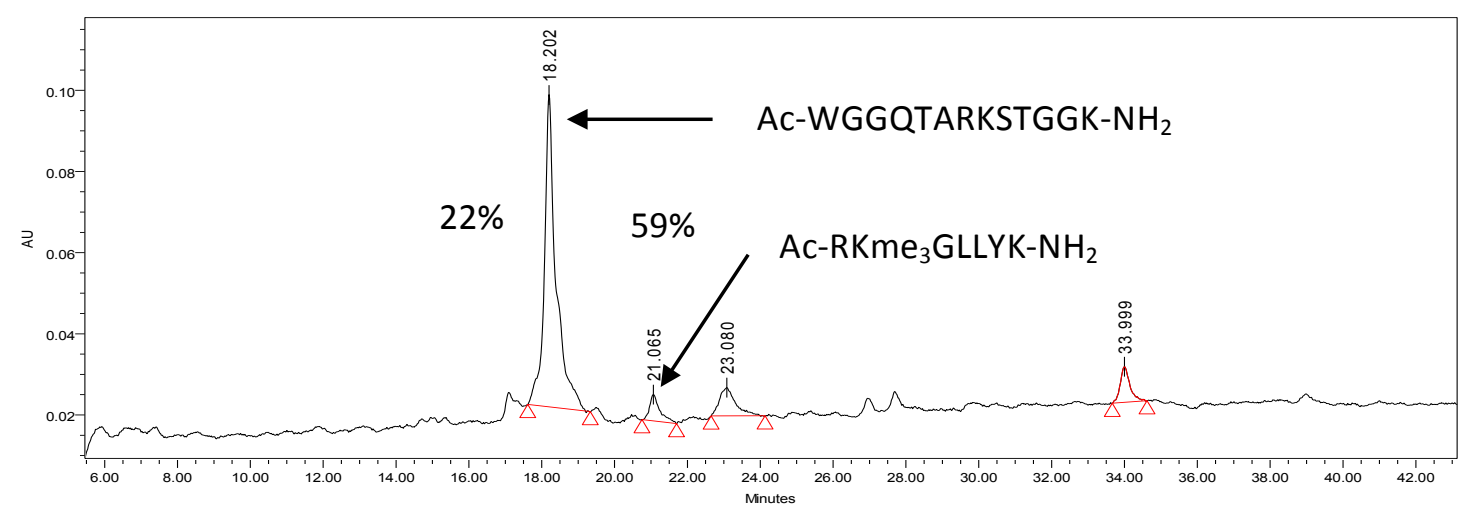

Figure S44. HPLC trace of the reaction of $40 \mu \mathrm{M}$ probe 5 with a mixture of $40 \mu \mathrm{M}$ K9K 14 and $20 \mu \mathrm{M} \mathrm{RKme}{ }_{3}$ GLLYK in $10 \mathrm{mM}$ sodium borate buffer, $\mathrm{pH} 8.6,100 \mathrm{mM} \mathrm{NaCl}$. After 24 hours, $22 \%$ of K9K14 reacted with the probe while $59 \%$ of RKme3GLLYK was labeled by the probe.

Table S3. Summary of peak integration and labeling data. Error estimated to be near 10\%.

\begin{tabular}{|r|r|r|r|r|rr|}
\hline & Retention Time & \multicolumn{1}{|c|}{ Area } & \% Area & Height & \multicolumn{2}{|c|}{ Percent of Peptide Labeled } \\
\hline 1 & 18.202 & 1725267 & 77.34 & 76903 & \\
\hline 2 & 21.065 & 127580 & 5.72 & 6488 & $59 \%$ \\
\hline 3 & 23.080 & 215293 & 9.65 & 6974 & \\
\hline 4 & 33.999 & 162552 & 7.29 & 8771 & & - \\
\hline
\end{tabular}




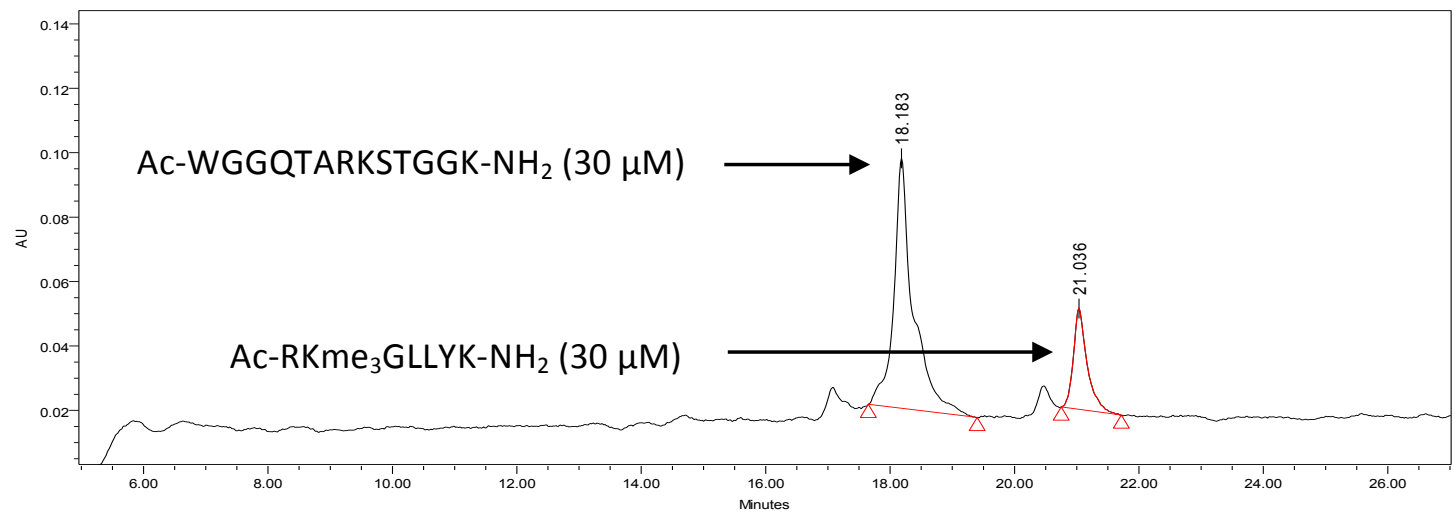

Figure S45. HPLC trace of a mixture of $30 \mu \mathrm{M} \mathrm{K9K14}$ and $30 \mu \mathrm{M} \mathrm{RKme}_{3}$ GLLYK in $10 \mathrm{mM}$ sodium borate buffer, $\mathrm{pH} 8.6,100 \mathrm{mM} \mathrm{NaCl}$ to provide a concentration reference.

Table S4. Summary of peak integration data. Error is estimated to be near $10 \%$.

\begin{tabular}{|r|r|r|r|r|}
\hline & Retention Time & \multicolumn{1}{|c|}{ Area } & \% Area & Height \\
\hline 1 & 18.183 & 1689794 & 77.88 & 77563 \\
\hline 2 & 21.036 & 479927 & 22.12 & 31370 \\
\hline
\end{tabular}




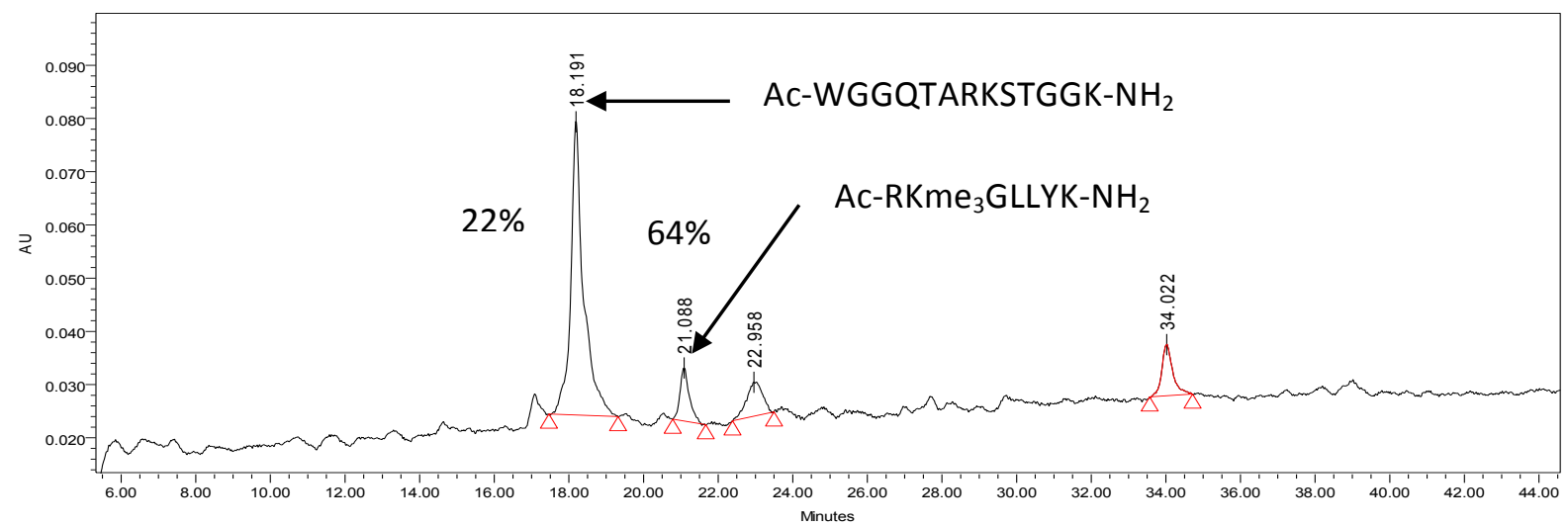

Figure S46. HPLC trace of the reaction of $40 \mu \mathrm{M}$ probe 5 with a mixture of $30 \mu \mathrm{M}$ K9K 14 and $30 \mu \mathrm{M} \mathrm{RKme}{ }_{3} \mathrm{GLLYK}$ in $10 \mathrm{mM}$ sodium borate buffer, $\mathrm{pH} 8.6,100 \mathrm{mM} \mathrm{NaCl}$. After 24 hours, $22 \%$ of $\mathrm{K} 9 \mathrm{~K} 14$ reacted with the probe while $64 \%$ of RKme3GLLYK was labeled by the probe.

Table S5. Summary of peak integration data. Error is estimated to be near $10 \%$.

\begin{tabular}{|l|r|r|r|r|r|}
\hline & Retention Time & \multicolumn{1}{c|}{ Area } & \% Area & Height & Percent of Peptide Labeled \\
\hline 1 & 18.191 & 1324422 & 70.17 & 55268 & $22 \%$ \\
\hline 2 & 21.088 & 174149 & 9.23 & 10016 & $64 \%$ \\
\hline 3 & 22.958 & 192180 & 10.18 & 6424 & - \\
\hline 4 & 34.022 & 196655 & 10.42 & 9641 & \\
\hline
\end{tabular}




\section{Turn-On Fluorescence Labeling Control Experiments}

Fluorescence labeling experiments were performed in black 96 well optical bottom plates (nontreated, non-sterile, polystyrene) using a POLARstar Omega (BMG Labtech, Inc.) plate reader. A fluorescence optic with a $485 \mathrm{~nm}$ excitation filter and a $520 \mathrm{~nm}$ emission filter was used. Labeling reactions were carried out at ambient temperature, and Titer Tops ${ }^{\circledR}$ sealing film was used to prevent evaporation. Fluorescence intensity was measured every hour for 24 hours.

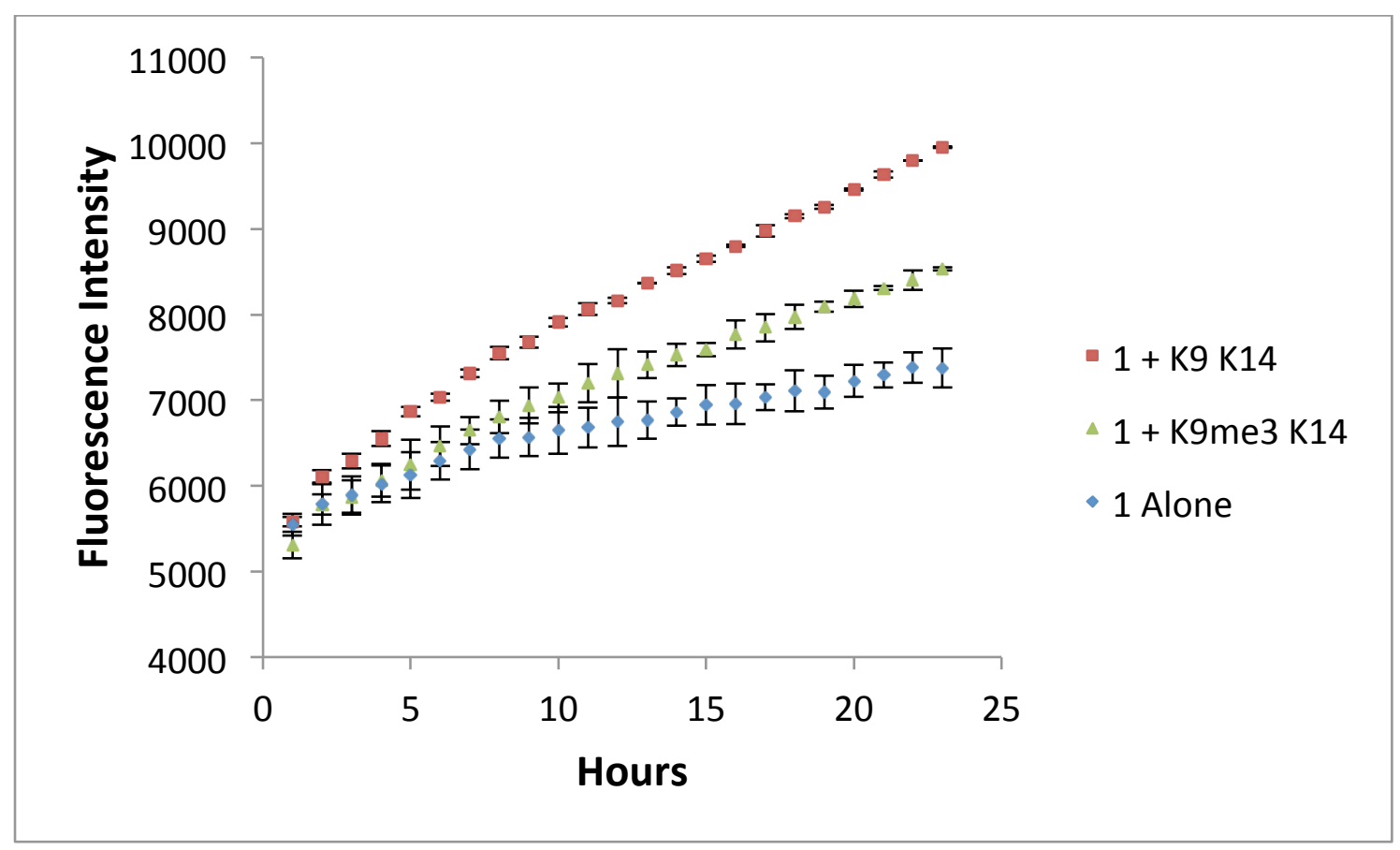

Figure S47. Turn-on fluorescence labeling negative control experiment. Labeling of $40 \mu \mathrm{M}$ of 1 alone (blue) or in the presence of $100 \mu \mathrm{M} \mathrm{K} 9 \mathrm{~K} 14$ (red) or $100 \mu \mathrm{M} \mathrm{K} 9 \mathrm{me}_{3} \mathrm{~K} 14$ (green) in 10 $\mathrm{mM}$ potassium phosphate buffer ( $\mathrm{pH}$ 7.4). Each data point represents an average of three runs. Error bars are standard deviations. 


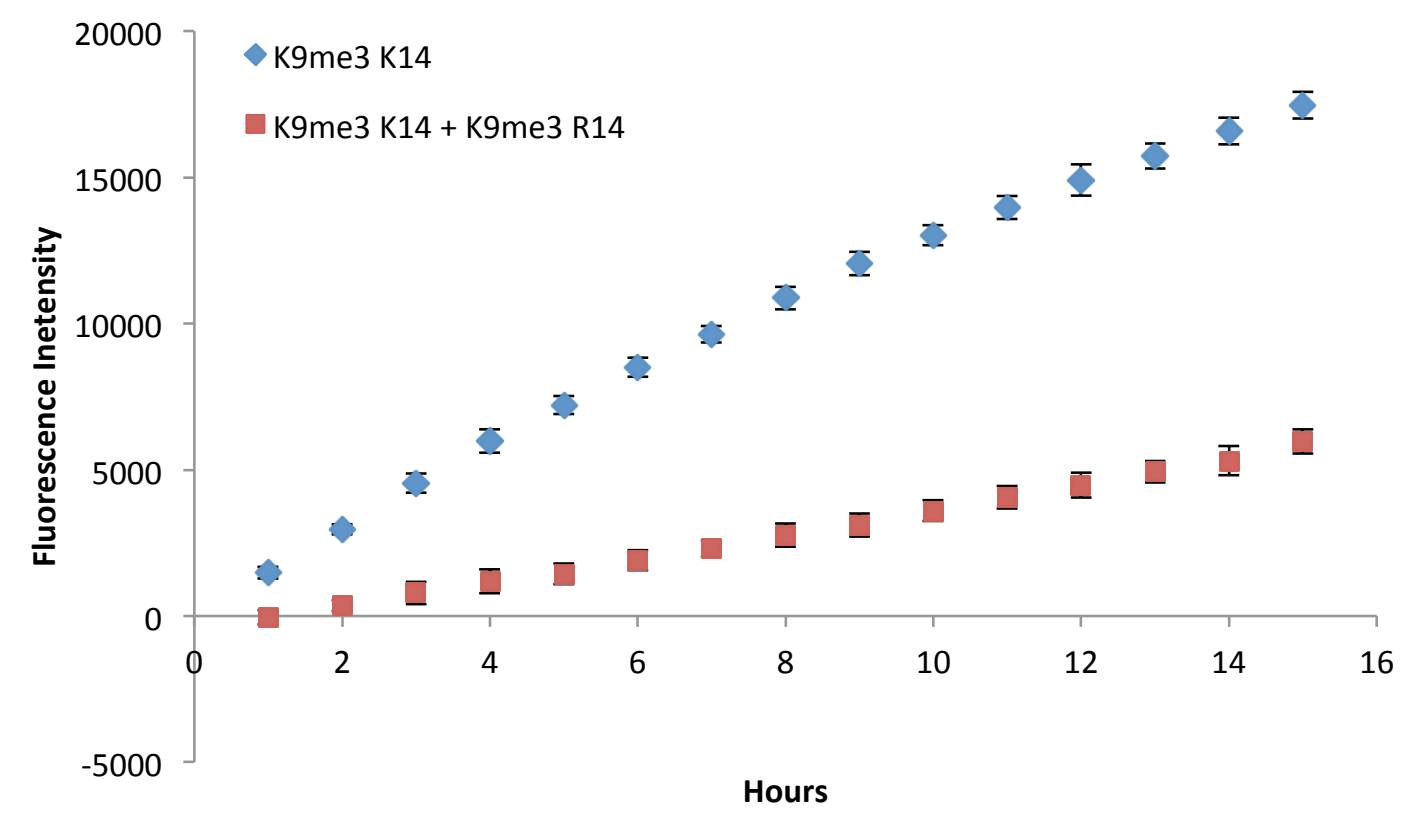

Figure S48. Turn-on fluorescence labeling competition experiment. $40 \mu \mathrm{M}$ of 5 was reacted with $20 \mu \mathrm{M} \mathrm{K} 9 \mathrm{me}_{3} \mathrm{~K} 14$ in the presence (red) or absence of $120 \mu \mathrm{M} \mathrm{K} 9 \mathrm{me}_{3} \mathrm{R} 14$ (blue) in $10 \mathrm{mM}$ sodium borate buffer ( $\mathrm{pH} \mathrm{8.6),100} \mathrm{mM} \mathrm{NaCl}$. Each data point represents an average of three runs. Error bars are standard deviations. 


\section{In Vitro HDAC Assay}

For HDAC1, enzymatic reactions were performed in $25 \mathrm{mM}$ Bicine buffer, $137 \mathrm{mM} \mathrm{NaCl}, 2.7$ $\mathrm{mM} \mathrm{KCl}, 1 \mathrm{mM} \mathrm{MgCl}_{2}$ (pH 8.02) with $0.1 \mu \mathrm{g} / \mu \mathrm{L}$ HDAC1 (purchased from Active Motif) and $200 \mu \mathrm{M}$ acetylated peptide at $37{ }^{\circ} \mathrm{C}$. After 1 hour, the reactions were diluted with buffer before adding to a 96-well plate containing probe 5 to give final concentrations of $20 \mu \mathrm{M}$ peptide, 40 $\mu \mathrm{M}$ probe 5 , and $10 \mathrm{ng} / \mu \mathrm{L}$ HDAC1 (reactions containing SAHA were diluted to contain $5 \mu \mathrm{M}$ SAHA). Fluorescence labeling was monitored every hour for 24 hours.

For in vitro inhibition experiments with HDAC3/NCOR1, a 5.5 dilution series (starting with 92 $\mu \mathrm{M}$ SAHA) was prepared in $50 \mathrm{mM}$ Bicine buffer, $137 \mathrm{mM} \mathrm{NaCl}, 2.7 \mathrm{mM} \mathrm{KCl}, 1 \mathrm{mM} \mathrm{MgCl}$, $0.5 \mathrm{mg} / \mathrm{mL}$ BSA ( $\mathrm{pH}$ 8.02). Enzymatic reactions were performed using $11.2 \mathrm{nM}$ HDAC3/NCOR1 (purchased from Enzo Life Sciences) and $100 \mu \mathrm{M}$ acetylated peptide at $37^{\circ} \mathrm{C}$. After 4 hours, the reactions were quenched with $10 \mu \mathrm{M}$ SAHA before adding to a 96-well plate containing probe 5 to give final concentrations of $77 \mu \mathrm{M}$ peptide, $40 \mu \mathrm{M}$ probe 5 , and $8.6 \mathrm{nM}$ HDAC3/NCOR1. Fluorescence labeling was monitored after 24 hours. The data were analyzed using KaleidaGraph version 3.6 to generate and fit a dose-response curve and to calculate IC50 values.

\section{HPLC Analysis of HDAC1 and HDAC3/NCOR1 Reactions}

Reactions were analyzed by analytical HPLC using a C18 column at a flow rate of $1 \mathrm{~mL} / \mathrm{min}$. Chromatographic separation was carried out using a 100 min linear gradient of solvent A ( $95 \%$ $\mathrm{H}_{2} \mathrm{O}, 5 \% \mathrm{CH}_{3} \mathrm{CN}$, and $0.1 \%$ TFA) and solvent $\mathrm{B}\left(95 \% \mathrm{CH}_{3} \mathrm{CN}, 5 \% \mathrm{H}_{2} \mathrm{O}\right.$, and $0.1 \%$ TFA). Absorbance was monitored at $280 \mathrm{~nm}$.

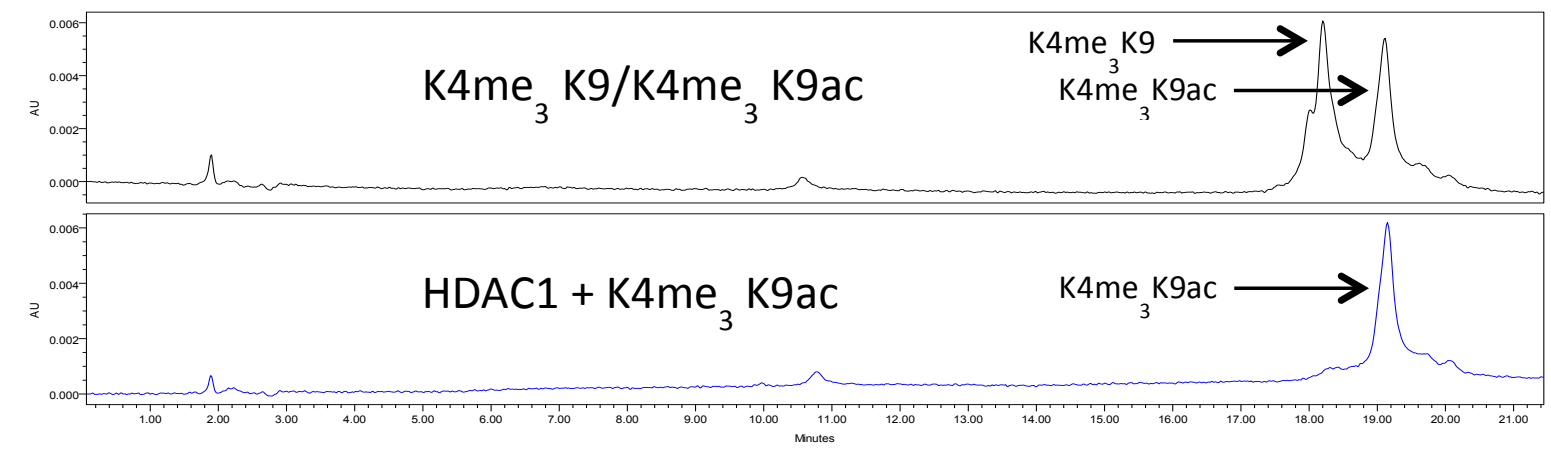

Figure S49. HPLC trace at $280 \mathrm{~nm}$ of a mixture of $20 \mu \mathrm{M} \mathrm{K} 4 \mathrm{me}_{3} \mathrm{~K} 9 \mathrm{ac}$ and $20 \mu \mathrm{M} \mathrm{K} 4 \mathrm{me}_{3} \mathrm{~K} 9$ (top) and the reaction of $0.007 \mu \mathrm{g} / \mu \mathrm{L}$ HDAC1 with $20 \mu \mathrm{M} \mathrm{K} 4 \mathrm{me}_{3} \mathrm{~K} 9 \mathrm{ac}$ after $30 \mathrm{~min}$ (bottom). 


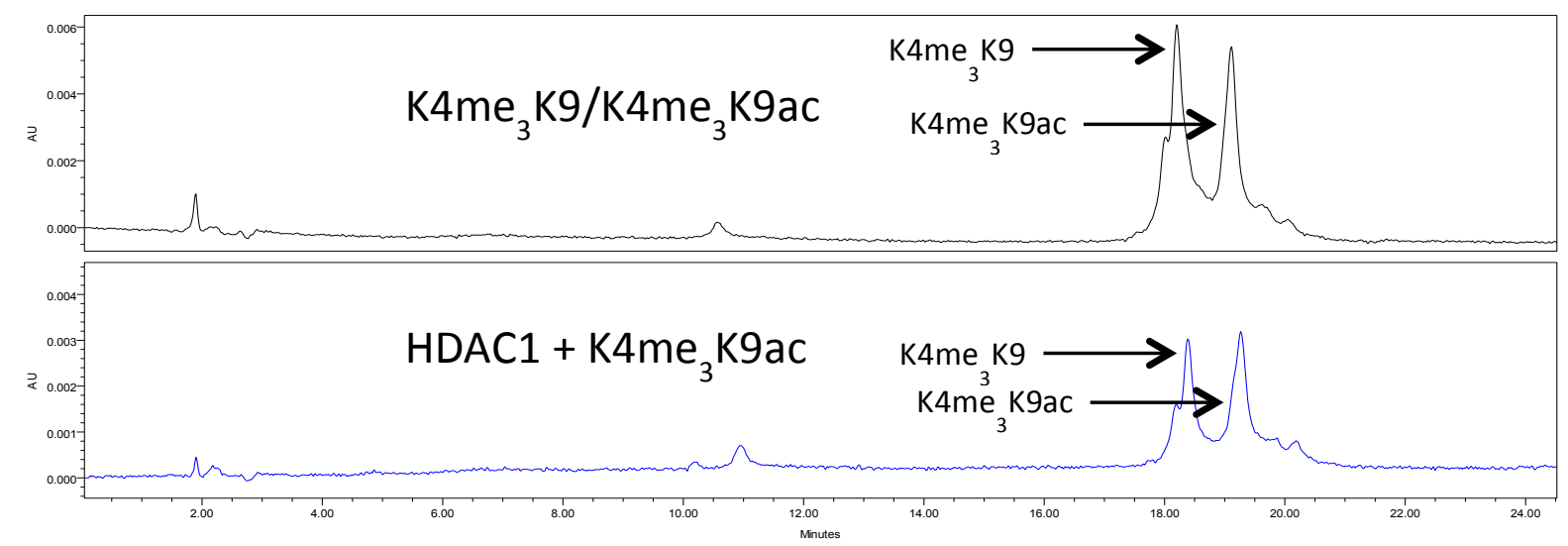

Figure S50. HPLC trace at $280 \mathrm{~nm}$ of a mixture of $20 \mu \mathrm{M} \mathrm{K} 4 \mathrm{me}_{3} \mathrm{~K}$ ac and $20 \mu \mathrm{M} \mathrm{K} 4 \mathrm{me}_{3} \mathrm{~K} 9$ (top) and the reaction of $0.1 \mu \mathrm{g} / \mu \mathrm{L}$ HDAC1 with $20 \mu \mathrm{M} \mathrm{K} 4 \mathrm{me}_{3} \mathrm{~K} 9 \mathrm{ac}$ after $30 \mathrm{~min}$ (bottom).

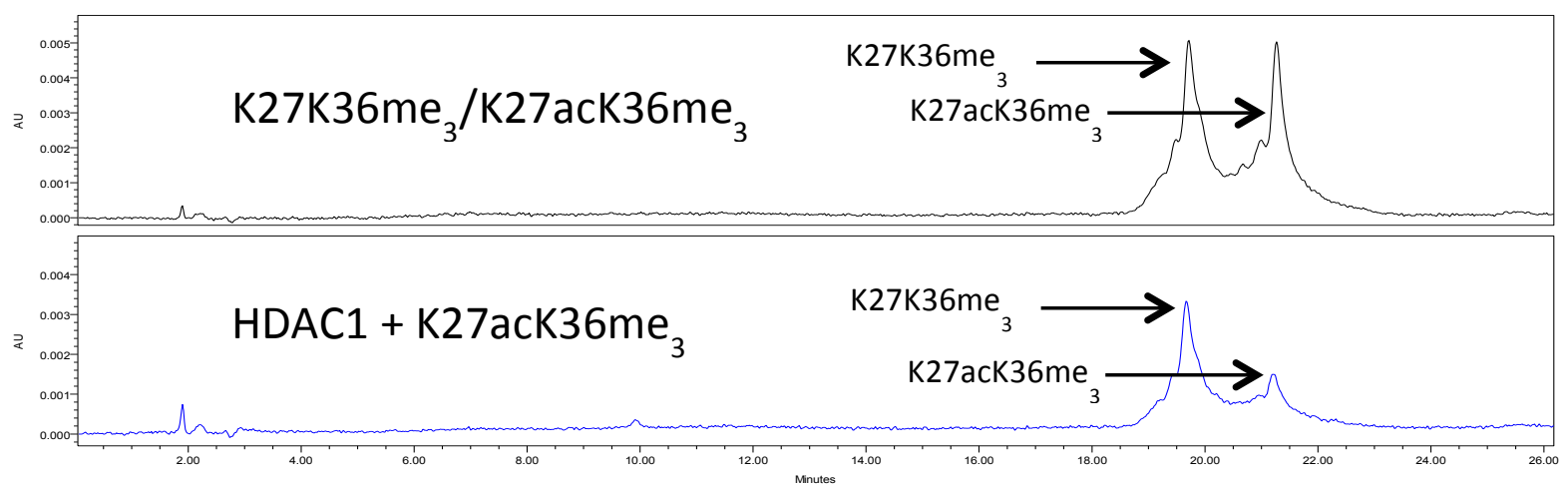

Figure S51. HPLC trace at $280 \mathrm{~nm}$ of a mixture of $20 \mu \mathrm{M} \mathrm{K} 27 \mathrm{ac} \mathrm{K} 36 \mathrm{me}_{3}$ and $20 \mu \mathrm{M} \mathrm{K} 27$

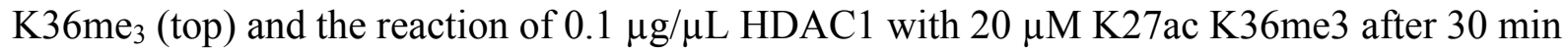
(bottom). 


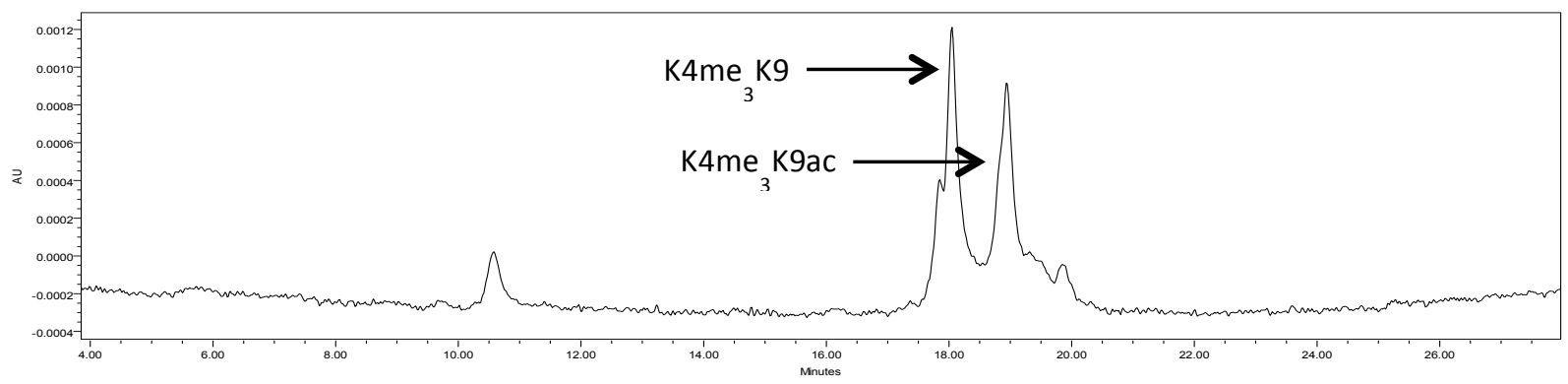

Figure S52. HPLC trace at $280 \mathrm{~nm}$ of the reaction of $0.1 \mu \mathrm{g} / \mu \mathrm{L}$ HDAC1 with $20 \mu \mathrm{M} \mathrm{K} 4 \mathrm{me}_{3}$ K9ac after 1 hour.

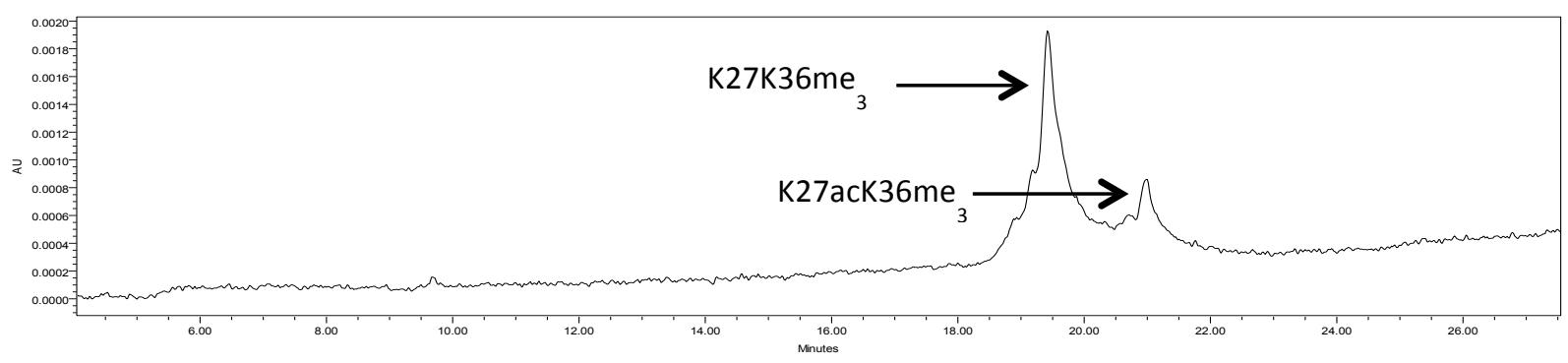

Figure S53. HPLC trace at $280 \mathrm{~nm}$ of the reaction of $0.1 \mu \mathrm{g} / \mu \mathrm{L}$ HDAC1 with $20 \mu \mathrm{M}$ K27ac $\mathrm{K} 36 \mathrm{me}_{3}$ after 1 hour.

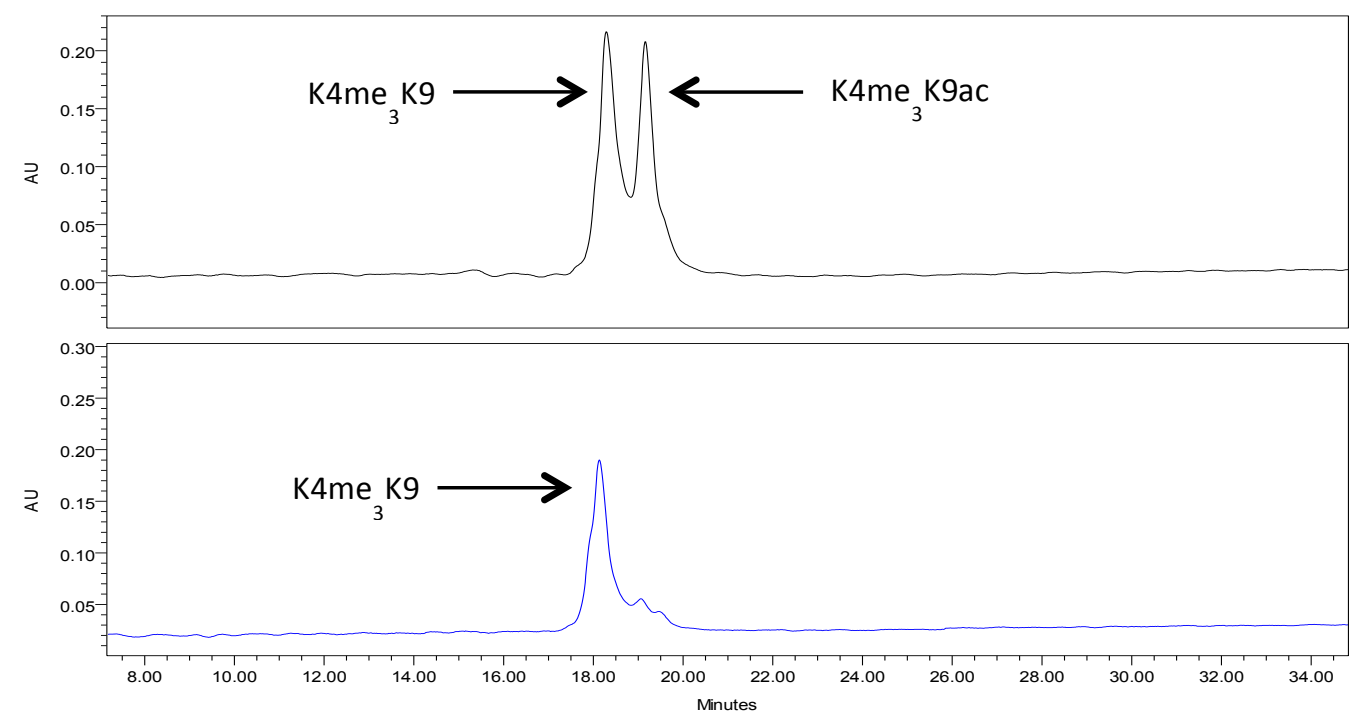

Figure S54. Top: HPLC trace of a 1:1 mixture of $100 \mu \mathrm{M} \mathrm{K} 4 \mathrm{me}_{3} \mathrm{~K} 9 \mathrm{ac}$ and $100 \mu \mathrm{M} \mathrm{K} 4 \mathrm{me}_{3} \mathrm{~K} 9$. Bottom: HPLC trace at 214 of the reaction of $11.2 \mathrm{nM}$ HDAC3/NCOR1 with $100 \mu \mathrm{M}$ $\mathrm{K} 4 \mathrm{me}_{3} \mathrm{~K} 9 \mathrm{ac}$ after 4 hours. 


\section{Turn-on Fluorescence HDAC1 Activity Assay}

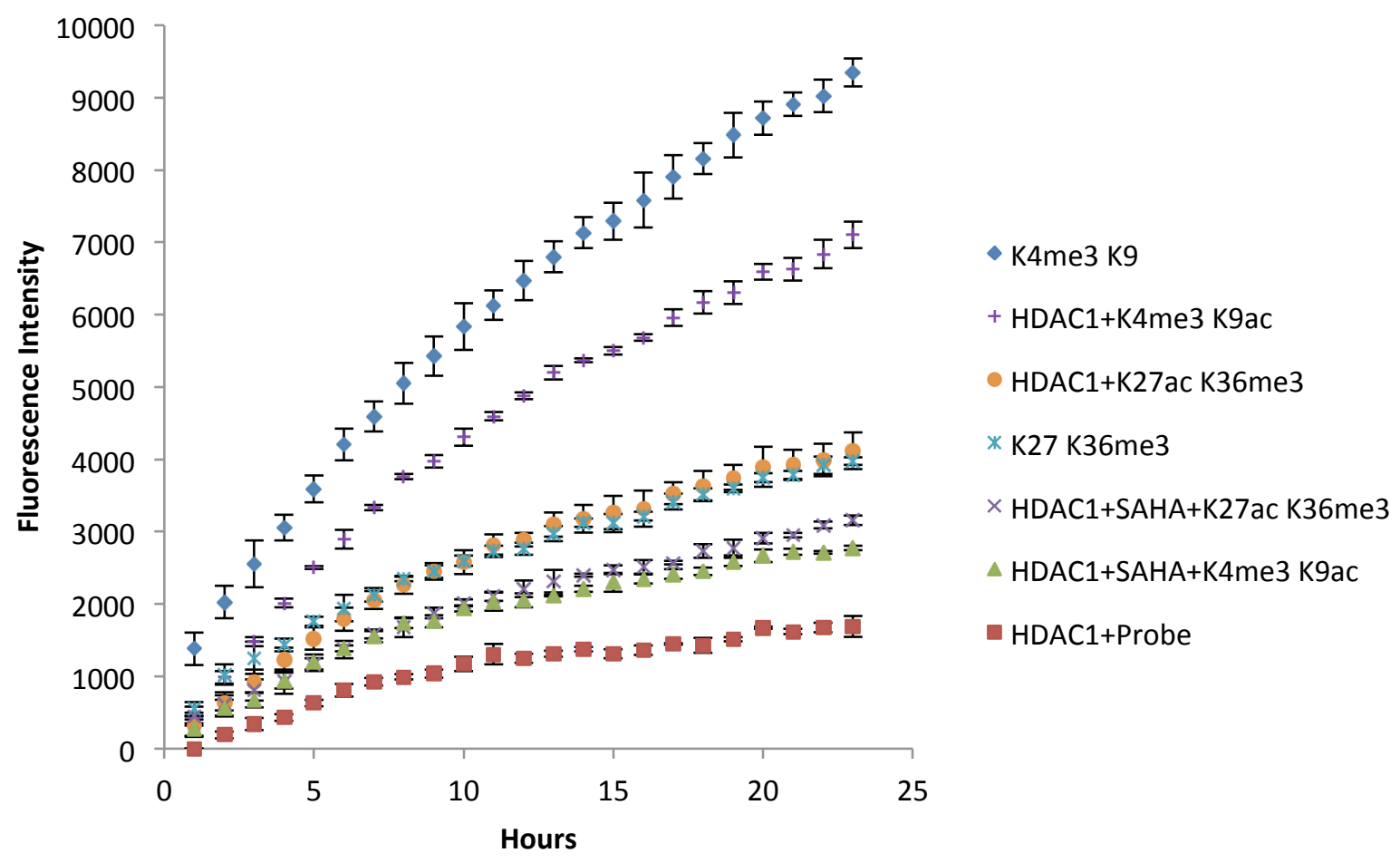

Figure S55. Turn-on fluorescence HDAC1 activity assay. Fluorescence monitoring of the deacetylation of histone $\mathrm{H} 3$ peptides $\mathrm{K} 4 \mathrm{me}_{3} \mathrm{~K} 9 \mathrm{ac}$ and $\mathrm{K} 27 \mathrm{ac} \mathrm{K} 36 \mathrm{me}_{3}$ with probe 5 after reaction with HDAC1 in the absence or presence of $5 \mu \mathrm{M}$ SAHA for 1 hour at $37^{\circ} \mathrm{C}$. Enzymatic reactions were performed in $25 \mathrm{mM}$ Bicine buffer, $137 \mathrm{mM} \mathrm{NaCl}, 2.7 \mathrm{mM} \mathrm{KCl}, 1 \mathrm{mM} \mathrm{MgCl}_{2}$ (pH 8.02) with $0.1 \mu \mathrm{g} / \mu \mathrm{L} \mathrm{HDAC} 1$ and $200 \mu \mathrm{M}$ acetylated peptide. After 1 hour, the reactions were diluted with buffer before adding to a 96-well plate containing probe 5 to give final concentrations of 20 $\mu \mathrm{M}$ peptide, $40 \mu \mathrm{M}$ probe 5 , and $10 \mathrm{ng} / \mu \mathrm{L}$ HDAC1 (reactions containing SAHA were diluted to contain $5 \mu \mathrm{M}$ SAHA). Fluorescence labeling was monitored every hour for 24 hours. Each data point represents an average of three runs. Error bars are standard deviations. 


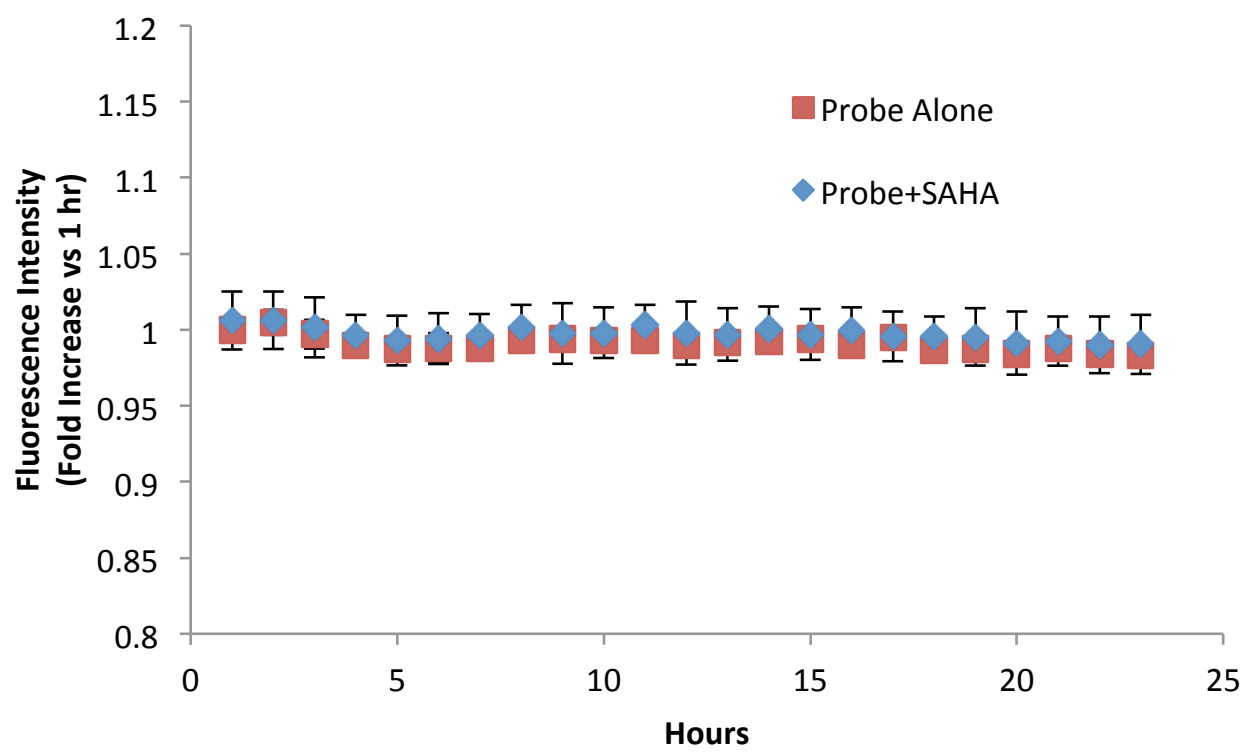

Figure S56. Turn-on fluorescence labeling SAHA control experiment. Labeling of $40 \mu \mathrm{M} 5$ alone (red) or in the presence of $5 \mu \mathrm{M}$ SAHA (blue) in $25 \mathrm{mM}$ Bicine buffer, $137 \mathrm{mM} \mathrm{NaCl}, 2.7$ $\mathrm{mM} \mathrm{KCl}, 1 \mathrm{mM} \mathrm{MgCl} 2$ (pH 8.02). Each data point represents an average of three runs. Error bars are standard deviations. 


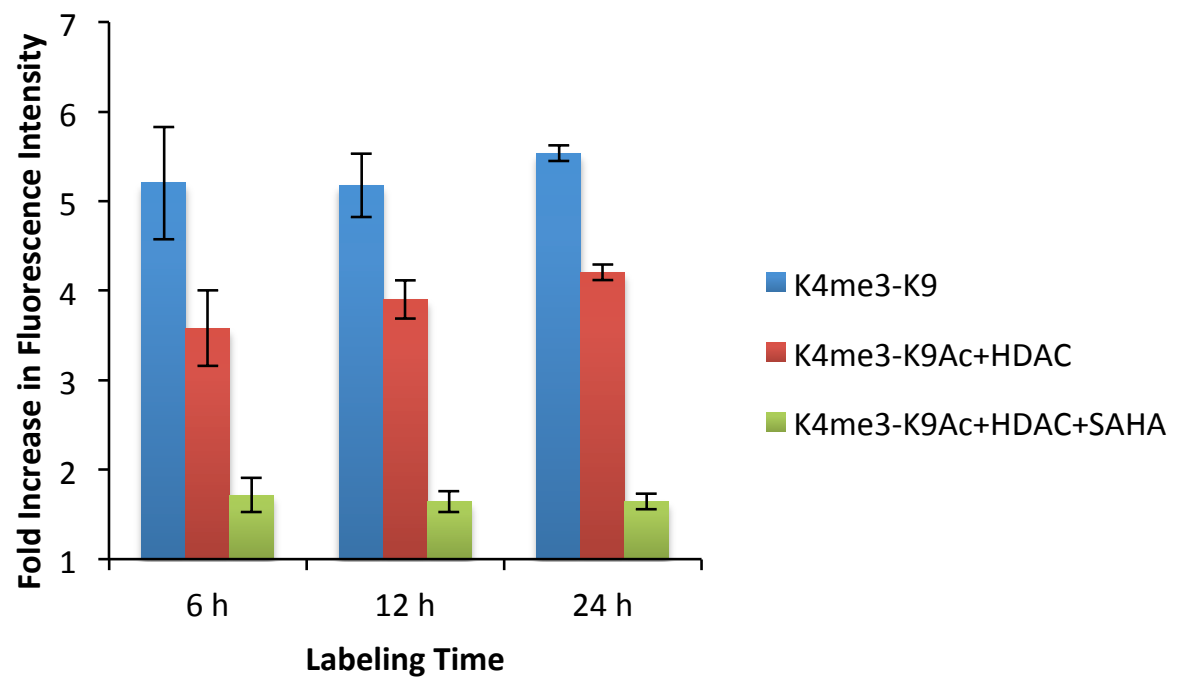

Figure S57. Turn-on fluorescence HDAC1 activity assay: fluorescence increase of deacetylated $\mathrm{K}_{4} \mathrm{me}_{3} \mathrm{~K} 9 \mathrm{ac}$ after labeling for 6, 12, or 24 hours. Fold increase in fluorescence intensity was normalized to the negative control containing HDAC1 and 5 alone after 6, 12, or 24 hours. Each data point represents an average of three runs. Error bars are standard deviations.

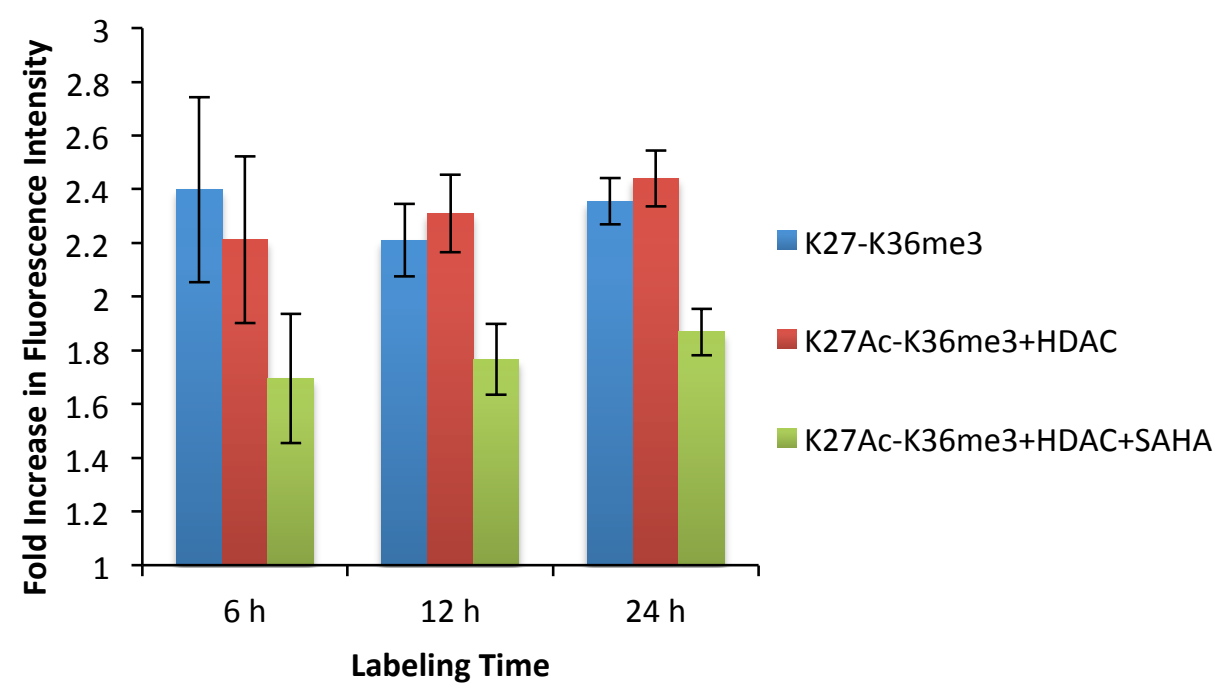

Figure S58. Turn-on fluorescence HDAC1 activity assay: fluorescence increase of deacetylated $\mathrm{K} 27 \mathrm{ac} \mathrm{K} 36 \mathrm{me}_{3}$ after labeling for 6,12 , or 24 hours. Fold increase in fluorescence intensity was normalized to the negative control containing HDAC1 and 5 alone after 6, 12, or 24 hours. Each data point represents an average of three runs. Error bars are standard deviations. 


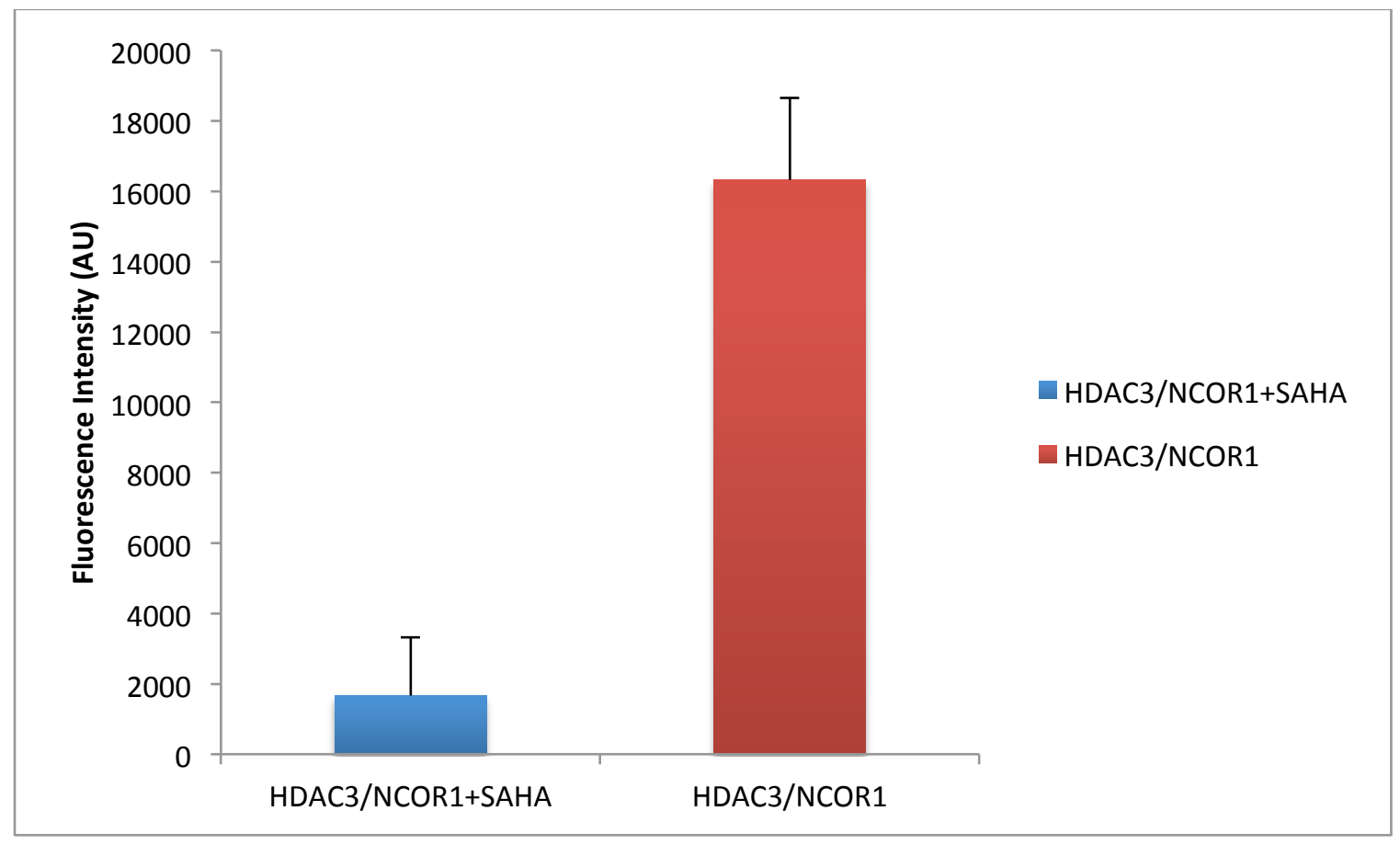

Figure S59. Turn-on fluorescence HDAC3/NCOR1 activity assay: fluorescence increase of deacetylated $\mathrm{K}_{4} \mathrm{me}_{3} \mathrm{~K} 9 \mathrm{ac}$ after labeling for 24 hours. Enzymatic reactions were performed using $11.2 \mathrm{nM}$ HDAC3/NCOR1, $100 \mu \mathrm{M}$ acetylated peptide, and with or without $17 \mu \mathrm{M}$ SAHA at 37 ${ }^{\circ} \mathrm{C}$. After 4 hours, the reactions were quenched with $10 \mu \mathrm{M}$ SAHA before adding to a 96-well plate containing probe 5 to give final concentrations of $77 \mu \mathrm{M}$ peptide, $40 \mu \mathrm{M}$ probe $\mathbf{5}$, and 8.6 nM HDAC3/NCOR1. Each data point represents an average of two runs. Error bars are standard deviations. 


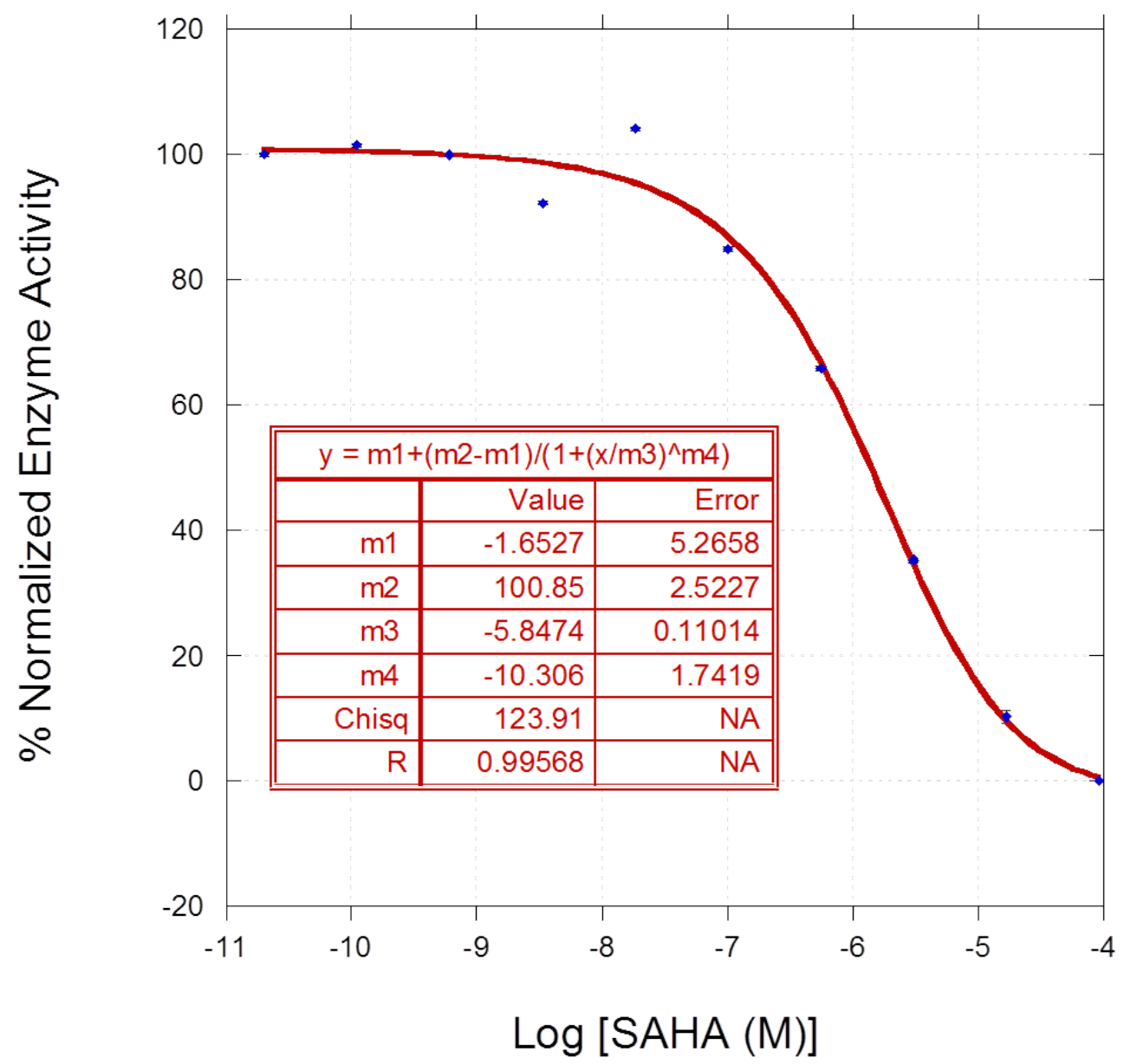

Figure S60. Plot of the dose response curve for the inhibition of HDAC3/NCOR1 activity by SAHA as monitored by the CX4-ONBD turn-on fluorescence HDAC assay. SAHA. Data are an average of duplicate measurements. Conditions: $40 \mu \mathrm{M} 5,75 \mu \mathrm{M}$ peptide, serial dilution of SAHA (starting from $92 \mu \mathrm{M}$ ) in $50 \mathrm{mM}$ bicine, $137 \mathrm{mM} \mathrm{NaCl}, 2.7 \mathrm{mM} \mathrm{KCl}, 1 \mathrm{mM} \mathrm{MgCl} 2, \mathrm{pH}$ $8.02,24 \mathrm{~h}$. Error bars represent the standard deviation of each data point. In the equation provided for the IC50 fit, $\mathrm{m} 1$ and $\mathrm{m} 2$ correspond to the minimum and maximum $\mathrm{Y}$ values, respectively. The value $\mathrm{m} 3$ is the IC50 value (the $\mathrm{X}$ value at a $\mathrm{Y}$ value of 50), and $\mathrm{m} 4$ is the slope at the midpoint of the curve. 


\section{Z Factor Determination}

For determining the suitability of the fluorogenic assay for HTS screening, the $\mathrm{Z}$ factor ${ }^{3}$ was calculated. Eight wells of positive control reaction and eight wells of negative control reaction were used in 96-well plate format. $\mathrm{K} 4 \mathrm{me}_{3} \mathrm{~K} 9 \mathrm{ac}$ was used as a negative control, and $\mathrm{K} 4 \mathrm{me}_{3} \mathrm{~K} 9$ was used as a positive control. Reactions were performed with $40 \mu \mathrm{M}$ probe 5 and $20 \mu \mathrm{M}$ peptide in $10 \mathrm{mM}$ sodium borate buffer, $\mathrm{pH} 8.6,100 \mathrm{mM} \mathrm{NaCl}$. After 24 hours, the fluorescence intensity was measured.

$$
Z^{\prime}=1-\frac{3\left(\sigma_{\mathrm{p}}+\sigma_{\mathrm{n}}\right)}{\left|\mu_{\mathrm{p}}-\mu_{\mathrm{n}}\right|}
$$

Figure S61. Equation for calculating Z'. The values $\sigma_{\mathrm{p}}$ and $\sigma_{\mathrm{n}}$ are the standard deviation of the positive control and negative control respectively. The values $\mu_{\mathrm{p}}$ and $\mu_{\mathrm{n}}$ refer to the mean of the fluorescence intensity for the positive control and negative control.

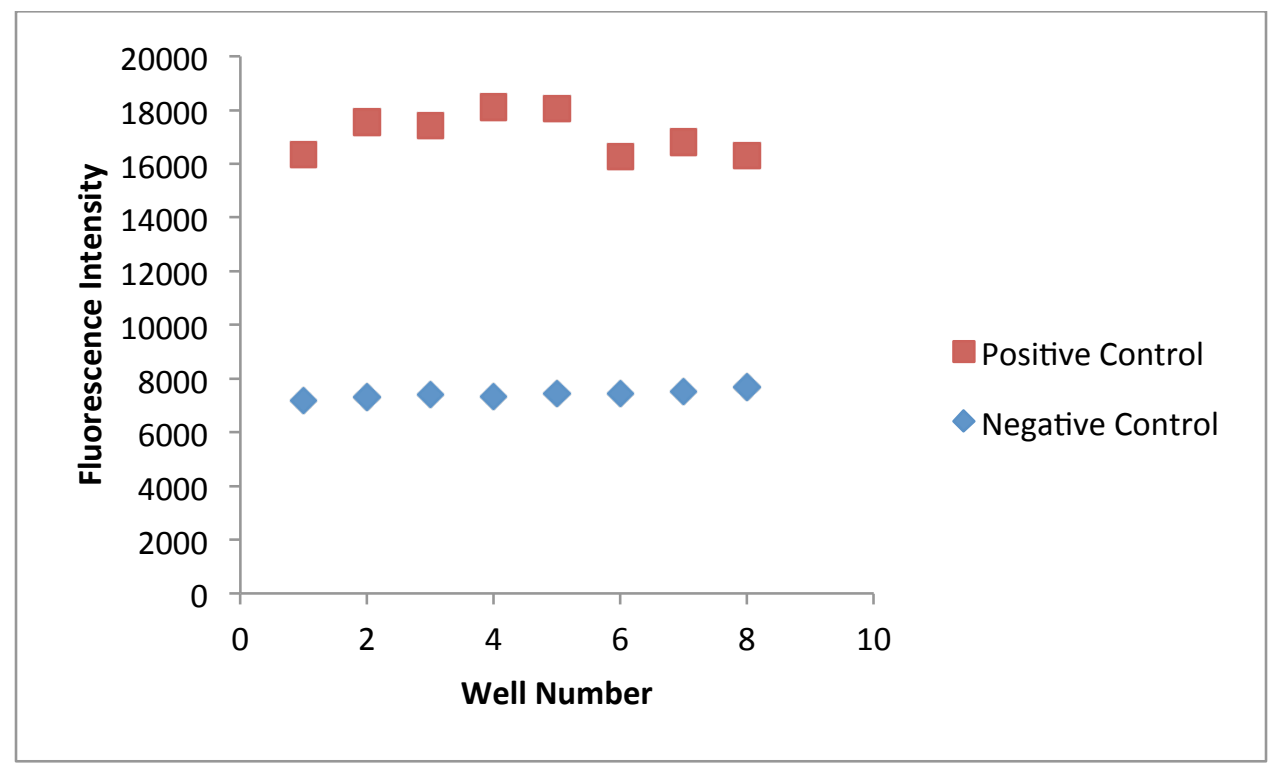

Figure S62. Fluorescence intensities of positive control reaction and negative control reactions for eight wells for Z' determination.

Table S6. Summary of Fluorescence Intensities and Z Factor Calculation

\begin{tabular}{|c|r|r|r|r|r|r|r|r|r|r|r|}
\hline & $\mathbf{1}$ & $\mathbf{2}$ & $\mathbf{3}$ & $\mathbf{4}$ & \multicolumn{1}{|c}{$\mathbf{5}$} & $\mathbf{6}$ & $\mathbf{7}$ & $\mathbf{8}$ & Avg & Stdev & Z Factor \\
\hline Positive Control & 16337 & 17561 & 17439 & 18120 & 18052 & 16282 & 16802 & 16319 & 17114 & 776.6812 & 0.712803 \\
\hline Negative Control & 7172 & 7299 & 7396 & 7345 & 7437 & 7446 & 7541 & 7673 & 7413.625 & 151.9567 & \\
\hline
\end{tabular}




\section{References:}

(1) Daze, K. D.; Ma, M. C. F.; Pineux, F.; Hof, F. Org. Lett. 2012, 14, 1512-1515.

(2) Bonger, K. M.; van den Berg, R. J. B. H. N.; Heitman, L. H.; IJzerman, A. P.; Oosterom, J.; Timmers, C. M.; Overkleeft, H. S.; van der Marel, G. A. Bioorg. Med. Chem. 2007, 15, 4841-4856.

(3) Zhang, J.; Chung, T.; Oldenburg, K. J. Biomol. Screen. 1999, 4, 67-73. 